Mayara Resende Alves

\title{
PREPARAÇÃO, CARACTERIZAÇÃO E APLICAÇÃO DE DERIVADOS DO ÁCIDO 12- TUNGSTOFOSFÓRICO SUPORTADO EM SBA-15
}

Orientador: Prof. Dr. José Alves Dias

Coorientador: Prof. Dr. Gesley Alex Veloso Martins

Brasília

2016 


\section{UnB - Universidade de Brasília}

Mayara Resende Alves

\section{PREPARAÇÃO, CARACTERIZAÇÃO E APLICAÇÃO DE DERIVADOS DO ÁCIDO 12-TUNGSTOFOSFÓRICO} SUPORTADO EM SBA-15

Dissertação apresentada ao Instituto de Química

da Universidade de Brasília como parte do requisito para obtenção do título de Mestre em Química.

Orientador: Prof. Dr. José Alves Dias

Coorientador: Prof. Dr. Gesley Alex Veloso Martins

$$
\text { Brasília - DF }
$$




\section{FOLHA DE APROVAÇÃO}

Comunicamos a aprovação da Defesa de Dissertação de Mestrado do (a) aluno (a) Mayara Resende Alves, matrícula $n \cong$ 14/0106791, intitulada "Preparação, Caracterização e Aplicação de Derivados do Ácido 12Tungstofosfórico Suportado em SBA-15", apresentada no (a) Auditório Azul do Instituto de Química (IQ) da Universidade de Brasília (UnB) em 23 de fevereiro de 2016.

Prof. Dr. José Alves Dias

Presidente de Banca (IQ/UnB)

Prof. Dr. Júlio Lemos de Macedo Membro Titular (IQ/UnB)

Prof. Dr. Marcello Moreira Santos Membro Titular (IQ/UnB)

Profa Dra Sílvia Cláudia Loureiro Dias Membro Suplente (IQ/UnB)

Em 23 de fevereiro de 2016.

$\square$ Caixa Postal 4478 - CEP: $70904-970$ - Brasilia - DF - BRASIL

ㅁww.unb.brfiq/pg pasgiq@unb.br 


\section{Agradecimentos}

Agradeço a Deus, por guiar meus passos e conceder as forças necessárias para vencer os obstáculos.

A minha mãe Ilsa e minha irmã Thaynara que me incentivaram durante esse período. Mãe agradeço a você por ter possibilitado meu acesso ao conhecimento. Não teria chegado a lugar algum, se não fosse seu amor, carinho e força dedicado a mim.

Ao professor Zeca por ter me acolhido no LabCat, pelo empenho, dedicação, paciência e orientação para a conclusão deste trabalho. A professora Sílvia pelos conselhos concedidos. Ao Prof. Gesley pela coorientação neste trabalho.

Ao professor Júlio pelas sugestões valiosas que contribuíram significativamente para este trabalho.

A Estelle pela amizade e apoio. Obrigada pelos constantes favores prestados, conhecimento compartilhado e descontração.

Aos meus amigos do LabCat: Mateus, Munique, Mariane e em especial aqueles que mais me ajudaram nesse trabalho: Elon e Júlia.

A Ana Paula pela amizade, estudos e companhia no almoço.

A minha amiga Jesyca da UFMT, pela amizade e pelo incentivo mesmo distante.

Ao professor Luis Carlos Cides da Silva pelas contribuições e pelas análises de SAXS na Universidade de São Paulo.

Ao Instituto de Biologia pela obtenção de imagens de MEV.

CAPES, MCT/CNPq, DPP/IQ/UnB, FINATEC, FAPDF, FINEP-CTPetro, FINEPCTInfra e Petrobras pelos auxílios financeiros.

E a todos que, de alguma forma, contribuíram para a realização deste trabalho. Mayara 


\section{Resumo}

Heteropoliácidos (HPA) têm sido utilizados na forma protônica ou suportada, sendo esta forma preferível por adquirir propriedades melhoradas em aplicações catalíticas. Esse trabalho relata a preparação, caracterização e aplicação de sais de prata substituídos, derivados do $\mathrm{H}_{3} \mathrm{PW}_{12} \mathrm{O}_{40}(\mathrm{HPW})$ nas seguintes estequiometrias: $\mathrm{Ag}_{\mathrm{x}} \mathrm{H}_{3-}$ ${ }_{x} \mathrm{PW}_{12} \mathrm{O}_{40}$, (sendo $\mathrm{x}=1,0 ; 1,5 ; 2,0 ; 2,5$ e 3,0). A atividade dos sais foi avaliada na reação de desidratação de etanol, a uma temperatura de $300{ }^{\circ} \mathrm{C}$, tendo como objetivo a formação de etileno. Para a série de sais de prata testada foi observada que a conversão de etanol para o catalisador $\mathrm{Ag}_{2} \mathrm{HPW}$ foi a mais elevada. Diante deste comportamento excepcional do catalisador $\mathrm{Ag}_{2} \mathrm{HPW}$, realizou-se um estudo da reação em diferentes temperaturas $\left(200,250,300,350\right.$ e $\left.400{ }^{\circ} \mathrm{C}\right)$ obtendo-se conversões de 27,$6 ; 50,2 ; 63,5 ; 69,9$ e $77,1 \%$, respectivamente. Por conseguinte, este sal foi escolhido para ser suportado em sílica mesoporosa do tipo SBA-15, com posterior avaliação na reação de desidratação. A estrutura do tipo Keggin da fase ativa foi mantida após a impregnação no suporte, enquanto a área específica aumentou de 5 para $576 \mathrm{~m}^{2} \mathrm{~g}^{-1}$, após a deposição sobre o substrato mesoporoso. A conversão do catalisador suportado $20 \% \mathrm{Ag}_{2} \mathrm{HPW} / \mathrm{SBA}-15$ foi testada nas temperaturas de 300 e $400{ }^{\circ} \mathrm{C}$, apresentando uma conversão de 86 e $100 \%$ e seletividade para etileno de 88 e 100\%, respectivamente. Esses resultados demonstraram que a conversão de etanol aumentou consideravelmente em comparação com a fase ativa pura do derivado de prata do HPW (i.e., $\mathrm{Ag}_{3} \mathrm{PW}$ ). 


\begin{abstract}
Heteropolyacids (HPA) have been used in the protonic or supported form, which is preferential in order to acquire enhanced properties for catalytic applications. This work reports the preparation, characterization and application of substituted silver salts derivatives of $\mathrm{H}_{3} \mathrm{PW}_{12} \mathrm{O}_{40}$ (HPW) using the following stoichiometries: $\mathrm{Ag}_{\mathrm{x}} \mathrm{H}_{3-}$ ${ }_{x} \mathrm{PW}_{12} \mathrm{O}_{40}$, (where $x=1.0 ; 1.5 ; 2.0 ; 2.5$ and 3.0). The conversion of the salts was evaluated in the ethanol dehydration reaction, at a temperature of $300^{\circ} \mathrm{C}$, aiming the formation of ethylene. In the series of the synthesized silver salts, the conversion of ethanol by $\mathrm{Ag}_{2} \mathrm{HPW}$ catalyst was the highest. In view of this exceptional behavior of $\mathrm{Ag}_{2} \mathrm{HPW}$ catalyst, it was carried out a study of the same reaction at different temperatures $\left(200,250,300,350\right.$ e $\left.400^{\circ} \mathrm{C}\right)$, which showed conversions of $27.6,50.2$, $63.5,69.9$ and $77.1 \%$, respectively. Therefore, this salt was chosen to be supported (20\%) on the mesoporous silica type SBA-15 and evaluated their conversion. The active phase with the Keggin structure was maintained after impregnation on the support, while the specific area increased from 5 to $576 \mathrm{~m}^{2} \mathrm{~g}^{-1}$ by deposition on the mesoporous substrate. The conversion of supported catalyst $20 \% \mathrm{Ag}_{2} \mathrm{HPW} / \mathrm{SBA}-15$ was evaluated at temperatures of 300 to $400{ }^{\circ} \mathrm{C}$, showing conversions of 86 and $100 \%$, whereas the selectivity to ethylene were 88 and $100 \%$, respectively. These results clearly demonstrate that the conversion of ethanol greatly increased compared to the active phase of silver salt derivative of HPW (i.e., $\mathrm{Ag}_{3} \mathrm{PW}$ ).
\end{abstract}




\section{Sumário}

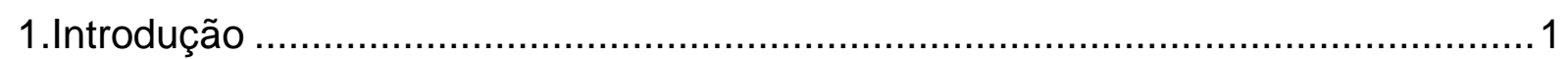

1.1. Revisão Bibliográfica........................................... Erro! Indicador não definido.

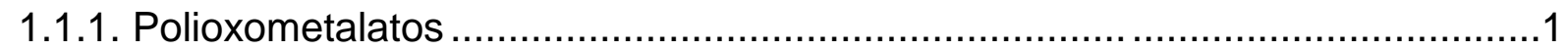

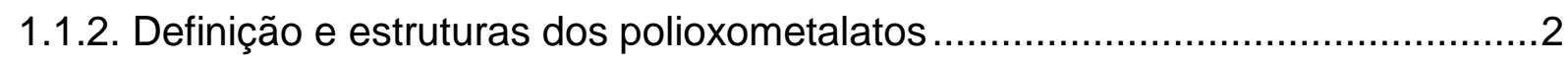

1.1.3. Heteropoliácidos de Keggin - Ácido 12-tungstofosfórico ..............................

1.2. Sólidos mesoporosos ordenados ...............................................................

1.2.1. Mecanismos de formação de materias mesoporos .......................................

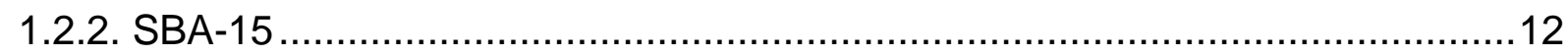

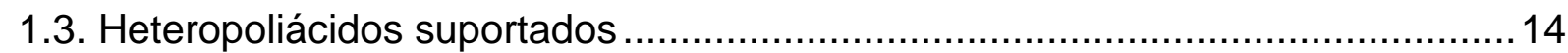

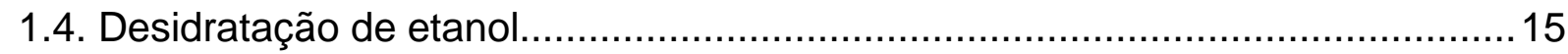

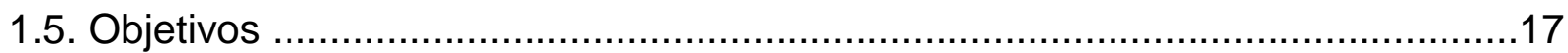

2. Experimental ........................................................... Erro! Indicador não definido.

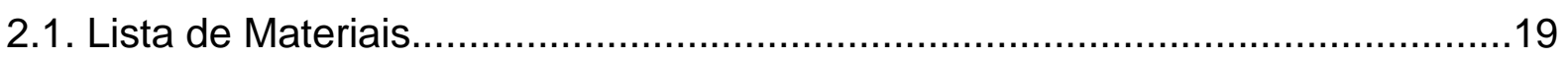

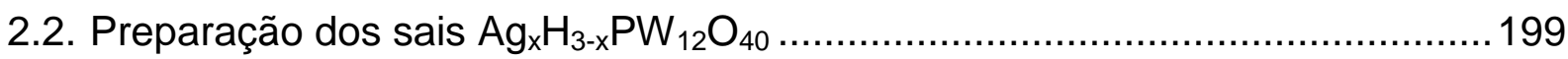

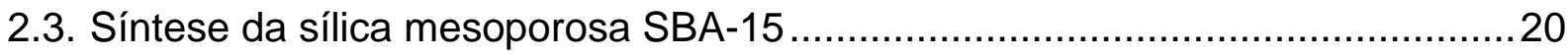

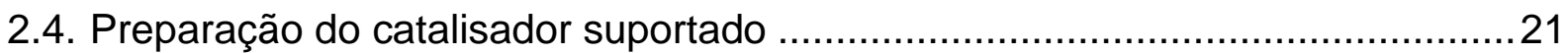

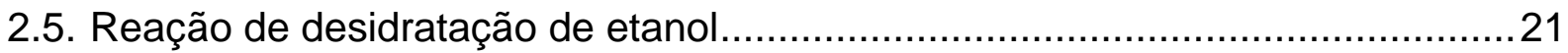

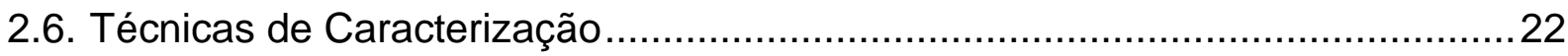

2.6.1. Espectroscopia de absorção na região do infravermelho...............................22

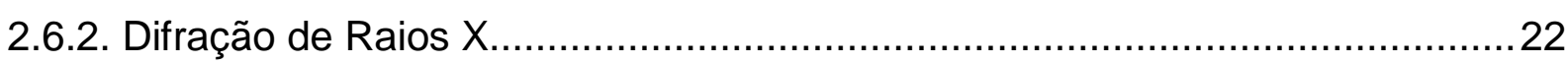

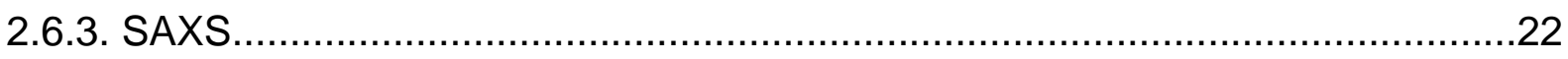

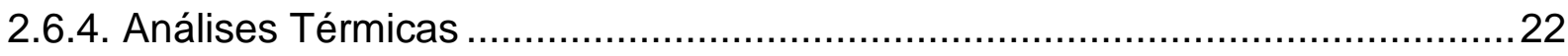

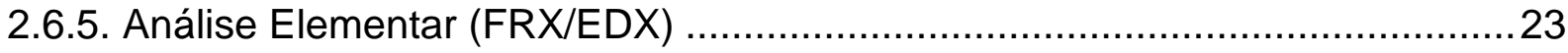

2.6.6. Ressonância Magnética Nuclear no Estado Sólido de ${ }^{29} \mathrm{Si} \mathrm{e}^{31} \mathrm{P}$ com rotação

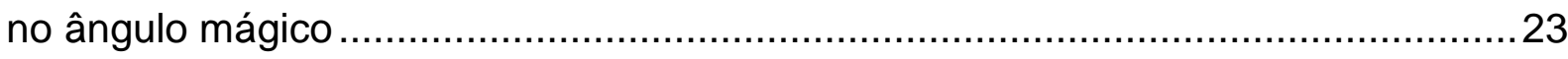

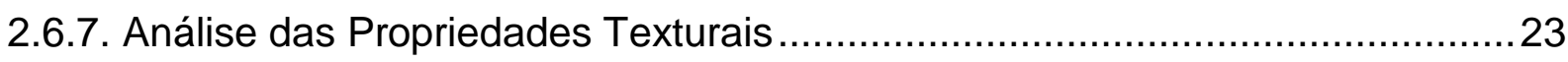

2.6.8. Microscopia Eletrônica de Varredura (MEV) ……….................................. 24

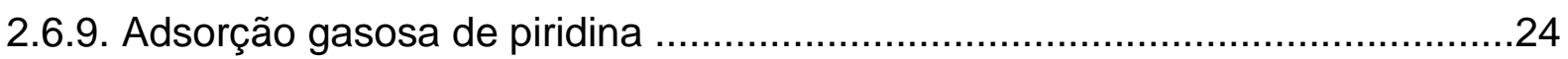

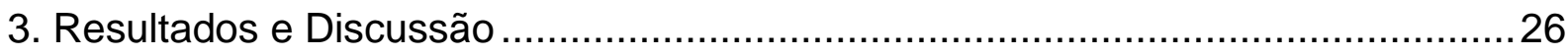

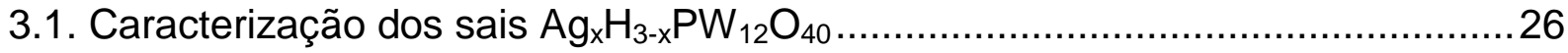

3.1.1. Espectroscopia na região do infravermelho ……........................................ 26

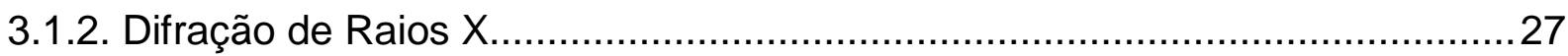


3.1.3. Análise elementar por Fluorescência de Raios X (FRX/EDX) ...................... 30

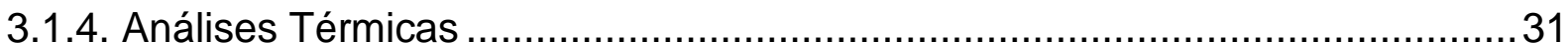

3.1.5. Ressonância Magnética Nuclear no Estado Sólido de ${ }^{31} \mathrm{P}$ com rotação no

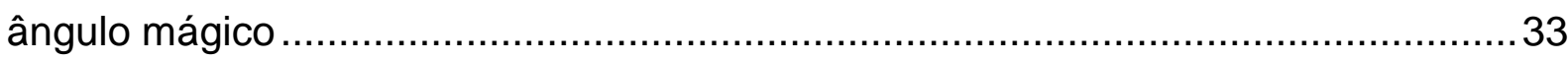

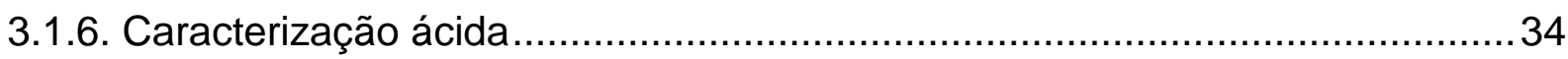

3.2. Caracterização da sílica mesoporosa SBA-15 ........................................ 37

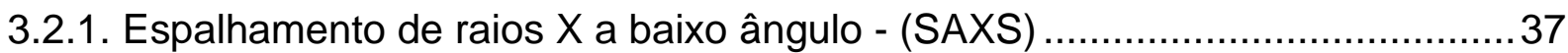

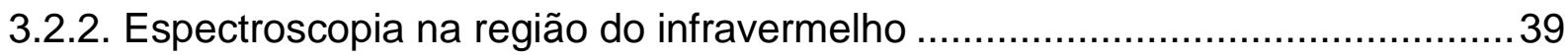

3.2.3. Ressonância Magnética Nuclear de ${ }^{29}$ Si no Estado Sólido ...........................40

3.2.4. Análise térmica ........................................................................ 42

3.2.5. Microscopia Eletrônica de Varredura (MEV) ...................................... 43

3.2.6. Adsorção de nitrogênio a baixa temperatura ....................................... 40

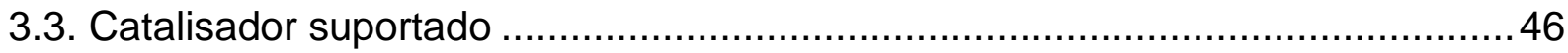

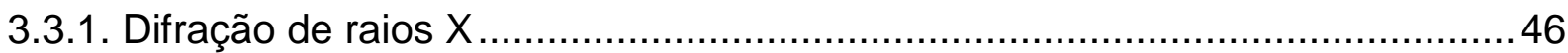

3.3.2. Ressonância Magnética Nuclear de ${ }^{31} \mathrm{P}$ no Estado Sólido com rotação no

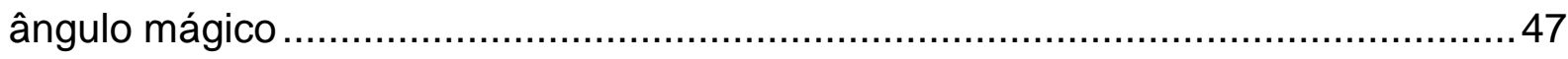

3.3.3. Adsorção de nitrogênio a baixa temperatura ...................................... 47

3.3.4. Microscopia Eletrônica de Varredura ............................................... 49

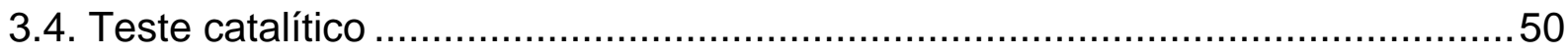

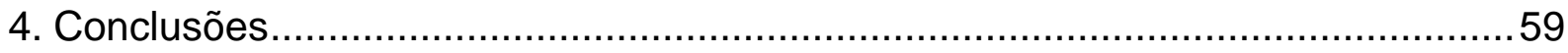

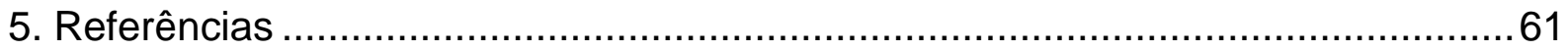

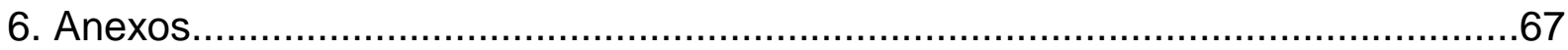

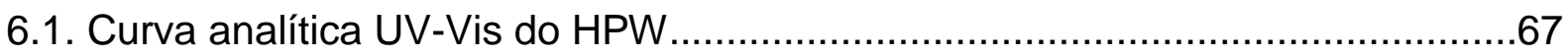

6.2. Espectro de FT-IR do HPW e dos seus derivados salinos de prata.................69 


\section{Lista de Abreviaturas e Acrônimos \\ (ordem alfabética)}

AgPW - $\mathrm{Ag}_{\mathrm{x}} \mathrm{H}_{3-\mathrm{X}} \mathrm{PW}_{12} \mathrm{O}_{40}(1,0 \leq \mathrm{X}<3,0)$

BET - Brunauer-Emmet-Teller

BJH - Barrett-Joyner-Halenda

DRX - difração de raios $X$

FRX/EDX - fluorescência de raios X por energia dispersiva

FT-IR - espectrosco pia na região do infravermelho com transformada de Fourier

HPA - heteropoliácido(s)

$\mathrm{HPW}-\mathrm{H}_{3} \mathrm{PW}_{12} \mathrm{O}_{40}$ (ácido 12-tungstofosfórico)

IUPAC - União Internacional de Química Pura e Aplicada

MAS RMN ${ }^{29} \mathrm{Si}$ e ${ }^{31} \mathrm{P}$ - Ressonância Magnética Nuclear no Estado Sólido com rotação no ângulo mágico de ${ }^{29} \mathrm{Si} \mathrm{e}{ }^{31} \mathrm{P}$

MEV - Microscopia Eletrônica de Varredura

$\mathrm{PEO}_{20}-\mathrm{PPO}_{70}-\mathrm{PEO}_{20}$ - (óxido de etileno) - poli (óxido de propileno) - poli (óxido de etileno)

POM - polioxometalato(s)

SBA-15 - Santa Barbara Amorphous-15

TEOS - tetraetilortosilicato

TMOS - tetrametilortosilicato 


\section{Lista de Tabelas}

Tabela 1. Principais estruturas de polioxometalatos

Tabela 2. Possíveis vias para a síntese de materiais mesoporosos

Tabela 3. Preparação e propriedades físico-químicas da SBA-15 hexagonal.

Tabela 4. Tamanho médio dos cristalitos dos sais de prata

Tabela 5. Análise de FRX/EDX dos catalisadores $\mathrm{Ag}_{1} \mathrm{H}_{2} \mathrm{PW}_{12} \mathrm{O}_{40 ;} \mathrm{Ag}_{1,5} \mathrm{H}_{1,5} \mathrm{PW}_{12} \mathrm{O}_{40}$; $\mathrm{Ag}_{2} \mathrm{H}_{1} \mathrm{PW}_{12} \mathrm{O}_{40} ; \mathrm{Ag}_{2,5} \mathrm{H}_{0,5} \mathrm{PW}_{12} \mathrm{O}_{40 ;} \mathrm{Ag}_{3} \mathrm{PW}_{12} \mathrm{O}_{40}$

Tabela 6. Comparação entre as estequiometrias teórica e obtida na análise de EDX

Tabela 7. Números de onda na região do infravermelho relacionadas a cada tipo de sítio ácido 35

Tabela 8. Paramêtros da deconvolução pela função composta Gaussiana Lorenzitiana.

Tabela 9. Resultados das propriedades texturais da SBA-15 por adsorção de $\mathrm{N}_{2}$ .45

Tabela 10. Propriedades texturais do $\mathrm{Ag}_{2} \mathrm{HPW}$, SBA-15 e $20 \% \mathrm{Ag}_{2} \mathrm{HPW} / \mathrm{SBA}-15 \ldots 48$

Tabela 11. Conversão e seletividade de etileno e dietiéter dos catalisadores $\operatorname{Ag}_{x} \operatorname{HPW}(x=2 ; 2,5$ e 3$)$ .51

Tabela 12. Estudo do efeito da temperatura na atividade do catalisador $\mathrm{Ag}_{2} \mathrm{HPW}$

Tabela 13. Comparação dos resultados da reação do $20 \% \mathrm{Ag}_{2} \mathrm{HPW} / \mathrm{SBA}-15$ e $\mathrm{Ag}_{2} \mathrm{HPW}$ .54

Tabela A1. Dados da curva analítica do HPW obtidos por UV-Vis 68 


\section{Lista de Figuras}

Figura 1. Representação da estrutura poliédrica do ânion de Keggin.

Figura 2. Representação da estrutura secundária do HPW hidratado

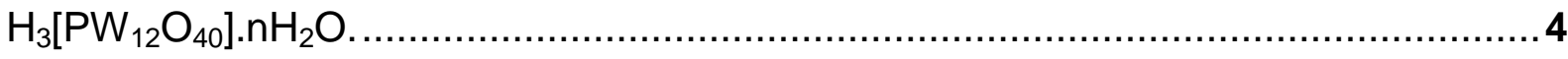

Figura 3. Estrutura terciária do heteropoliácido ……........................................

Figura 4. Estruturas dos materiais da família M41S: A-hexagonal, B-cúbica e Clamelar 18

Figura 5. Mecanismo do molde cristal-líquido (LCT) na formação do MCM-41 com duas vias mecanísticas possíveis 9

Figura 6. Mecanismo de formação de materiais mesoporosos .12

Figura 7. Resumo do procedimento experimental para a preparação dos sais $\mathrm{Ag}_{x} \mathrm{H}_{3 \times} \mathrm{PW}_{12} \mathrm{O}_{40}$. .20

Figura 8. Espectros de FTIR do HPW e dos seus derivados salinos calcinados a $300^{\circ} \mathrm{C}$ : a) $\mathrm{HPW}$

b) $\mathrm{Ag}_{1} \mathrm{H}_{2} \mathrm{PW}_{12} \mathrm{O}_{40}$;

c) $\mathrm{Ag}_{1,5} \mathrm{H}_{1,5} \mathrm{PW}_{12} \mathrm{O}_{40}$

d) $\mathrm{Ag}_{2} \mathrm{H}_{1} \mathrm{PW}_{12} \mathrm{O}_{40}$;

$\mathrm{Ag}_{2,5} \mathrm{H}_{0,5} \mathrm{PW}_{12} \mathrm{O}_{40}$; f) $\mathrm{Ag}_{3} \mathrm{PW}_{12} \mathrm{O}_{40}$ .27

Figura 9. Difratogramas do HPW e dos seus derivados salinos calcinados a $300^{\circ} \mathrm{C}$ :
a) HPW;
b) $\mathrm{Ag}_{1} \mathrm{H}_{2} \mathrm{PW}_{12} \mathrm{O}_{40}$;
c) $\mathrm{Ag}_{1,5} \mathrm{H}_{1,5} \mathrm{PW}_{12} \mathrm{O}_{40}$;
d) $\mathrm{Ag}_{2} \mathrm{H}_{1} \mathrm{PW}_{12} \mathrm{O}_{40}$;

$\mathrm{Ag}_{2,5} \mathrm{H}_{0,5} \mathrm{PW}_{12} \mathrm{O}_{40}$; f) $\mathrm{Ag}_{3} \mathrm{PW}_{12} \mathrm{O}_{40}$

Figura 10. Microscopia Eletrônica de Varredura da amostra $\mathrm{Ag}_{2} \mathrm{HPW}$

Figura 11. Curvas de DTG de: a) a) HPW; b) $\mathrm{Ag}_{1} \mathrm{H}_{2} \mathrm{PW}_{12} \mathrm{O}_{40}$; c) $\mathrm{Ag}_{1,5} \mathrm{H}_{1,5} \mathrm{PW}_{12} \mathrm{O}_{40}$; d) $\mathrm{Ag}_{2} \mathrm{H}_{1} \mathrm{PW}_{12} \mathrm{O}_{40}$; e) $\mathrm{Ag}_{2,5} \mathrm{H}_{0,5} \mathrm{PW}_{12} \mathrm{O}_{40}$; f) $\mathrm{Ag}_{3} \mathrm{PW}_{12} \mathrm{O}_{40}$ 33 
Figura 12. Espectros de MAS RMN de ${ }^{31} \mathrm{P}$ de: a) $\mathrm{HPW}$; b) $\mathrm{Ag}_{1} \mathrm{H}_{2} \mathrm{PW}_{12} \mathrm{O}_{40}$; c) $\mathrm{Ag}_{1,5} \mathrm{H}_{1,5} \mathrm{PW}_{12} \mathrm{O}_{40}$; d) $\mathrm{Ag}_{2} \mathrm{H}_{1} \mathrm{PW}_{12} \mathrm{O}_{40}$; e) $\mathrm{Ag}_{2,5} \mathrm{H}_{0,5} \mathrm{PW}_{12} \mathrm{O}_{40}$; f) $\mathrm{Ag}_{3} \mathrm{PW}_{12} \mathrm{O}_{40}$ calcinados a $300^{\circ} \mathrm{C}$

Figura 13. Sítios ácidos dos sais $\mathrm{Ag}_{\mathrm{x}} \mathrm{H}_{3-\mathrm{x}} \mathrm{PW}_{12} \mathrm{O}_{40}$ após adsorção de piridina gasosa 36

Figura 14. Difratograma de raios-X a baixos ângulos da amostra de sílica mesoporosa ordenada SBA-15 calcinada

Figura 15. Representação esquemática da estrutura dos materiais mesoporosos hexagonais, com distância interplanar e parâmetro de rede.

Figura 16. Espectro de infravermelho da amostra SBA-15 calcinada

Figura 17. Estruturas das espécies químicas referentes ao silício na sílica em

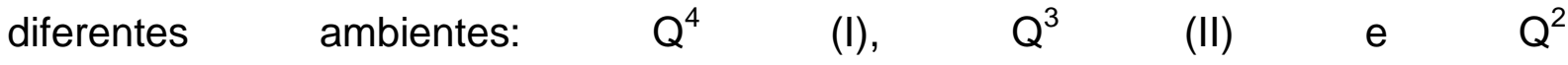
(III)

Figura 18. Espectro de MAS RMN de ${ }^{29} \mathrm{Si}$ da amostra de SBA-15 sem calcinar.

Figura 19. Espectro de MAS RMN de ${ }^{29} \mathrm{Si}$ da amostra de SBA-15 calcinada.

Figura 20. Deconvolução do espectro de MAS RMN de ${ }^{29} \mathrm{Si}$ da amostra de SBA-15 calcinada

Figura 21. Análise térmica da SBA-15 calcinada:

TG/DTG

Figura 22. Imagens de microscopia eletrônica de varredura da SBA15. 
Figura 23. Isotermas de adsorção e dessorção de $\mathrm{N}_{2}$ da amostra de SBA15 45

Figura 24. Difratograma do compósito 20\% $\mathrm{Ag}_{2} \mathrm{HPW} / \mathrm{SBA}$ 15

Figura 25. Espectro de MAS RMN ${ }^{31} \mathrm{P}$ do catalisador $20 \% \mathrm{Ag}_{2} \mathrm{HPW} / \mathrm{SBA}-15$ calcinado 47

Figura 26. Isoterma de adsorção/dessorção de $\mathrm{N}_{2}$ da amostra $20 \% \mathrm{Ag}_{2} \mathrm{HPW} / \mathrm{SBA}-$ 15 48

Figura 27. Micrografias por microscopia eletrônica de varredura $20 \% \mathrm{Ag}_{2} \mathrm{HPW} / \mathrm{SBA}$ 15.

Figura A 1: Curva analítica do HPW em solução aquosa ácida, no UV-Vis, a 260 $\mathrm{nm}$. 67

Figura A2. Espectros de FT-IR do HPW e dos seus derivados salinos de prata, calcinados a $300{ }^{\circ} \mathrm{C}$ 69 


\section{Introdução, Revisão}

\section{Bibliográfica \& Objetivos}




\section{INTRODUÇÃO}

O desenvolvimento de novos processos de produção de derivados químicos que sejam menos prejudiciais ao meio ambiente é requisitado para atender aos princípios consonantes da Química Verde. ${ }^{1,2}$ Neste contexto, a catálise heterogênea é uma alternativa para diminuir a produção de produtos secundários indesejados nas reações, empregando catalisadores que contribuem significativamente para redução da poluição, resultando em processos mais eficientes e ecologicamente corretos. ${ }^{1}$

$\mathrm{Na}$ busca pela preparação de catalisadores com esses potenciais, os heteropoliácidos (HPA) têm sido amplamente estudados na sua forma protônica ou suportados para aplicação como catalisadores heterogêneos. Os HPA são considerados ácidos fortes ${ }^{3}$ e tem substituído os tradicionais catalisadores ácidos homogêneos, tais como: ácido sulfúrico e ácido fluorídrico, pois são menos corrosivos, reutilizáveis e produzem menores quantidades de resíduos. ${ }^{1,4}$

Portanto, o desenvolvimento de novos métodos de preparação de sistemas suportados, de preparação de novos compósitos e a síntese de novos HPA é uma área que continua a atrair a comunidade científica visando à aplicação destes materiais em processos industrias, em química fina e em processos de interesse ambiental. ${ }^{1}$

\subsection{REVISÃO BIBLIOGRÁFICA}

\subsubsection{Polioxometalatos}

O primeiro relato associado a polioxometalatos (POM) data de 1826 , quando Berzelius sintetizou e descreveu a formação do primeiro heteropolissal, o 12molibdofosfato de amônio $\left(\mathrm{NH}_{4}\right)_{3}\left[\mathrm{PMO}_{12} \mathrm{O}_{40}\right]$. Em 1908, já haviam sido reportados aproximadamente $70 \mathrm{POM}$, porém pelo fato das técnicas de caracterização serem limitadas, muitas estruturas eram desconhecidas. ${ }^{5-7}$ 
No entanto, diversas teorias foram propostas nas primeiras décadas do século XX por Werner, Miolati, Rosenheim e Pauling para elucidar as estruturas destas espécies químicas. $^{5}$ Em 1933, J. F. Keggin determinou com mais precisão a estrutura cristalina do ácido 12-tungstofosfórico por meio da difração de Raios X em monocristal. ${ }^{5,8}$

\subsubsection{Definição e estruturas dos polioxometalatos}

Por definição, existem duas espécies de POM, sendo estes poliânions metálicos distinguidos pela presença ou não de $X$ e representados pelas fórmulas gerais: isopoliânion $\left[\mathrm{M}_{\mathrm{m}} \mathrm{O}_{\mathrm{y}}\right]^{\mathrm{p}-}$ ou heteropoliânion $\left[\mathrm{X}_{\mathrm{x}} \mathrm{M}_{\mathrm{m}} \mathrm{O}_{\mathrm{y}}\right]^{\mathrm{q-}}(\mathrm{x} \leq \mathrm{m})$, sendo $\mathrm{M}$ um metal de transição (geralmente, Mo, W, Ta e Nb) em seus estados de oxidação mais elevados (V ou VI) e o X é um heteroátomo (usualmente $\mathrm{P}, \mathrm{Si}, \mathrm{As}, \mathrm{Sb}$ e Ge). ${ }^{5}$

Os POM são formados pela condensação de oxoânions em meio ácido, conforme exemplos das Equações 1 e 2: ${ }^{5,6}$

$$
\begin{gathered}
7 \mathrm{MoO}_{4}{ }^{2-}+8 \mathrm{H}^{+} \rightarrow\left[\mathrm{Mo}_{7} \mathrm{O}_{24}\right]^{6-}+4 \mathrm{H}_{2} \mathrm{O} \\
12 \mathrm{WO}_{4}{ }^{2-}+\mathrm{HPO}_{4}{ }^{2-}+23 \mathrm{H}^{+} \rightarrow\left[\mathrm{PW}_{12} \mathrm{O}_{40}\right]^{3-}+12 \mathrm{H}_{2} \mathrm{O}
\end{gathered}
$$

Os heteropoliânions quando estão em sua forma protônica, são denominados de heteropoliácidos (HPA). ${ }^{4}$ Os POM podem apresentar diversas estruturas com diferentes fórmulas. Dentre as mais empregadas estão à estrutura de Keggin, Dawson, Waugh e Anderson. ${ }^{5}$ As estruturas são classificadas de acordo com a razão entre o número de heteroátomos e poliátomos (Tabela 1). 
Tabela 1. Principais estruturas de polioxometalatos, adaptada da referência 5.

\begin{tabular}{|c|c|c|c|c|}
\hline $\begin{array}{c}\text { Razão } \\
\text { X:M }\end{array}$ & Estrutura & Heteroátomo (X) & Poliátomo (M) & Fórmula \\
\hline 1:12 & Keggin & $\begin{array}{c}\mathrm{P}(\mathrm{V}), \mathrm{As}(\mathrm{V}) \\
\mathrm{Si}(\mathrm{IV}), \mathrm{Ge}(\mathrm{IV})\end{array}$ & $\mathrm{Mo}, \mathrm{W}$ & {$\left[X^{n+} M_{12} O_{40}\right]^{(n-8)-}$} \\
\hline 2:18 & Dawson & $\mathrm{P}(\mathrm{V}), \mathrm{As}(\mathrm{V})$ & Mo, W & {$\left[\mathrm{X}_{2}^{5+} \mathrm{M}_{18} \mathrm{O}_{62}\right]^{6-}$} \\
\hline $1: 9$ & Waugh & $\mathrm{Mn}(\mathrm{IV}), \mathrm{Ni}(\mathrm{V})$ & Mo & {$\left[\mathrm{X}_{4}^{+} \mathrm{M}_{9} \mathrm{O}_{32}\right]^{6-}$} \\
\hline 1:6 & Anderson & Te (IV), I (VII) & Mo, W & {$\left[\mathrm{X}^{\mathrm{n}+} \mathrm{M}_{6} \mathrm{O}_{24}\right]^{(\mathrm{n}-12)-}$} \\
\hline
\end{tabular}

\subsubsection{Heteropoliácidos de Keggin - Ácido 12-tungstofosfórico}

A estrutura completa dos heteropoliácidos de Keggin, especificamente o ácido 12-tungstofosfórico $\left(\mathrm{H}_{3} \mathrm{PW}_{12} \mathrm{O}_{40}, \mathrm{HPW}\right)$ é descrita considerando as subestruturas chamadas de: primária, secundária e terciária. A estrutura primária consta do ânion de Keggin, a qual é composta de um tetraedro $\left(\mathrm{XO}_{4} ; \mathrm{X}\right.$ é normalmente $\mathrm{P}$, Si ou $\left.\mathrm{Ge}\right)$ rodeado por um arranjo de 12 octaedros de $\mathrm{WO}_{6}$ compartilhados pelas arestas e vértices, formando os quatro grupos de $\mathrm{M}_{3} \mathrm{O}_{13}$. Cada grupo $\mathrm{M}_{3} \mathrm{O}_{13}$ é conectado a um heteroátomo de fósforo no tetraedro central, conforme a Figura 1.7,9,10

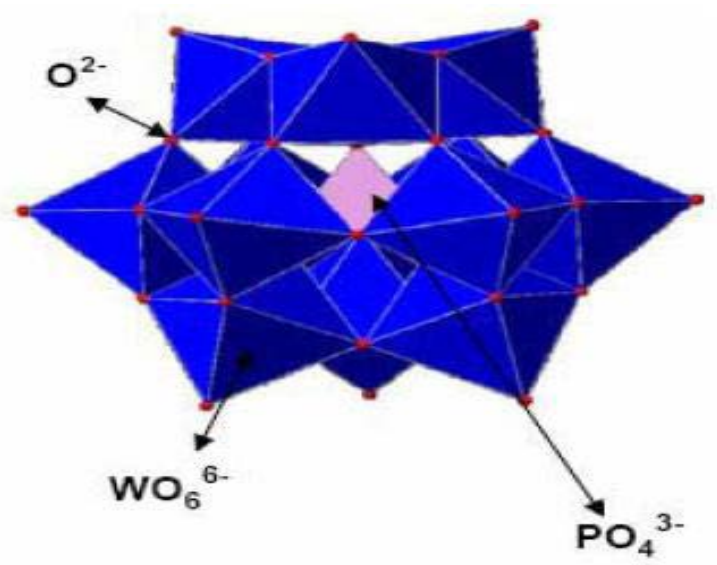

Figura 1. Estrutura poliédrica do ânion de Keggin, adaptada da referência 11.

A estrutura secundária diz respeito ao arranjo tridimensional a qual engloba os poliânions (estrutura primária), contra-ions e água de cristalização. ${ }^{3,4}$ A estrutura do cristal de HPA depende da quantidade de água de hidratação do composto, interligando os heteropoliânions por meio de ligações de hidrogênio com os 
oxigênios terminais. ${ }^{3,9,10} \mathrm{~A}$ rede cristalina é formada pelo empacotamento de cada ânion, formando uma estrutura cúbica de corpo centrado (Figura 2).
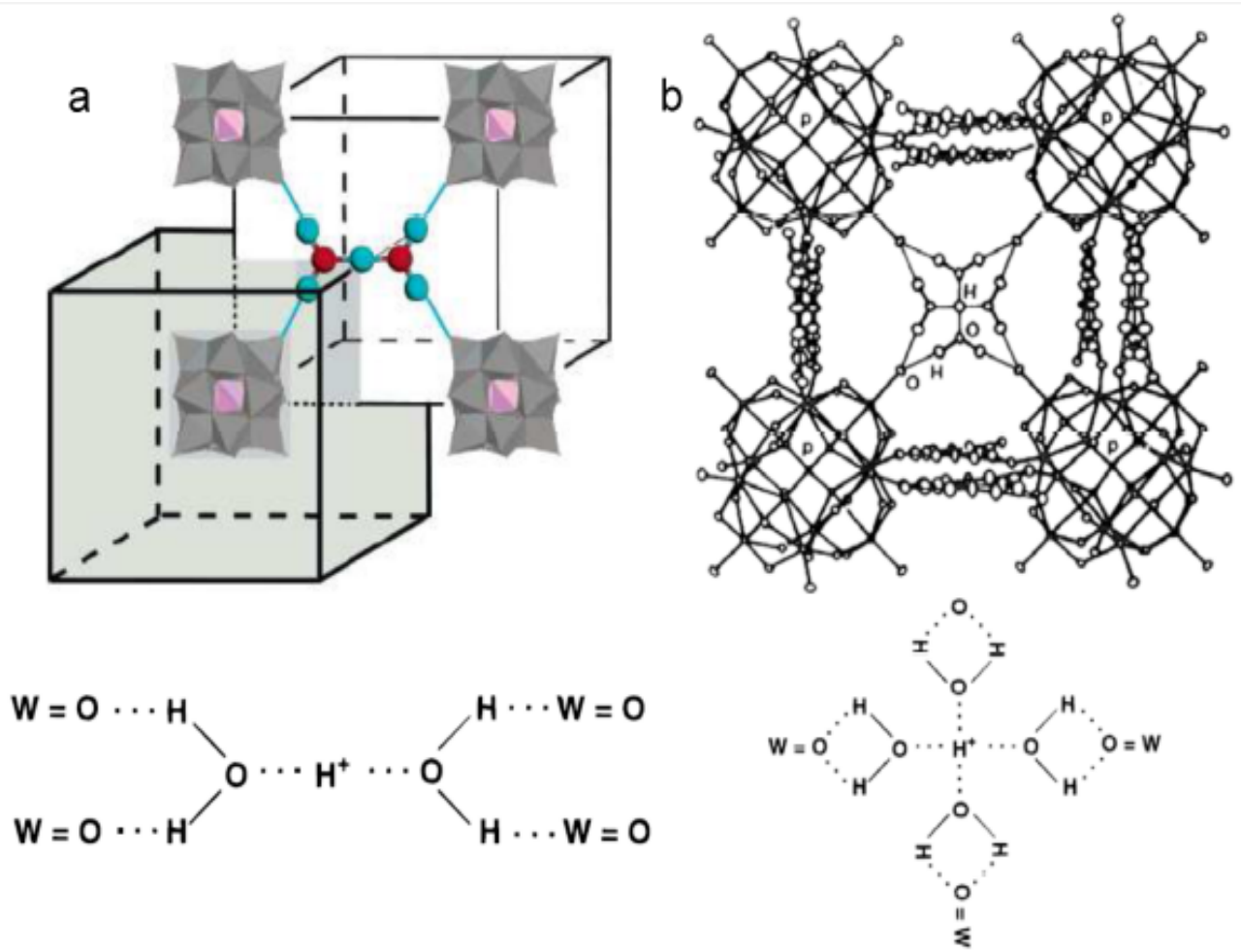

Figura 2. Representação da estrutura secundária do $\mathrm{HPW}$ hidratado $\mathrm{H}_{3}\left[\mathrm{PW}_{12} \mathrm{O}_{40}\right] \cdot \mathrm{nH}_{2} \mathrm{O}$. (a) Espécies do tipo $\mathrm{H}_{5} \mathrm{O}_{2}{ }^{+}(\mathrm{H}=$ cor azul, $\mathrm{O}=$ cor vermelha), com prótons duplamente hidratados, conectam 4 ânions de Keggin por meio de ligações de hidrogênio, formando uma estrutura hexahidratada $\left(\mathrm{H}_{3}\left[\mathrm{PW}_{12} \mathrm{O}_{40}\right] \cdot 6 \mathrm{H}_{2} \mathrm{O}\right)$. (b) Espécies do tipo $\mathrm{H}_{9} \mathrm{O}_{4}{ }^{+}$geram a estrutura dodecahidratada $\left(\mathrm{H}_{3}\left[\mathrm{PW}_{12} \mathrm{O}_{40}\right] \cdot 12 \mathrm{H}_{2} \mathrm{O}\right) .{ }^{62}$

A estrutura terciária (Figura 3) consiste na estrutura completa do sólido, representando as partículas iônicas que estão relacionadas com o tamanho das partículas, distribuição dos poros e área superficial. Esta estrutura terciária é a que tem maior influência nas propriedades de um heteropoliácido. O método de preparação de troca iônica de prótons do ácido por diversos cátions (e.g., $\mathrm{Cs}^{+}, \mathrm{NH}_{4}^{+}$) podem resultar em diferenças significativas na estrutura terciária destes sais e, portanto, em suas propriedades. ${ }^{3,10}$ 


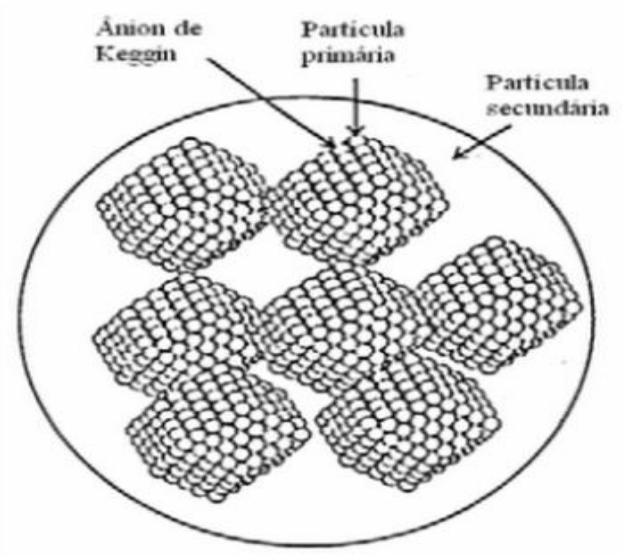

Figura 3. Estrutura terciária do heteropoliácido, adaptado da referência 10.

Entre os HPA com estrutura de Keggin, o ácido 12-tungstofosfórico é amplamente estudado para aplicações catalíticas, juntamente com os seus derivados salinos, devido à sua maior estabilidade e forte acidez. ${ }^{3,4,9}$ No entanto, as suas principais desvantagens são a área superficial muito baixa ${ }^{3}\left(<5 \mathrm{~m}^{2} \mathrm{~g}^{-1}\right)$ e elevada solubilidade em água e solventes polares, o que conduz a processos catalíticos homogêneos nestes meios. A hidrofobicidade é uma propriedade desejável para os HPA, porque os torna mais resistentes à desativação por água ou outros solventes polares, potencializando-os para possíveis reciclagens. ${ }^{4}$ Por conseguinte, a substituição dos prótons do HPA por amônio e metais alcalinos tem sido apontada como alternativa para aumentar a sua microporosidade, a área superficial e transformar os sais de HPA em compostos mais hidrofóbicos. Os HPA apresentam esta flexibilidade estrutural que possibilita a troca iônica e não prejudica a estrutura de Keggin. ${ }^{9}$

O aperfeiçoamento destas propriedades peculiares dos sais de HPA, tais como solubilidade, microporosidade, acidez, e volume de poro e estabilidade térmica estão relacionados ao tamanho do cátion substituído, de acordo com Moffat e colaboradores. $^{15}$ 
Os sais obtidos podem ser divididos em dois grupos de acordo com suas propriedades. ${ }^{15} \mathrm{~A}$ troca iônica dos prótons do heteropoliácido por cátions pequenos , como $\mathrm{Na}^{+} \mathrm{e} \mathrm{Li}^{+}$, sendo estes denominados sais do grupo $\mathrm{A},{ }^{15}$ forma sais solúveis e não há aumento significativo na área superficial em relação ao ácido precursor. Em contraste, a troca por cátions monovalentes maiores e com baixa valência, como $\mathrm{NH}_{4}^{+}, \mathrm{K}^{+}, \mathrm{Cs}^{+}$, sendo estes denominados sais do grupo $\mathrm{B},{ }^{15}$ apresenta uma rígida estrutura microporosa e aumento na área superficial. ${ }^{9}$ De acordo com as propriedades físico-químicas, os sais de prata de HPW são entre o grupo soluvéis A e o grupo insolúvel B. ${ }^{16}$

O raio do íon $\mathrm{Ag}^{+}(0.100 \mathrm{~nm})$ está entre o raio de $\mathrm{Na}^{+}(0.0095 \mathrm{~nm})$ e do $\mathrm{K}^{+}$ (0,133 nm) para o mesmo número de coordenação IV. A entalpia absoluta de hidratação do íon $\mathrm{Ag}^{+}$está entre $\mathrm{Na}^{+}$e $\mathrm{K}^{+}$. Assim, pode-se esperar também que a solubilidade dos sais de $\mathrm{Ag}^{+}$de HPW é entre as solubilidades dos sais de sódio e de potássio de HPW. ${ }^{70}$

Os sais AgHPW neutro ou ácidos têm atraído grande interesse devido às suas atividades multifuncionais. Os sais de prata de HPW mostram significativa acidez medida por sorção de amoníaco, que é cerca de uma ordem de grandeza superior ao sal de césio derivado do HPW. ${ }^{38}$ Supõe-se que esta elevada acidez é produzida pela dissociação das moléculas de água coordenadas com os cátions de prata. ${ }^{33,35}$ Os HPA de prata apresentam uma alta estabilidade térmica, tornando-os potencialmente promissores para diversas aplicações. O HPW decompõe-se em uma temperatura de $465^{\circ} \mathrm{C} .{ }^{4,9}$

Zieba e colaboradores realizaram o estudo da área específica dos sais de AgHPW e verificaram que os mesmos não apresentaram uma alteração significativa na área, em comparação com o HPW. ${ }^{17}$ Por conseguinte, o uso de suportes para 
imobilizar estes sais pode ser uma alternativa para obtenção de um aumento significativo da área específica e consequentemente do seu desempenho catalítico. Na literatura, o modelo da estrutura secundária dos sais derivados de HPW já foi postulada. Ele assume que uma camada monomolecular de HPW é depositada sobre o núcleo do seu sal neutro. Por exemplo, a camada de superfície autoorganizada do HPW é isoestrutural com o núcleo $\mathrm{K}_{3} \mathrm{PW}_{12} \mathrm{O}_{40}$ que modifica a sorção e propriedades catalíticas do sal $\mathrm{K}_{2} \mathrm{HPW}_{12} \mathrm{O}_{40} \cdot{ }^{33}$

De forma geral, tanto os compostos com prótons remanescentes, como aqueles totalemente substituídos, ou seja, com sais neutros, estão sendo pesquisados e aplicados como bons catalisadores em diversas reações.

\subsection{Sólidos mesoporosos ordenados}

Segundo a União Internacional de Química Pura e Aplicada (IUPAC), os materiais porosos são definidos de acordo com o tamanho do poro e classificados em três classes: microporosos $(<2 \mathrm{~nm})$, mesoporosos $(2-50 \mathrm{~nm})$ e macroporosos $(>50 \mathrm{~nm})^{18}$

As zeólitas, são os materiais mais estudados e utilizados na classe dos microporosos, apresentando excelentes propriedades catalíticas em virtude de sua rede de aluminossilicato cristalino. ${ }^{18}$ As aplicações das zeólitas são: adsorção, catálise, craqueamento de petróleo, dentre outras. ${ }^{1}$ Entretanto as suas aplicações são limitadas a processos que envolvem compostos grandes, em virtude da distribuição e do tamanho de seus poros (máximo 1,2 nm). A restrição destes materiais microporosos em algumas reações levou ao desenvolvimento das sílicas mesoporosas. $^{19}$

A primeira síntese de um material mesoporoso ordenado foi descrito em uma patente na literatura, em 1969. No entanto, devido à ausência de análises mais 
aprofundadas, as propriedades marcantes deste produto não foram reconhecidas. ${ }^{20}$ Em 1992, um material similar foi obtido pelo cientistas da Mobil Oil Corporation, que descobriu as características marcantes deste material de sílica, sendo nomeado como família M41S. ${ }^{20}$ Desde então, várias estruturas mesoporosas foram sintetizadas, variando-se os precursores e as condições de síntese, obtendo-se as sílicas mesoporosas com estruturas de poros diferentes, entre elas a forma hexagonal (MCM-41), cúbica (MCM-48) e lamelar (MCM-50). ${ }^{20}$ A Figura 4 mostra as estruturas mais comuns dos materiais da família da M41S.

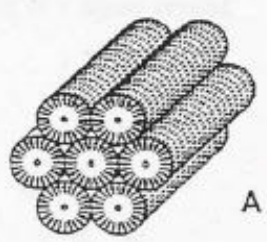

A

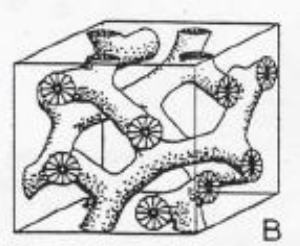

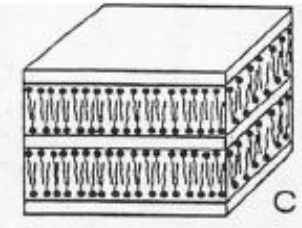

Figura 4. Estruturas dos materiais da família M41S: A-hexagonal, B-cúbica e C-lamelar, adaptada da referência 28.

Por meio da utilização de compostos direcionadores de estruturas, estas sílicas são caracterizadas por grandes áreas superficiais e estreita distribuição dos tamanhos dos poros. A MCM-41, por exemplo, é preparada com a utilização de surfactantes catiônicos hexagonais em soluções básicas, produzindo sólidos porosos ordenados com tamanhos de poros de 2 a 3 nm. ${ }^{18,20,21}$

Em 1998, Zhao e colaboradores desenvolveram uma nova família de sílicas mesoporosas altamente ordenadas com tamanhos de poros uniformes de até $30 \mathrm{~nm}$, denominadas Santa Barbara Amorphous (SBA), empregando copolímeros tribloco não iônicos em meio ácido. ${ }^{22-24}$ Esses novos materiais com tamanho de poros entre 2 e $30 \mathrm{~nm}$ foram identificados como estruturas cúbicas (SBA-11), hexagonal 3D (SBA-12), hexagonal 2D (SBA-15) e cúbica em forma de gaiola (SBA-16). ${ }^{22}-25$ 


\subsubsection{Mecanismos de formação de materias mesoporos}

Materiais mesoporosos ordenados são sintetizados, em geral, utilizando uma fonte de sílica, surfactantes que agem como agentes direcionadores estruturais em meio ácido ou básico.

Os surfatantes funcionam como moldes para formar um compósito orgânicoinorgânico ordenado. Por meio de calcinação, o surfatante é removido, restando a rede de sílica porosa. ${ }^{18}$ Ao contrario do que ocorre com as zeólitas, os moldes não são moléculas orgânicas simples e sim moléculas de surfatante líquido cristalino auto-agregadas. A formação do compósito orgânico-inorgânico ordenado é baseada em interações eletrostáticas entre os surfatantes carregados positivamente e as espécies de silicato carregadas negativamente. ${ }^{18} \mathrm{~A}$ forma como o precursor inorgânico interage com o surfatante torna-se um assunto no qual os modelos divergem quanto à formação e as classes de materiais mesoporosos. Há várias propostas de modelos para esclarecer a formação de materiais mesoporosos, fornecendo base para o estabelecimento de várias rotas de síntese. ${ }^{18}$

Os cientistas da Mobil Oil Corporation propuseram dois caminhos mecanísticos para explicar a formação de materiais mesoporosos, sendo um destes conhecido como mecanismo de direcionamento por cristal líquido "liquid-crystal templating" (LCT) e o segundo denominado rota cooperativa. ${ }^{21}$

No primeiro, os monômeros do tensoativo se agrupam em um arranjo hexagonal, ou seja, a fase cristal líquido se forma antes que as espécies de silicato sejam adicionadas. As espécies de silicato são polimerizadas na superfície dos agregados micelares através das interações de cargas, formando as paredes da estrutura hexagonal. Em seguida, remove-se o tensoativo e obtêm-se o material mesoporoso. No segundo, a organização cooperativa entre os ânions silicato e os 
cátions do tensoativo é a responsável pela produção dos tubos micelares que ao desenvolverem formam a estrutura final da fase. A segunda rota é em geral a mais aceita pelos pesquisadores. ${ }^{21}$

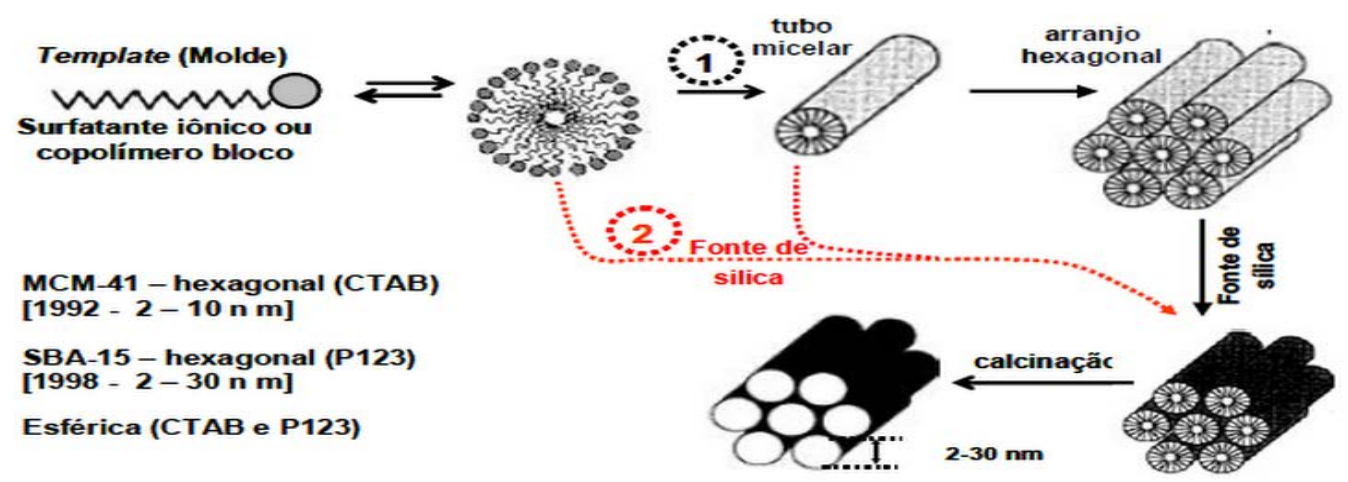

Figura 5. Mecanismo do molde cristal-líquido (LCT) na formação do MCM-41 com duas vias mecanísticas. ${ }^{18,25}$

O estudo do mecanismo de formação dos silicatos mesoporosos foi estendido por Stuck e colaboradores, ${ }^{26}$ os quais propuseram o chamado "Cooperative Templating“. Inicialmente foram descritos quatro caminhos mecanísticos:

(1) As interações cooperativas ocorrem entre um tensoativo catiônico $\left(\mathrm{S}^{+}\right)$e uma espécie inorgânica (Iº, por exemplo, o silicato. Essa via foi usada na síntese dos materiais M41S originais;

(2) As interações ocorrem com combinação de carga inversa $\left(\mathrm{S}^{-}{ }^{+}\right)$. É utilizado como direcionador um tensoativo aniônico e as espécies inorgânicas catiônicas;

(3) O tensoativo e a espécie inorgânica estão carregados negativamente na presença de uma espécie de carga oposta mediada por um contra ion $\left(\mathrm{S}^{-} \mathrm{M}^{+} \mathrm{I}^{-}, \mathrm{M}^{+}=\right.$ íon metal alcalino);

(4) O tensoativo e a espécie inorgânica estão carregados positivamente na presença de uma espécie de carga oposta mediada por um contra ion $\left(\mathrm{S}^{+} \mathrm{X}^{-} \mathrm{I}^{+}, \mathrm{X}^{-}=\right.$ haleto). ${ }^{18,25}$ 
Além das sínteses baseadas em interações iônicas, a abordagem cristal líquido gerou mais duas vias mecanísticas que mostram a interação orgânicainorgânica que não seja iônica. Sob condições neutras, as mesoestruturas são formadas usando tensoativos neutros $\left(\mathrm{S}^{0}\right)$ ou tensoativos não iônicos $\left(\mathrm{N}^{0}\right)$. Nesta abordagem $\left(\mathrm{S}^{0} / \mathrm{N}^{0} \mathrm{I}^{0}\right)$ as ligações hidrogênio são consideradas responsáveis pela formação da mesofase. No mecanismo do molde cristal-líquido ligante assistido, as ligações covalentes são formadas entre as espécies precursoras inorgânicas e as moléculas dos tensoativos seguida pela auto-montagem do tensoativo. ${ }^{18,25} \mathrm{De}$ acordo com a molécula orgânica molde utilizada na síntese e a interação de espécies inorgânicas, os materiais mesoporosos podem ser classificados de acordo com a Tabela 2.

Tabela 2. Possíveis vias para a síntese de materiais mesoporosos, adaptado da referência 34.

\begin{tabular}{|c|c|c|c|c|}
\hline Template & Interação & \multicolumn{2}{|c|}{ Condições de sintese } & Exemplos \\
\hline \multirow[t]{4}{*}{$\begin{array}{l}\text { Surfactante } \\
\text { iônico }\end{array}$} & $\begin{array}{l}\text { Interação direta } \\
\text { (Iônica) }\end{array}$ & $\mathrm{ISS}^{+}$mmm & Básico & $\begin{array}{l}\text { MCM-41, MCM-48, } \\
\text { MCM-50, FSM-16 }\end{array}$ \\
\hline & & $\mathrm{I}^{+} \mathrm{S}^{-}$мmm & Básico-neutro & $\begin{array}{l}\text { Alumínio, ferro, } \\
\text { óxido de chumbo, } \\
\text { AMS }\end{array}$ \\
\hline & \multirow{2}{*}{$\begin{array}{l}\text { Interação via } \\
\text { intermediário } \\
\text { (Iônica) }\end{array}$} & $\mathrm{I}^{+} \mathrm{XS}^{+}$mm & Ácido & $\begin{array}{l}\text { SBA-1, SBA-2, SBA- } \\
3 \text {, }\end{array}$ \\
\hline & & $\mathrm{IX}^{+} \mathrm{S}^{-}$mm & Básico & $\begin{array}{l}\text { Alumínio, óxido de } \\
\text { zinco }\end{array}$ \\
\hline \multirow{2}{*}{$\begin{array}{l}\text { Surfactante } \\
\text { não iônico }\end{array}$} & \multirow[t]{2}{*}{ Não iônica } & $\mathrm{I}^{0} \mathrm{~S} \mathrm{O}^{0} \mathrm{~mm}$ & Ácido & HMS \\
\hline & & $\mathrm{I}^{0} \mathrm{~N}^{0}$ mиm & Ácido & MSU, SBA-15 \\
\hline $\begin{array}{l}\text { Copolímero } \\
\text { (ligante } \\
\text { assistido) }\end{array}$ & $\begin{array}{l}\text { Ligação } \\
\text { covalente }\end{array}$ & I-Smm & Ácido & Nb-TMS, Ta-TMS \\
\hline Nanomolde & - & - & - & CMK-n \\
\hline
\end{tabular}




\subsubsection{SBA-15}

SBA-15 é sintetizada utilizando um copolímero tribloco anfifílico, $-\mathrm{PEO}_{20^{-}}$ $\mathrm{PPO}_{70}-\mathrm{PEO}_{20}$ - (óxido de etileno)-poli (óxido de propileno)-poli (óxido de etileno), comercialmente conhecido e aqui denominado como $\mathrm{P} 123$, sendo este um agente direcionador estruturante orgânico. ${ }^{22}$

A síntese da SBA-15 se inicia com a organização das moléculas de copolímero para formar micelas. Posteriormente, as micelas se agrupam formando tubos cilíndricos. Após a adição do precursor de sílica observa-se a formação de diferentes camadas de silicatos ao redor da interface da micela. Posteriormente ocorre uma série de reações de condensação e polimerização (processo sol-gel) das espécies de silício sobre a interface dos tubos, dando lugar à formação de uma rede inorgânica com estrutura hexagonal de íons silicato-copolímero, conforme a Figura $6 .^{27}$

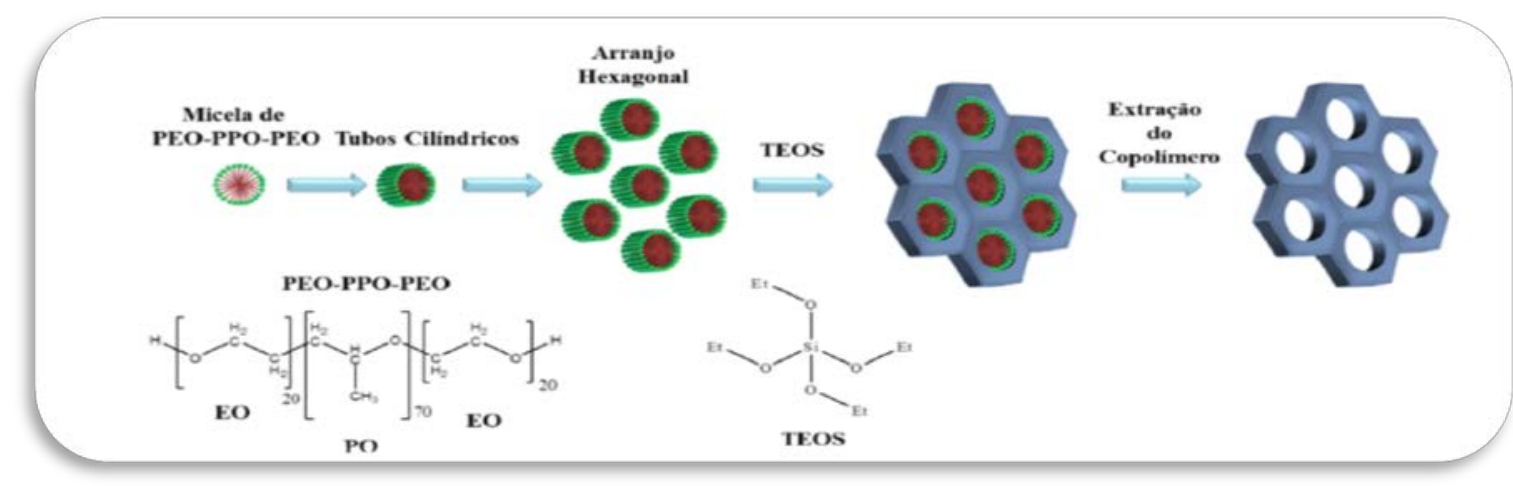

Figura 6. Mecanismo de formação de materiais mesoporos.

A sílica mesoporosa do tipo SBA-15 apresenta estrutura hexagonal com poros altamente ordenados e interligados de aproximadamente $6,0 \mathrm{~nm}$ de diâmetro, maior que os poros característicos da estrutura da MCM-41, paredes relativamente espessas (3,1 - 6,4 nm), notável estabilidade térmica, hidrotérmica, mecânica e área superficial na faixa de 600 e $1000 \mathrm{~m}^{2} \mathrm{~g}^{-1} \cdot{ }^{22-24}$ As propriedades adquiridas pela SBA- 
15 variam de acordo com as condições sintéticas estabelecidas para a preparação do material, como o tamanho de poro e a espessura da parede podendo ser ajustada através da variação da temperatura de aquecimento $\left(35\right.$ a $\left.140{ }^{\circ} \mathrm{C}\right)$ e tempo (11 a 72 h) da reação. A Tabela 3 identifica estas variáveis. ${ }^{22}$

Tabela 3. Condições de preparação ${ }^{a}$ e propriedades físico-químicas da SBA-15 hexagonal tais como: área específica por $\mathrm{BET}\left(\mathrm{S}_{\mathrm{BET}}\right)$, tamanho de poro $\left(\mathrm{P}_{\mathrm{S}}\right)$ e volume de poro $\left(\mathrm{V}_{\mathrm{p}}\right){ }^{22}$

\begin{tabular}{|c|c|c|c|c|c|}
\hline Copolímero & $\begin{array}{l}\text { Temperatura } \\
\text { reacional }\left({ }^{\circ} \mathrm{C}\right)\end{array}$ & $d(100)(\mathrm{nm})$ & $\begin{array}{c}\mathrm{S}_{\mathrm{BET}} \\
\left(\mathrm{m}^{2} \mathrm{~g}^{-1}\right)\end{array}$ & $\begin{array}{c}\mathbf{P}_{\mathrm{s}} \\
(\mathrm{nm})\end{array}$ & $\begin{array}{c}V_{p} \\
\left(\mathrm{~cm}^{3} \mathrm{~g}^{-1}\right)\end{array}$ \\
\hline $\mathrm{EO}_{5} \mathrm{PO}_{70} \mathrm{EO}_{5}$ & 35 & $11,8(11,7)$ & 630 & 10 & $\overline{1,04}$ \\
\hline $\mathrm{EO}_{20} \mathrm{PO}_{70} \mathrm{EO}_{20}$ & 35 & $10,4(9,57)$ & 690 & 4,7 & 0,56 \\
\hline $\mathrm{EO}_{20} \mathrm{PO}_{70} \mathrm{EO}_{20}$ & $35,80^{*}$ & $10,5(9,75)$ & 780 & 6,0 & 0,80 \\
\hline $\mathrm{EO}_{20} \mathrm{PO}_{70} \mathrm{EO}_{20}$ & $35,80^{*}$ & $10,3(9,95)$ & 820 & 7,7 & 1,03 \\
\hline $\mathrm{EO}_{20} \mathrm{PO}_{70} \mathrm{EO}_{20}$ & $35,90 *$ & $10,8(10,5)$ & 920 & 8,5 & 1,23 \\
\hline $\mathrm{EO}_{20} \mathrm{PO}_{70} \mathrm{EO}_{20}$ & $35,100 *$ & $10,5(10,4)$ & 850 & 8,9 & 1,17 \\
\hline $\mathrm{EO}_{17} \mathrm{PO}_{55} \mathrm{EO}_{17}$ & 40 & $9,75(8,06)$ & 770 & 4,6 & 0,70 \\
\hline $\mathrm{EO}_{20} \mathrm{PO}_{30} \mathrm{EO}_{20}$ & 60 & $7,76(7,76)$ & 1000 & 5,1 & 1,26 \\
\hline $\mathrm{EO}_{26} \mathrm{PO}_{39} \mathrm{EO}_{26}$ & 40 & $9,26(8,82)$ & 960 & 6,0 & 1,08 \\
\hline $\mathrm{EO}_{13} \mathrm{PO}_{70} \mathrm{EO}_{13}$ & 60 & $8,06(8,05)$ & 950 & 5,9 & 1,19 \\
\hline $\mathrm{PO}_{19} \mathrm{EO}_{33} \mathrm{PO}_{19}$ & 60 & $7,45(7,11)$ & 1040 & 4,8 & 1,15 \\
\hline
\end{tabular}

a $\overline{\text { Reação a } 35^{\circ} \mathrm{C} \text { durante } 20 \mathrm{~h} \text {; em seguida, aquecimento para a temperatura mais elevada, durante }}$ $24 \mathrm{~h}$, ou para a segunda entrada para $80^{\circ} \mathrm{C}, 48 \mathrm{~h}$. ${ }^{a}$ Preparação e propriedades físico-químicas da SBA-15 hexagonal preparada com copolímeros tribloco de poli (óxido de alquileno). O valor de d(100) dentro de parênteses é o valor para o produto SBA-15 calcinado a $500^{\circ} \mathrm{C}$ durante $6 \mathrm{~h}$. Distribuições de tamanho de poro, volume de poro e isoterma BET foram determinadas a partir de experimentos de adsorção-dessorção de $\mathrm{N}_{2}$ a $-196{ }^{\circ} \mathrm{C}$. As espessuras de parede foram calculadas como: $a_{0}$-tamanho do poro $\left(a_{0}=2 d(100) / \sqrt{ } 3\right){ }^{22}$

A SBA-15 é tipicamente sintetizada em uma temperatura de reação de $35^{\circ} \mathrm{C}$ durante $24 \mathrm{~h}$, seguido de tratamento hidrotérmico a $80{ }^{\circ} \mathrm{C}$ durante 24 a $48 \mathrm{~h} .{ }^{22,23} \mathrm{~A}$ 
temperatura ambiente, apenas sílica em pó amorfa ou produtos de baixa cristalinidade são obtidos. ${ }^{22}$ Tetraetilortosilicato (TEOS) e tetrametilortosilicato (TMOS) são fontes adequadas de sílica para a preparação de SBA-15. ${ }^{23}$

Em valores de $\mathrm{pH}$ entre 2 e 6 , acima do ponto isoelétrico de sílica $(\mathrm{pH}=2)$ nenhuma precipitação ou formação de gel de sílica ocorre. Em um pH neutro $(\cong 7)$ apenas sílica amorfa desordenada é obtida. Mesoporos hexagonais de SBA-15 são formados sob condições ácidas $(\mathrm{pH}=1)$ com $\mathrm{HCl}, \mathrm{HBr}^{22}$

Este material tem sido amplamente utilizado com potenciais aplicações que vão desde adsorção e catálise a nanotecnologia e biotecnologia. $^{28-30}$ Especificamente, a investigação de materiais mesoporosos para aplicações biomédicas e biólogicas tem experimentado um aumento notável nos últimos anos, sendo utilizado como matriz para liberação controlada de drogas e diagnóstico do câncer e terapia. ${ }^{31}$

\subsection{Heteropoliácidos suportados}

Os HPA têm sido utilizados na forma protônica ou suportada, sendo esta forma preferível por adquirir novas propriedades catalíticas interessantes para aplicações. $^{32} \mathrm{O}$ HPW é um ácido forte sólido, porém a acessibilidade dos reagentes em reações na fase gás - sólido para os prótons cataliticamente ativos é limitada, devido à sua baixa área superficial específica $\left(5 \mathrm{~m}^{2} \mathrm{~g}^{-1}\right){ }^{33}$ No entanto, a sua atividade catalítica pode ser melhorada utilizando dois métodos: (i) substituição parcial ou total dos prótons do HPW por cátions e (ii) impregnação do HPW em suportes porosos. A impregnação em suportes porosos de diferentes óxidos, como $\mathrm{ZrO}_{2}$ e $\mathrm{SiO}_{2}{ }^{9,68,69}$ ou óxidos mistos, como $\mathrm{SiO}_{2}-\mathrm{Al}_{2} \mathrm{O}_{3}$, que dispersam o heteropoliácido, tornando-o insolúvel em solventes polares, aumentam sua área superficial e melhoram sua atividade catalítica em relação ao HPA não suportados. ${ }^{7}$ 
De acordo com dados de dessorção térmica de amônia, a força ácida de espécies HPW suportadas diminui na seguinte ordem: $\mathrm{SiO}_{2}>\alpha-\mathrm{Al}_{2} \mathrm{O}_{3}>$ carvão ativado. ${ }^{9}$ Porém, o tipo de HPA e o suporte, a natureza da interação entre o HPA e o suporte, bem como os parâmetros experimentais durante a síntese determinam consideravelmente a atividade dos catalisadores obtidos. ${ }^{16}$

A sílica mesoporosa do tipo SBA-15 (Santa Barbara Amorphous-15) apresenta uma série de propriedades catalíticas promissoras para ser utilizada como suporte, como alta área superficial, estrutura hexagonal de poros altamente ordenados e notável estabilidade térmica. ${ }^{22}$ Por conseguinte, o uso da SBA-15, para suportar nanopartículas de HPA e seus derivados salinos pode ser uma alternativa para obtenção de um aumento significativo da área específica e melhor acessibilidade do substrato aos centros ativos. Estes materiais mesoporosos têm a vantagem de apresentarem uma baixa taxa de coque em decorrência do elevado diâmetro médio de poros. ${ }^{34}$

\subsection{Desidratação de etanol}

Em virtude do alto preço do petróleo e sua carência iminente, é prudente buscar meios economicamente viáveis para produzir olefinas tais como: etileno e propileno, proveniente de matéria prima renovável.

O etileno é um dos principais substratos para a indústria química, sendo utilizado na síntese de vários produtos, por exemplo, polietileno (PE), cloreto de polivinila (PVC), óxido de etileno e dicloreto de etileno. ${ }^{35}$ Convencionalmente, tem sido produzido pelo craqueamento térmico de gás liquefeito de petróleo (GLP) ou nafta. Este processo consiste em uma reação endotérmica de altas temperaturas $\left(600\right.$ - $\left.1000{ }^{\circ} \mathrm{C}\right) \cdot{ }^{36} \mathrm{Em}$ comparação com a rota convencional, a desidratação catalítica de etanol para etileno é muito atrativa, já que requer temperatura mais 
baixa e oferece maior rendimento. Neste contexto, a produção de etileno por desidratação catalítica de etanol tornou-se uma importante via de síntese alternativa, pois o etanol pode ser facilmente obtido a partir de fontes renováveis, como a biomassa. $^{35}$

A desidratação de etanol é realizada em fase vapor, na presença de catalisadores sólidos ácidos tais como: zeólitas, alumina e óxidos metálicos, dentre outros. ${ }^{37}$ Os principais produtos obtidos nesta reação podem ser éter dietílico, de acordo com a equação (3) e etileno, equação (4). O éter diétilico é o produto termodinamicamente favorecido; sendo formado a temperaturas mais baixas, e a seletividade para o etileno aumenta com o aumento da temperatura de reação, proveniente de éter diétilico. ${ }^{37}$

$$
\begin{gathered}
2 \mathrm{CH}_{3} \mathrm{CH}_{2} \mathrm{OH} \rightarrow \mathrm{CH}_{3} \mathrm{CH}_{2} \mathrm{OCH}_{2} \mathrm{CH}_{3}+\mathrm{H}_{2} \mathrm{O} \\
\mathrm{CH}_{3} \mathrm{CH}_{2} \mathrm{OH} \rightarrow \mathrm{CH}_{2} \mathrm{CH}_{2}+\mathrm{H}_{2} \mathrm{O}
\end{gathered}
$$




\subsection{OBJETIVOS}

O objetivo geral deste trabalho foi a preparação e caracterização de sais de prata derivados do ácido 12-tungstofosfórico para suporta-los em sílica mesoporosa tipo SBA-15 e realizar uma avaliação da atividade catalítica dos materiais sintetizados na reação de desidratação do etanol.

\subsubsection{Objetivos específicos:}

i) Preparar sais derivados do HPW, parcialmente e completamente substituídos pelo contraíon de prata, formando $\mathrm{Ag}_{\mathrm{x}} \mathrm{H}_{3-\mathrm{x}} \mathrm{PW}_{12} \mathrm{O}_{40}$, sendo $(\mathrm{x}=$ $1,0 ; 1,5 ; 2,0 ; 2,5$ e 3,0$)$.

ii) Caracterizar os heteropolissais sintetizados por meio de diferentes técnicas de análise de estrutura e de acidez, como: MEV, FT-IR, DRX, FRX/EDX, MAS RMN de ${ }^{31} \mathrm{P}$, adsorção de $\mathrm{N}_{2}$, TG e adsorção de piridina.

iii) Sintetizar sílica mesoporosa do tipo SBA-15 e caracterizar por MEV, FTIR, SAXS, TG, MAS RMN de ${ }^{29} \mathrm{Si}$, adsorção de $\mathrm{N}_{2}$.

iv) Aplicar os heteropolissais na reação modelo de desidratação de etanol e identificar a ordem de maior conversão

v) Impregnar o sal de maior atividade no suporte de SBA-15 e comparar sua estrutura, propriedades texturais e atividade catalítica. 


\section{Experimental}




\section{EXPERIMENTAL}

\subsection{Lista de Materiais}

- Ácido 12 - tungstofosfórico, $\mathrm{H}_{3} \mathrm{PW}_{12} \mathrm{O}_{40} \cdot \mathrm{nH}_{2} \mathrm{O}$, Aldrich

- Nitrato de prata, $\mathrm{AgNO}_{3}$, pureza = 99,99\%, Reagentes Analíticos - Impex;

- Peneira molecular 3A, Aldrich;

- Poli(etileno glicol) - B- Poli (propileno glicol) - B - Poli(etileno glicol), $\mathrm{PEO}_{20}-\mathrm{PPO}_{70}-\mathrm{PEO}_{20}$, Aldrich;

- Ácido Clorídrico, $\mathrm{HCl}, 37 \%$, Vetec;

- Etanol (EtOH), $\mathrm{CH}_{3} \mathrm{CH}_{2} \mathrm{OH}$, pureza $\geq 99,8 \%$, Vetec;

- Hélio, He, pureza $\geq 99,999 \%$, White Martins;

- Nitrogênio, $\mathrm{N}_{2}$, pureza $\geq 99,999 \%$, White Martins;

- Ar sintético, pureza $\geq 99,999 \%$, White Martins;

- Piridina anidra (Py), $\mathrm{C}_{5} \mathrm{H}_{5} \mathrm{~N}$, pureza = 99,8\%, Aldrich;

- Brometo de Potássio, $\mathrm{KBr}$, pureza $\geq 99,5 \%$, Merck;

\subsection{Preparação dos Sais $\mathrm{Ag}_{\mathrm{x}} \mathrm{H}_{3-\mathrm{x}} \mathrm{PW}_{12} \mathrm{O}_{40}$}

Os sais de $\mathrm{Ag}_{x} \mathrm{H}_{3-\mathrm{x}} \mathrm{PW}_{12} \mathrm{O}_{40}$, (sendo $\mathrm{x}=1,0 ; 1,5 ; 2,0 ; 2,5 ; 3,0$ ) foram preparados de acordo com procedimento descrito por Haber e colaboradores. ${ }^{20}$

O nitrato de prata (Impex) foi previamente seco à vácuo a $25^{\circ} \mathrm{C}$ por $2 \mathrm{~h}$ antes da preparação da solução. A concentração do HPW (Sigma) foi determinada por espectrofotometria de UV-Vis a partir de uma curva analítica padrão do ácido (com leituras do máximo de absorbância em 260 nm, Figura A1 em anexo). Os sais de $\mathrm{Ag}_{\mathrm{x}} \mathrm{H}_{3-\mathrm{x}} \mathrm{PW}_{12} \mathrm{O}_{40}$ foram obtidos por um procedimento em que os volumes correspondentes as quantidades estequiométricas desejadas de uma solução de 
$\operatorname{AgNO}_{3}\left(0,1 \mathrm{~mol} \mathrm{~L}^{-1}\right)$ foram adicionadas a solução aquosa do HPW $\left(0,08 \mathrm{~mol} \mathrm{~L}^{-1}\right), \mathrm{a}$ uma taxa de adição de $1 \mathrm{~mL} \min ^{-1}$, sob agitação magnética constante. As soluções resultantes com os precipitados foram deixadas em repousos por $8 \mathrm{~h}$, sendo posteriormente evaporadas a $40{ }^{\circ} \mathrm{C}$ até a secura. Após esta secagem, os sólidos foram calcinados a $300^{\circ} \mathrm{C}$ por $2 \mathrm{~h}$. A Figura 7 ilustra o procedimento dessa síntese.

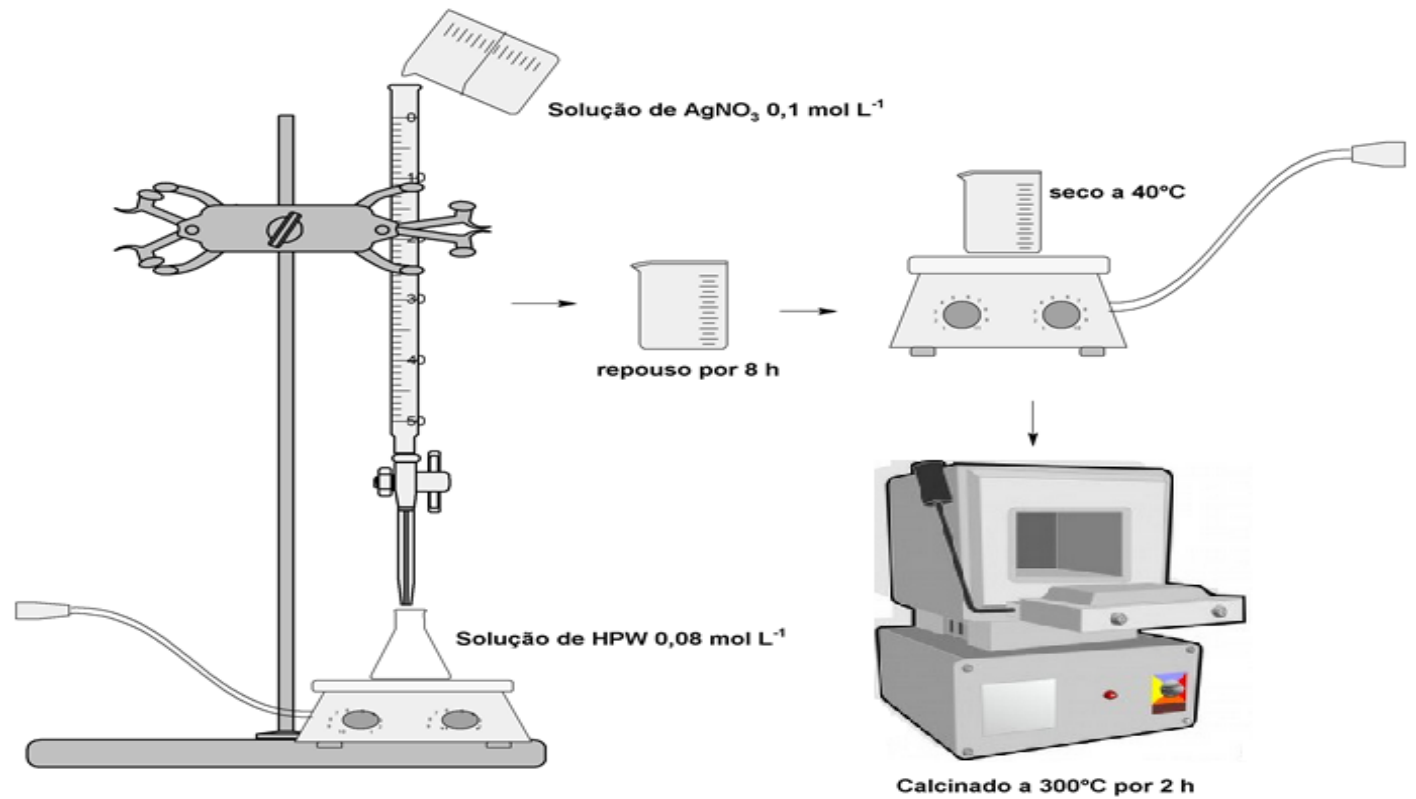

Figura 7. Resumo do procedimento experimental para a preparação dos sais $\mathrm{Ag}_{x} \mathrm{H}_{3-\mathrm{x}} \mathrm{PW}_{12} \mathrm{O}_{40}$.

\subsection{Síntese da Sílica Mesoporosa SBA-15}

A sílica mesoporosa foi sintetizada de acordo com o procedimento descrito por Zhao e colaboradores. ${ }^{22}$ Nesta síntese, $4 \mathrm{~g}$ de um copolímero tribloco, o surfactante Pluronic P123, $\mathrm{PEO}_{20}-\mathrm{PPO}_{70}-\mathrm{PEO}_{20}$ - (óxido de etileno) -poli (óxido de propileno) -poli (óxido de etileno), fornecido pela Aldrich, foi solubilizado em $100 \mathrm{~mL}$ de $\mathrm{HCl} 1,6 \mathrm{~mol} \mathrm{~L}^{-1}$ e aqueceu-se a solução a uma temperatura constante de $35{ }^{\circ} \mathrm{C}$, sob agitação. Depois da completa solubilização, adicionou-se 7,5 mL do precursor de sílica, tetraetilortosilicato (TEOS, Sigma-Aldrich), sob agitação. Foi distribuido este volume nas autoclaves, as quais foram levadas para estufa a $100{ }^{\circ} \mathrm{C}$ por $48 \mathrm{~h}$ e 
depois filtrado e seco a $50{ }^{\circ} \mathrm{C}$. O produto foi calcinado em um forno tubular a $300{ }^{\circ} \mathrm{C}$ por $4 \mathrm{~h}$ sob fluxo de nitrogênio, e depois a $540{ }^{\circ} \mathrm{C}$ por $8 \mathrm{~h}$ sob fluxo de ar atmosférico, com uma taxa de aquecimento de $2{ }^{\circ} \mathrm{C} \min ^{-1}$.

\subsection{Preparação do catalisador suportado}

O compósito 20\% $\mathrm{Ag}_{2} \mathrm{HPW} / \mathrm{SBA}-15$ foi preparado de acordo com 0 procedimento descrito por Holclajtner-Antunovic e colaboradores ${ }^{16}$ usando-se $^{2}$ quantidades adequadas dos precurssores para obtenção de $\mathrm{Ag}_{2} \mathrm{HPW}$. O nitrato de prata foi dissolvido em uma mistura de metanol - água (1:1) e suportado em SBA-15 por impregnação. Essa amostra foi envelhecida por $24 \mathrm{~h}$, seca a $110{ }^{\circ} \mathrm{C}$ e calcinada a $300{ }^{\circ} \mathrm{C}$ por $3 \mathrm{~h}$. Posteriormente, o HPW foi impregnado usando-se uma solução aquosa, seguida pelo mesmo procedimento de envelhecimento, secagem e calcinação descrito acima.

\subsection{Reação de desidratação de etanol}

A conversão dos compostos sintetizados foi testada na reação modelo de desidratação de etanol. O sistema utilizado para o experimento consiste de um micro reator de pulso desenvolvido no LabCat/IQ/UnB e acoplado a um cromatógrafo de fase gás com um detector de ionização de chama (Shimadzu GC-FID, modelo 2010; coluna Restek Rtx fase Wax ${ }^{\circledR}$ com as dimensões de $\left.30 \mathrm{~m} \times 0,25 \mathrm{~mm} \times 0,25 \mu \mathrm{m}\right) .{ }^{38}$

Antes da reação, as amostras foram peletizadas de forma que as dimensões dos grânulos fossem uniformes. Cada catalisador a ser analisado foi colocado no interior do reator e ativado a $300{ }^{\circ} \mathrm{C}$ por $1 \mathrm{~h}$. Uma sequência de 5 injecções de etanol (VETEC, previamente seco com peneira molecular 3A) foi realizada. Para 
cada injeção, foi gerado um cromatograma, cujos picos foram integrados para calcular a conversão e seletividade.

\subsection{Técnicas de Caracterização}

\subsubsection{Espectroscopia de Absorção na Região do Infravermelho}

A presença de grupos funcionais na estrutura dos materiais foi verificada por meio de espectroscopia no infravermelho por transformada de Fourier (FT-IR). Os espectros de infravermelho abrangendo a região de $4000-400 \mathrm{~cm}^{-1}$ foram obtidos em um espectrômetro Thermo Scientific, modelo Nicolet 6700. As medidas foram realizadas usando-se pastilhas de $\mathrm{KBr}$, resolução de $4 \mathrm{~cm}^{-1}$ e com 128 varreduras.

\subsubsection{Difração de Raios $X$}

Os difratogramas dos sais de $\mathrm{Ag}_{\mathrm{x}} \mathrm{H}_{3-\mathrm{x}} \mathrm{PW}_{12} \mathrm{O}_{40}$ foram obtidos em um difratômetro Bruker, modelo D8 Focus com radiação Cu K $\alpha(\lambda=1,5418 \AA$ Á), potência do tubo em 40 kV e 30 mA. A varredura do ângulo de difração $2 \theta$ foi feita no intervalo de 2 a $60^{\circ}$ com velocidade angular de $1^{\circ} \mathrm{min}^{-1}$.

\subsubsection{SAXS}

Os experimentos de difração de raios $X$ a baixos ângulos (DRX) foram realizados em um equipamento Nanostar da Bruker Instruments com um detector de filamento bidimensional, usando uma câmara de vácuo. Os parâmetros experimentais utilizados para estas medidas foram: comprimento de onda de raios $X$, $\lambda=0.15418 \mathrm{~nm}$, de 1,5 kW, colimado por um sistema de espelhos da Gobel e um sistema de 3 fendas, faixa do $q$ de 0,13 até $3,4 \mathrm{~nm}^{-1}$ e 20 min de exposição para a coleta de dados. Está análise foi executada sob supervisão do Prof. Dr. Luis Carlos Cides da Silva no Instituto de Física da Universidade de São Paulo.

\subsubsection{Análises Térmicas}

A análise da estabilidade térmica dos catalisadores foi verificada pelas curvas TG/DTG obtidas em um analisador térmico da TA-Instruments (modelo SDT 2960) 
sob fluxo de $110 \mathrm{~mL} \mathrm{~min}^{-1}$ de ar sintético $(99,999 \%)$ numa taxa de aquecimento de $10^{\circ} \mathrm{C} \min ^{-1}$, na faixa de $25-700^{\circ} \mathrm{C}$

\subsubsection{Análise Elementar (FRX/EDX)}

Os dados de fluorescência de raios $X$ por Energia Dispersiva dos materiais foram obtidos utilizando o equipamento EDX 720 (Shimadzu) com um tubo de raios X com alvo de ródio. As amostras foram analisadas em vácuo a 15 e 50 kV. O teor dos óxidos foi determinado por comparação com padrões fundamentais.

\subsubsection{Ressonância Magnética Nuclear no Estado Sólido de ${ }^{29} \mathrm{Si}$ e ${ }^{31} \mathrm{P} \mathrm{com}$} rotação no ângulo mágico

A técnica de ressonância magnética nuclear (RMN) foi utilizada para caracterização dos materiais sintetizados. As aquisições foram realizadas com rotação no ângulo mágico (MAS RMN) e foram analisados os ambientes químicos do átomo de ${ }^{29} \mathrm{Si} \mathrm{e}{ }^{31} \mathrm{P}$. Os espectros foram obtidos em um equipamento Bruker Avance III HD Ascend de 14,1 T, relativo a $600 \mathrm{MHz}$ para o núcleo de ${ }^{1} \mathrm{H}$. Utilizou-se uma sonda para sólidos CP/MAS de $4 \mathrm{~mm}$, empacotando-se as amostras em um rotor de zircônia com as seguintes condições específicas para cada núcleo:

- $\quad$ MAS RMN de ${ }^{29} \mathrm{Si}(119,3 \mathrm{MHz})$ a uma velocidade de $10 \mathrm{kHz}$, duração do pulso de 4,25 $\mu$ s com intervalo entre pulsos de 20 s e mínimo de 1024 aquisições. A referência utilizada foi o $\mathrm{Si}\left(\mathrm{CH}_{3}\right)_{4}(\mathrm{TMS}, \delta=0$ ppm).

- MAS RMN de ${ }^{31} \mathrm{P}(243,1 \mathrm{MHz})$ a uma velocidade de $10 \mathrm{kHz}$, duração do pulso de 4,75 us com intervalo entre pulsos de 10 s e 64 aquisições. A referência utilizada foi o $\mathrm{NH}_{4} \mathrm{H}_{2} \mathrm{PO}_{4}\left(\delta=0,9\right.$ ppm, relativo ao $\mathrm{H}_{3} \mathrm{PO}_{4}, \delta$ $=0$ ppm). Os espectros de ${ }^{31} \mathrm{P}$ foram referenciados ao $\mathrm{H}_{3} \mathrm{PO}_{4}$, fazendose os ajustes necessários. 


\subsubsection{Análise das Propriedades Texturais}

O diâmetro de poro, o volume de poro e a área superficial específica dos sólidos foram determinados utilizando o equipamento ASAP 2020C (Accelerated Surface Area and Porosimetry System) da Micromeritics, usando nitrogênio gasoso a $-196{ }^{\circ} \mathrm{C}$ para o processo de adsorção e dessorção. A área específica foi baseada na isoterma de adsorção de Brunauer-Emmet-Teller (BET). O volume e diâmetro médio de poros foi baseado no modelo Barrett-Joyner-Halenda (BJH). As amostras foram pré-tratadas a temperatura de $300{ }^{\circ} \mathrm{C}$ por $4 \mathrm{~h}$ e sob vácuo, para retirada de água e degaseificação da mesma.

\subsubsection{Microscopia Eletrônica de Varredura (MEV)}

As imagens por MEV foram obtidas utilizando-se um microscópio eletrônico de varredura de emissão de campo da marca JEOL modelo JSM-7001S, operando a $15 \mathrm{kV}$. A amostra na forma de pó foi fixada sobre uma fita de carbono dupla face no suporte ("stub") e metalizada com platina.

\subsubsection{Adsorção Gasosa de Piridina}

As amostras contidas em cadinhos de platina foram colocadas em um prato de porcelana, o qual foi inserido em um reator de vidro, adaptado a um forno tubular (Termolyne, modelo F21100). Os catalisadores foram desidratados em atmosfera de $\mathrm{N}_{2}\left(100 \mathrm{~mL} \mathrm{~min}^{-1}\right)$ a $300{ }^{\circ} \mathrm{C}$ por $1 \mathrm{~h}$, e em seguida foram resfriados a $100{ }^{\circ} \mathrm{C}$. Mantendo essa temperatura, foi permitida a passagem de $N_{2}$ no sistema contendo piridina por mais $1 \mathrm{~h}$. Após adsorção da piridina, a temperatura foi mantida a $120^{\circ} \mathrm{C}$ com o fluxo de $\mathrm{N}_{2}$ por mais $1 \mathrm{~h}$ para remover o excesso de piridina fisicamente adsorvida na superfície dos materiais. ${ }^{39}$ 
Resultados e Discussões 


\section{RESULTADOS E DISCUSSÕES}

\subsection{Caracterização dos sais $\mathrm{Ag}_{\mathrm{x}} \mathrm{H}_{3-\mathrm{x}} \mathrm{PW}_{12} \mathrm{O}_{40}$}

\subsubsection{Espectroscopia na região do infravermelho}

A estrutura primária dos sais $\mathrm{Ag}_{x} \mathrm{H}_{3-\mathrm{x}} \mathrm{PW}_{12} \mathrm{O}_{40}$ foi investigada utilizando a espectroscopia na região do infravermelho. A Figura 8 mostra os espectros de FT-IR dos sais sintetizados de $\mathrm{Ag}_{\mathrm{x}} \mathrm{PW}$ e do HPW na região da impressão digital do ânion de Keggin. As bandas vibracionais características de HPW estão localizadas em $1080,983,887$ e $803-813 \mathrm{~cm}^{-1}$. A banda em $1080 \mathrm{~cm}^{-1}$, correspondente à vibração $v_{\text {as }}\left(\mathrm{P}-\mathrm{O}_{\mathrm{a}}\right)$ do átomo de fósforo central; em $983 \mathrm{~cm}^{-1}$, correspondente à vibração $v_{a s}\left(\mathrm{~W}-\mathrm{O}_{\mathrm{d}}\right)$ dos oxigênios terminais e em 887 e $803-813 \mathrm{~cm}^{-1}$, correspondente as vibrações $v_{a s}\left(\mathrm{~W}-\mathrm{O}_{\mathrm{b}}-\mathrm{W}\right)$ e $v_{\mathrm{as}}\left(\mathrm{W}-\mathrm{O}_{\mathrm{c}}-\mathrm{W}\right){ }^{40}$ As bandas em 596 e $524 \mathrm{~cm}^{-1}$ são atribuídas a deformações dos oxigênios do vértice $v_{a s}(P-O-P)$ e $v_{a s}\left(W-O_{c}-W\right)$, respectivamente ${ }^{41}$ (Figura A2 em anexo). Os átomos de oxigênio do ânion de Keggin são indicados como, $\mathrm{O}_{a}-$ interno, $\mathrm{O}_{d}-$ terminal, $\mathrm{O}_{b}-$ compartilhamento pelo vértice e $\mathrm{O}_{c}-$ compartilhamento pela aresta.

A mudança de posição da banda $\mathrm{W}-\mathrm{O}_{\mathrm{c}}-\mathrm{W}$ nos espectros dos sais de prata pode estar relacionado com as respectivas estruturas secundárias. ${ }^{33}$ Por exemplo, no sal $\mathrm{Ag}_{2} \mathrm{PW}$ a ligação $\mathrm{W}-\mathrm{O}_{\mathrm{c}}-\mathrm{W}$ na camada superficial do HPW cobre o núcleo do sal $\mathrm{Ag}_{3} \mathrm{PW}$ tornando-se ligeiramente mais forte em comparação com o HPW, porque a banda em $803 \mathrm{~cm}^{-1}$ no HPW é deslocada para $808 \mathrm{~cm}^{-1}$ no sal $\mathrm{Ag}_{2} \mathrm{PW}$. Aparentemente, a mesma ligação no núcleo do $\mathrm{Ag}_{3} \mathrm{PW}$ é ligeiramente mais fraca do que a ligação representada pela banda em $813 \mathrm{~cm}^{-1}$ sendo deslocada para $808 \mathrm{~cm}^{-1}$. Ambos os fenômenos resultam do ajustamento da camada superficial do HPW para o núcleo $\mathrm{Ag}_{3} \mathrm{PW}$ e o núcleo $\mathrm{Ag}_{3} \mathrm{PW}$ para a camada de superfície do $\mathrm{HPW}$, respectivamente. ${ }^{33}$ Assim, pode-se concluir que durante o processo de formação dos 
sais de prata somente a força da ligação $W-O_{c}-W$ é alterada. Isto é importante, porque o oxigênio na ligação $\mathrm{W}-\mathrm{O}_{\mathrm{c}}-\mathrm{W}$ tem sido muitas vezes considerado como um local para a protonação. ${ }^{33}$ Matachowski e colaboradores $^{33}$ observaram $^{3}$ comportamento similar para sais de potássio derivados do HPW. Kozhevnikov ${ }^{8}$ verificou que no HPW sólido desidratado, os oxigênios terminais são os centros ativos predominantes para a protonação. Assim, a alteração da ligação do oxigênio $\left(\mathrm{O}_{\mathrm{c}}\right)$ pode ser relacionado com a mudança das propriedades dos sais de prata derivados do HPW que podem influenciar na sua atividade na desidratação de etanol.

Todos os sais $\mathrm{Ag}_{\mathrm{x}} \mathrm{PW}$ exibiram as bandas características em relação ao HPW. Isso indica que a estrutura dos ânions Keggin do HPW é conservada quando os prótons são substituídos pelos cátions prata.

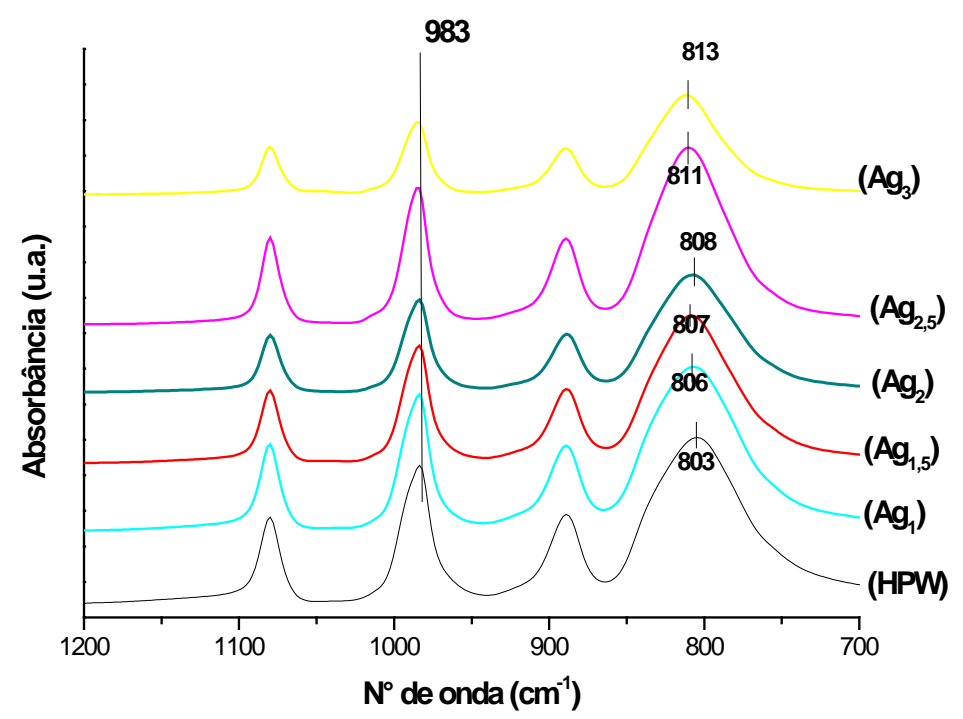

Figura 8. Espectros de FT-IR do HPW e dos seus derivados salinos de prata, calcinados a $300{ }^{\circ} \mathrm{C}$.

\subsubsection{Difração de Raios $X$}

Outra investigação relativa à estrutura dos sais $\mathrm{Ag}_{\mathrm{x}} \mathrm{PW}$ foi realizada por difração de raios X. Por meio deste método, obtemos informações sobre a estrutura 
secundária do HPW. O HPW puro apresenta picos de difração característicos em $2 \theta$ $=10,3^{\circ} ; 25,3^{\circ}$ e $34,6^{\circ} .42$

Observa-se que as principais reflexões atribuídas ao AgxPW (Figura 9) são deslocados, em comparação ao HPW puro, para parâmetros de rede menores com o aumento do teor de cátions de prata, variando de $\mathrm{a}_{0}=11,99 \AA$ para o sal $\mathrm{Ag}_{1} \mathrm{PW}$ e $\mathrm{a}_{0}=11,92 \AA$ para o sal $\mathrm{Ag}_{3} \mathrm{PW} .^{14}$

HPW tem um parâmetro de célula unitária de $12,1 \AA$, de modo que com a troca dos prótons ácidos presentes na estrutura secundária do heteropoliácido na forma de íons hidrônio $\mathrm{H}_{5} \mathrm{O}_{2}^{+}$para cátions de prata hidratados ocasiona a contração da célula unitária. ${ }^{4,14}$ Este comportamento de parâmetros de células decrescentes foi observada para outros sais monovalentes $\left(\mathrm{K}^{+}, \mathrm{NH}_{4}^{+}, \mathrm{Cs}^{+}, \mathrm{Ag}^{+}\right.$e $\left.\mathrm{Rb}^{+}\right)$de HPAs e tem sido descritos na literatura..$^{14,42,43}$

Cada padrão indicou a existência de uma única fase cristalina e as reflexões estavam próximas ao da estrutura cúbica do $\mathrm{H}_{3} \mathrm{PW}_{12} \mathrm{O}_{40} \cdot 6 \mathrm{H}_{2} \mathrm{O}$, o que significa que os derivados sais de prata são formados do HPW.

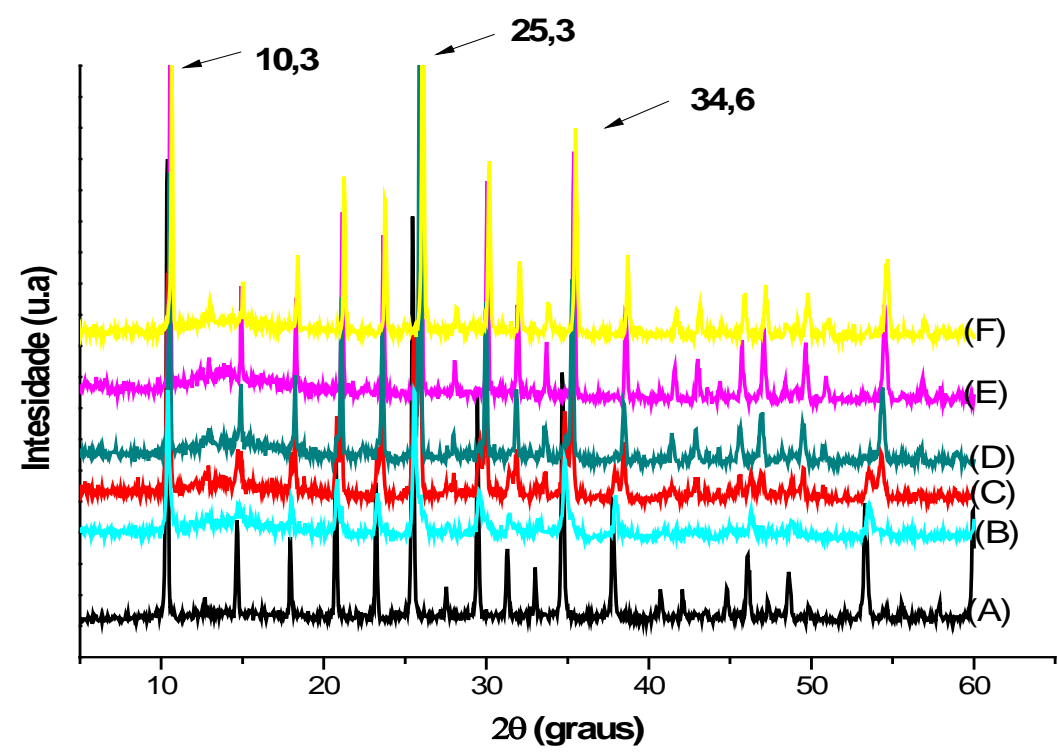

Figura 9. Difratogramas do HPW e dos seus derivados salinos calcinados a $300{ }^{\circ} \mathrm{C}$ : a) HPW; b) $\mathrm{Ag}_{1} \mathrm{H}_{2} \mathrm{PW}_{12} \mathrm{O}_{40}$; c) $\mathrm{Ag}_{1,5} \mathrm{H}_{1,5} \mathrm{PW}_{12} \mathrm{O}_{40}$; d) $\mathrm{Ag}_{2} \mathrm{H}_{1} \mathrm{PW}_{12} \mathrm{O}_{40}$; e) $\mathrm{Ag}_{2,5} \mathrm{H}_{0,5} \mathrm{PW}_{12} \mathrm{O}_{40}$ e $\mathrm{Ag}_{3} \mathrm{PW}_{12} \mathrm{O}_{40}$. 
Portanto, os sais preparados preservaram a estrutura de Keggin original após a troca iônica parcial ou total, de prótons ácidos por cátions de prata, sendo confirmadas por FT-IR e difração de raios X.

O estudo do tamanho médio dos cristalitos dos sais de prata foi calculado a partir da equação de Scherrer:

$$
D=\frac{K \cdot \lambda}{\beta \cdot \cos \theta}
$$

Na qual:

$\mathrm{D}$ = diâmetro médio dos cristalitos do material em nm;

$K=$ constante da forma dos cristalitos (neste caso $=0,9$ );

$\lambda=$ comprimento de onda da radiação $\operatorname{CuK}(1,5418 \mathrm{~nm})$;

$\beta=$ medida da largura a meia altura do pico corrigido em radianos;

$\theta$ ângulo de Bragg;

Para esta análise foi utilizado o ângulo em $2 \theta=25,3^{\circ}$ (hkl 110) por ser o mais significativo (maior intensidade) e estar presente em todos os difratogramas. A Tabela 4 apresenta os tamanhos médios dos cristalitos. Os resultados obtidos para os sais $\mathrm{Ag}_{\mathrm{x}} \mathrm{HPW}$ estão de acordo com a literatura. ${ }^{44}$

Tabela 4. Tamanho médio dos cristalitos dos sais de prata.

$\begin{array}{lc}\text { Catalisadores } & \text { Tamanho médio dos cristalitos (nm) } \\ & \\ \mathrm{Ag}_{1} \mathrm{HPW} & 64,2 \\ \mathrm{Ag}_{1,5} \mathrm{HPW} & 74,4 \\ \mathrm{Ag}_{2} \mathrm{HPW} & 63,4 \\ \mathrm{Ag}_{2,5} \mathrm{HPW} & 80,5 \\ \mathrm{Ag}_{3} \mathrm{HPW} & 66,4\end{array}$


Os valores dos tamanhos dos cristalitos para os sais de prata calculado a partir da equação de Scherrer pode ser explicado pelo suposto mecanismo de formação de agregados, onde as interfaces epitaxiais são formadas para dar uma morfologia termodinamicamente estável (ou seja, dodecaedro, conforme a imagem da Figura 10). Um grande número de nanocristais epitaxiais são ligados uns aos outros, tornando assim seus planos cristalinos coerentes. As interfaces epitaxiais dos sais de prata são formadas pela ligeira dissolução e reprecipitação dos nanocristais.

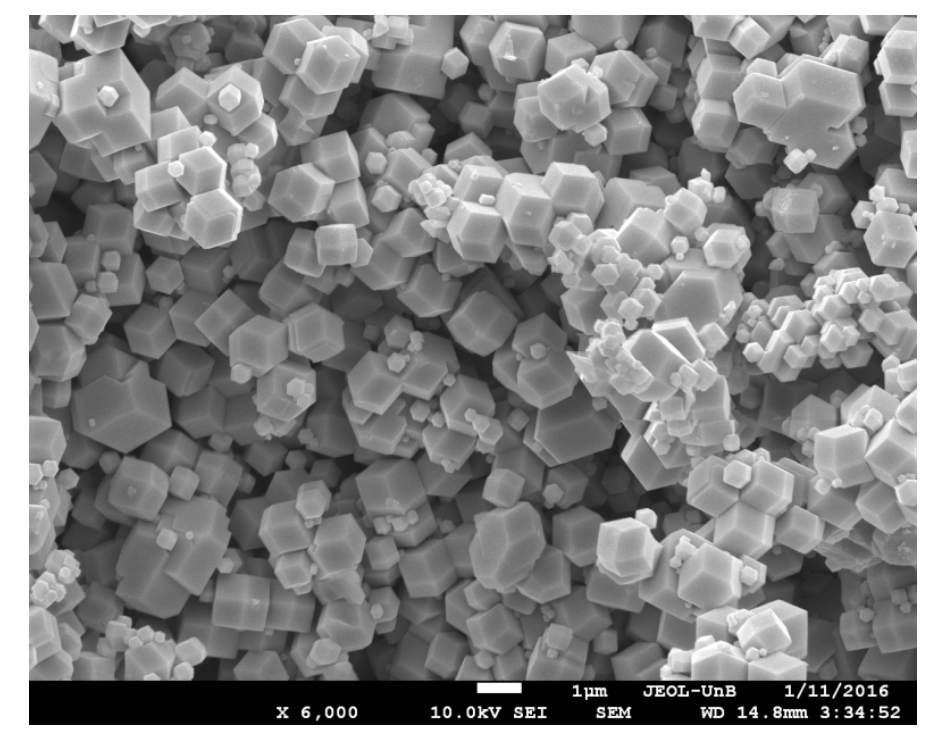

Figura 10. Microscopia Eletrônica de Varredura da amostra $\mathrm{Ag}_{2} \mathrm{HPW}$.

\subsubsection{Análise Elementar por Fluorescência de Raios X (FRX/EDX)}

A estequiometria dos sais $\mathrm{Ag}_{\mathrm{x}} \mathrm{PW}$ foram investigadas pela técnica de fluorescência de raios $X$ (FRX/EDX). Os catalisadores sintetizados foram previamente calcinados até $1000{ }^{\circ} \mathrm{C}$ para formação dos óxidos mais estáveis dos elementos. ${ }^{62}$ Como a evolução do fósforo pode acontecer em torno de $600^{\circ} \mathrm{C}$ e este apresenta uma porcentagem mássica muito inferior aos outros elementos, os valores de apresentados de fósforo na análise elementar são teóricos. ${ }^{62}$ A Tabela 5 
apresenta os valores dos óxidos nos catalisadores sintetizados (experimental e teórico). A estequiometria desejada para os sais sintetizados por troca iônica em solução seria: $\mathrm{Ag}_{x} \mathrm{H}_{3-\mathrm{x}} \mathrm{PW}_{12} \mathrm{O}_{40}$ (sendo $\mathrm{x}=1.0,1.5,2.0,2.5$ e 3.0). A formação dos sais de prata derivados do ácido 12-tungstofosfórico procede de acordo com a seguinte Equação 5:

$$
\mathrm{H}_{3} \mathrm{PW}_{12} \mathrm{O}_{40}+x \mathrm{AgNO}_{3} \rightarrow \mathrm{Ag}_{x} \mathrm{H}_{3-x} \mathrm{PW}_{12} \mathrm{O}_{40}+x \mathrm{HNO}_{3}
$$

Tabela 5. Análise de FRX/EDX dos catalisadores $\mathrm{Ag}_{\mathrm{x}} \mathrm{H}_{3-\mathrm{x}} \mathrm{PW}_{12} \mathrm{O}_{40}$.

\begin{tabular}{|c|c|c|c|c|c|c|c|c|c|c|}
\hline & $\mathrm{Ag}_{1}{ }^{\mathrm{a}}$ & $\mathrm{Ag}_{1}{ }^{\mathrm{b}}$ & $\mathrm{Ag}_{1,5}{ }^{\mathrm{a}}$ & $\mathrm{Ag}_{1,5} \mathrm{~b}$ & $\mathrm{Ag}_{2}{ }^{\mathrm{a}}$ & $\mathrm{Ag}_{2}{ }^{\mathrm{b}}$ & $\mathrm{Ag}_{2,5}{ }^{\mathrm{a}}$ & $\mathrm{Ag}_{2,5} \mathrm{~b}$ & $\mathrm{Ag}_{3}{ }^{\mathrm{a}}$ & $\mathrm{Ag}_{3}{ }^{\mathrm{b}}$ \\
\hline $\mathrm{WO}_{3}(\%)$ & 94.13 & 93.14 & 92.24 & 91.50 & 90.74 & 89.92 & 89.32 & 88.40 & 87.28 & 86.92 \\
\hline $\mathrm{Ag}_{2} \mathrm{O}(\%)$ & 3.49 & 3.88 & 5.43 & 5.72 & 6.96 & 7.49 & 8.42 & 9.20 & 10.50 & 10.86 \\
\hline $\mathrm{P}_{2} \mathrm{O}_{5}(\%)$ & 2.38 & 2.38 & 2.44 & 2.33 & 2.29 & 2.29 & 2.26 & 2.26 & 2.22 & 2.22 \\
\hline
\end{tabular}

Tabela 6. Comparação entre as estequiometrias teórica e obtida pela análise de FRX/EDX.

\begin{tabular}{ll}
\hline $\begin{array}{l}\text { Estequiometria } \\
\text { teórica }\end{array}$ & $\begin{array}{l}\text { Estequiometria } \\
\text { experimental }\end{array}$ \\
\hline $\mathrm{Ag}_{1} \mathrm{H}_{2} \mathrm{PW}_{12} \mathrm{O}_{40}$ & $\mathrm{Ag}_{0,9} \mathrm{H}_{2,1} \mathrm{PW}_{12} \mathrm{O}_{40}$ \\
$\mathrm{Ag}_{1,5} \mathrm{H}_{1,5} \mathrm{PW}_{12} \mathrm{O}_{40}$ & $\mathrm{Ag}_{1,4} \mathrm{H}_{1,6} \mathrm{PW}_{12} \mathrm{O}_{40}$ \\
$\mathrm{Ag}_{2} \mathrm{H}_{1} \mathrm{PW}_{12} \mathrm{O}_{40}$ & $\mathrm{Ag}_{1,9} \mathrm{H}_{1,1} \mathrm{PW}_{12} \mathrm{O}_{40}$ \\
$\mathrm{Ag}_{2,5} \mathrm{H}_{0,5} \mathrm{PW}_{12} \mathrm{O}_{40}$ & $\mathrm{Ag}_{2,3} \mathrm{H}_{0,7} \mathrm{PW}_{12} \mathrm{O}_{40}$ \\
$\mathrm{Ag}_{3} \mathrm{PW}_{12} \mathrm{O}_{40}$ & $\mathrm{Ag}_{2,9} \mathrm{H}_{0,1} \mathrm{PW}_{12} \mathrm{O}_{40}$ \\
\hline
\end{tabular}

\subsubsection{Análises Térmicas}

A análise térmica através da TG é um experimento que permite avaliar a perda de massa de uma determinada substância em um ambiente que é aquecido a uma taxa controlada, tendo como variáveis o tempo e/ou temperatura. A derivada da 
perda de massa, conhecida por DTG é usada para facilitar a visualização, na faixa de temperatura que ocorreu o evento, do seu valor máximo. As curvas de DTG dos sais de prata derivados do HPW, comparados ao HPW são mostradas na Figura 11. Inicialmente, em relação ao HPW, a curva mostra uma perda de massa até aproximadamente $250{ }^{\circ} \mathrm{C}$ correspondendo a remoção de moléculas de água fisicamente adsorvida e de hidratação. Esses dois tipos de água são características da estrutura do HPA. Em relação ao sais de prata sintetizados, observa-se que ocorre perda de massa em três eventos e em temperaturas maiores que as observadas para o HPW, sendo correspondentes a perda de moléulas de água fisicamente adsorvida e de hidratação e o último evento sendo relacionado a remoção de água coordenada a prata. De acordo com a esse resultado, confirma que os sais de prata derivados do HPW são formados. A perda de massa entre 400 e $530{ }^{\circ} \mathrm{C}$ do HPW corresponde etapa de desprotonação, é, para a desidratação das moléculas de água formadas a partir de prótons "livre" e a partir de átomos de oxigênio do ânion de Keggin. Não existe tal processo, no caso do sal neutro $\mathrm{Ag}_{3} \mathrm{PW}{ }^{44}$

Dessa forma, o comportamento térmico de sais $\mathrm{Ag}_{\mathrm{x}} \mathrm{PW}$ é semelhante ao HPW, mas o grau de hidratação é menor.

O HPW e os sais de prata sintetizados são estáveis até uma temperatuta de $465{ }^{\circ} \mathrm{C}$. Considerando os dados térmicos, conclui-se que a substituição dos prótons do HPW por prata não aumenta a estabilidade térmica destes sais em comparação com o HPW puro, como é observado no caso dos sais alcalinos insolúveis. ${ }^{44}$ 


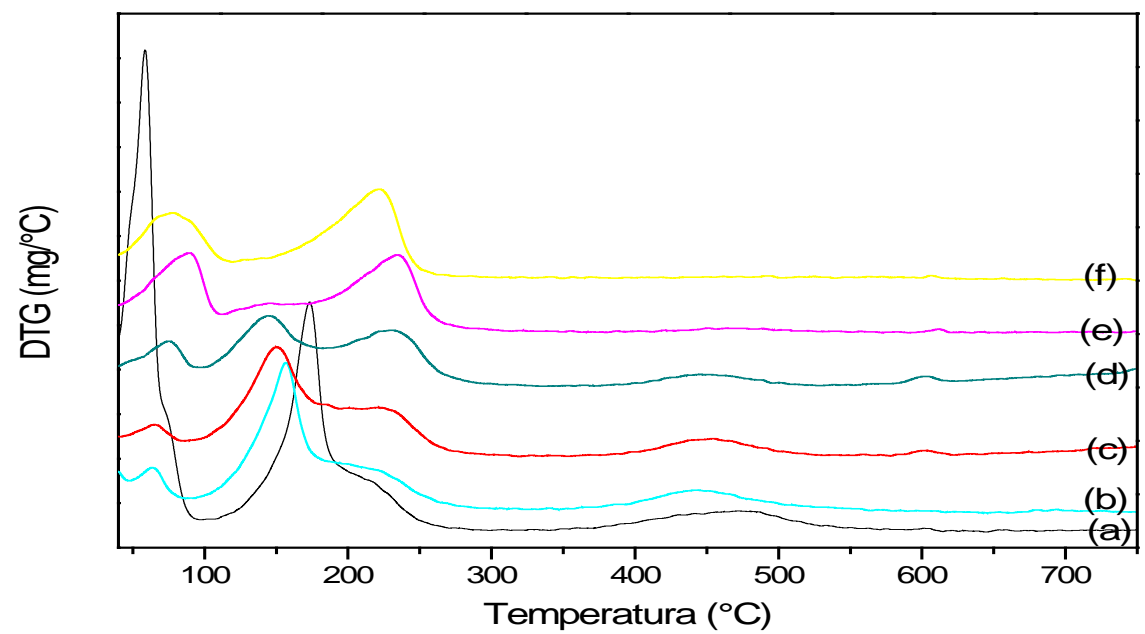

Figura 11. Curvas de DTG de: a) HPW; b) $\mathrm{Ag}_{1} \mathrm{H}_{2} \mathrm{PW}_{12} \mathrm{O}_{40}$; c) $\mathrm{Ag}_{1,5} \mathrm{H}_{1,5} \mathrm{PW}_{12} \mathrm{O}_{40}$; d) $\mathrm{Ag}_{2} \mathrm{H}_{1} \mathrm{PW}_{12} \mathrm{O}_{40}$; e) $\mathrm{Ag}_{2,5} \mathrm{H}_{0,5} \mathrm{PW}_{12} \mathrm{O}_{40} ;$ f) $\mathrm{Ag}_{3} \mathrm{PW}_{12} \mathrm{O}_{40}$.

\subsubsection{Ressonância Magnética Nuclear no Estado Sólido de ${ }^{31} \mathrm{P}$ com rotação no ângulo mágico}

A troca de prótons por um átomo de prata provoca um pequeno aumento na densidade eletrônica do núcleo de fósforo. O aumento resultante na densidade dos elétrons pode ser observado nos espectros de MAS RAM de ${ }^{31} \mathrm{P}$ dos sais sólidos de prata, o qual é dependente do grau de hidratação. ${ }^{45}$ No $\mathrm{HPW} \cdot \mathrm{nH}_{2} \mathrm{O}$ os valores variam de $-15,9$ a $-14,7$ ppm para $n=6$ e $-11,1$ a $-10,5$ para $n=0$, de acordo com dados da literatura. ${ }^{45,46}$ No HPW.6 $\mathrm{H}_{2} \mathrm{O}$, os prótons ácidos estão ligados à água de

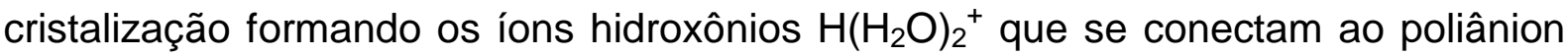
através dos oxigênios terminais por ligação hidrogênio e não há prótons diretamente ligados ao poliânion. No ácido anidro, os prótons estão ligados diretamente aos átomos de oxigênio do poliânion. ${ }^{45}$

O sinal único nestes espectros está relacionado ao alto grau de hidratação dos materiais. As amostras hidratadas possuem grande mobilidade de prótons que 
distribui densidade eletrônica similar ao redor dos ânions de Keggin ${ }^{45}$, e, portanto, conferindo um único sinal para o núcleo de ${ }^{31} \mathrm{P}$.

As amostras apresentam um único sinal nos espectros que se desloca no campo de $\delta=-15,5 ;-15,3 ;-15,2 ;-15,1 ;-15,1$ e -14,9 ppm para a série $x=0,1 ; 1,5$; 2,0; 2,5 e 3, respectivamente (Figura 12).

O sinal único nos sais podem estar relacionados à distribuição homogênea de espécies $\left(\mathrm{H}^{+} \mathrm{e} \mathrm{Ag}^{+}\right)$ao redor do átomo de fósforo criando ambientes químicos similares. Como os deslocamentos estão próximos aos de HPW hidratado (-15,5 ppm), podemos dizer que nestes sais os prótons não estão ligados diretamente aos poliânions, mas formando íons hidroxônios $\mathrm{H}_{5} \mathrm{O}_{2}^{+}$que se ligam aos oxigênios terminais. ${ }^{4}$

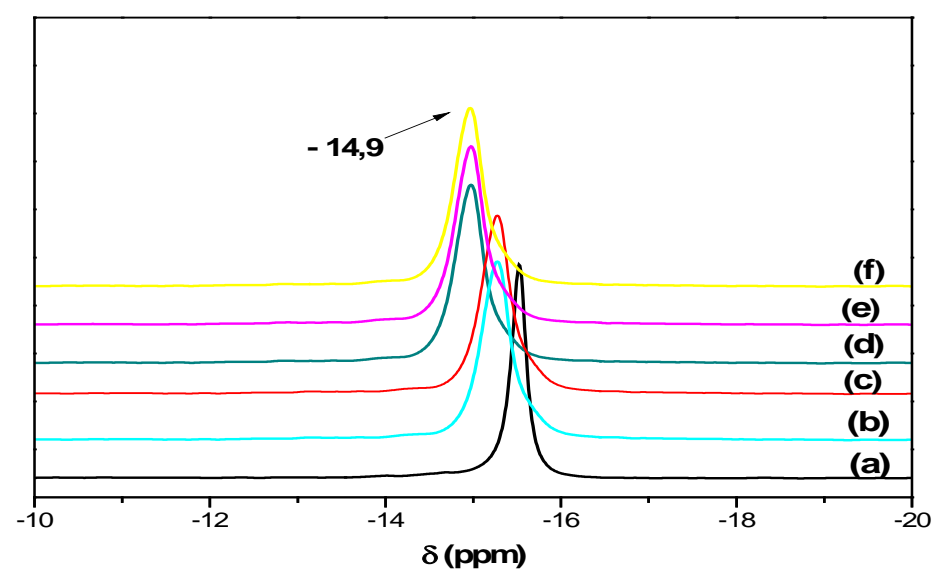

Figura 12. Espectros de MAS RAM ${ }^{31} \mathrm{P}$ de: a) HPW; b) $\mathrm{Ag}_{1} \mathrm{H}_{2} \mathrm{PW}_{12} \mathrm{O}_{40}$; c) $\mathrm{Ag}_{1,5} \mathrm{H}_{1,5} \mathrm{PW}_{12} \mathrm{O}_{40}$; d) $\mathrm{Ag}_{2} \mathrm{H}_{1} \mathrm{PW}_{12} \mathrm{O}_{40} ;$ e) $\mathrm{Ag}_{2,5} \mathrm{H}_{0,5} \mathrm{PW}_{12} \mathrm{O}_{40}$ e f) $\mathrm{Ag}_{3} \mathrm{PW}_{12} \mathrm{O}_{40}$ calcinados a $300^{\circ} \mathrm{C}$.

\subsubsection{Caracterização ácida}

A constatação da existência de sítios ácidos nos heteropoliácidos é proveniente da capacidade desses materiais de adsorver moléculas básicas, como a 
piridina. Esses sítios são também conhecidos como centros ativos por serem o local onde ocorre a catálise de uma dada reação.

O FT-IR têm sido usado para determinação do tipo de sítio ácido de cada catalisador por adsorção de molécula sonda. ${ }^{47}$ Segundo estudos realizados por Parry, ${ }^{47}$ a concentração de sítios ácidos de Brønsted (formação do íon piridínio), de Lewis e ligação hidrogênio podem ser determinadas pela interação da molécula de piridina com os sólidos ácidos. A Tabela 7 mostra as frequências das bandas de infravermelho para cada tipo de sítio.

Tabela 7. Frequências na região do infravermelho relacionadas a cada tipo de sítio ácido, modificada da referência 47.

\begin{tabular}{ccc}
\hline Sítios de Brønsted $\left(\mathbf{c m}^{-1}\right)$ & Sítios de Lewis $\left.\mathbf{( c m}^{-1}\right)$ & Ligação Hidrogênio $\left.\mathbf{~ ( c m ~}^{-1}\right)$ \\
\hline & $1447-1460$ & $1400-1477$ \\
$1485-1500$ & $1488-1503$ & $1485-1490$ \\
1540 & 1580 & $1580-1600$ \\
& $1600-1633$ & \\
\hline
\end{tabular}

No espectro de FT-IR das amostras com piridina adsorvida (Figura 13) verifica-se a presença de bandas de vibração da piridina adsorvida em 1635, 1612, 1540, e $1487 \mathrm{~cm}^{-1}$. A banda que aparece em $1420 \mathrm{~cm}^{-1}$ é referente às vibrações do anel da piridina adsorvida. ${ }^{48}$

As bandas presentes em 1487, 1540 e $1612 \mathrm{~cm}^{-1}$ estão relacionadas à formação do íon piridínio, ou seja, adsorção da piridina à sítios de Brønsted do catalisador. A presença do ombro observado em $1540 \mathrm{~cm}^{-1}$ está relacionada a formação do íon piridínio interagindo com outra molécula de piridina. Isto ocorre 
devido ao sistema de adsorção utilizado, o qual trabalha sob fluxo de $\mathrm{N}_{2}$ e não segundo um regime de vácuo, o que acaba não permitindo a total dessorção total de piridina fisicamente adsorvida. A banda em $1635 \mathrm{~cm}^{-1}$ esta relacionada à água de hidratação do material. As bandas referentes à formação do íon piridínio e à ligação hidrogênio estão relacionadas aos centros ácidos contendo ligações O-H com pouca ou nenhuma evidência de sítios ácidos de Lewis. No heteropolissal neutro $\left(\mathrm{Ag}_{3} \mathrm{PW}\right)$, não observa-se as bandas em 1540 e $1487 \mathrm{~cm}^{-1}$. Esta ausência de prótons geradores de acidez de Brønsted pode ser contornada por meio de um prétratamento do sólido com vapor de água. ${ }^{35}$

De acordo com Filek e colaboradores, ${ }^{71}$ as propriedades ácidas dos heteropolissais resultam da presença dos prótons residuais inalterados derivados do HPW e/ou a partir de moléculas de água coordenadas ao cátion de prata que foram introduzidas nos heteropolissais. A água coordenada aos átomos metálicos $\left[\mathrm{M}\left(\mathrm{H}_{2} \mathrm{O}\right)_{\mathrm{m}}\right]^{\mathrm{n}+}$ pode ser dissociada e gerar prótons ácidos adicionais, conforme a Equação 6 abaixo:

$$
\mathrm{M}^{\mathrm{n}+}+\mathrm{mH}_{2} \mathrm{O} \rightarrow\left[\mathrm{M}\left(\mathrm{H}_{2} \mathrm{O}\right)_{\mathrm{m}}\right]^{\mathrm{n+}} \rightarrow\left[\mathrm{M}\left(\mathrm{H}_{2} \mathrm{O}\right)_{\mathrm{m}-1}(\mathrm{OH})\right]^{(\mathrm{n}-1)+}+\mathrm{H}^{+}
$$

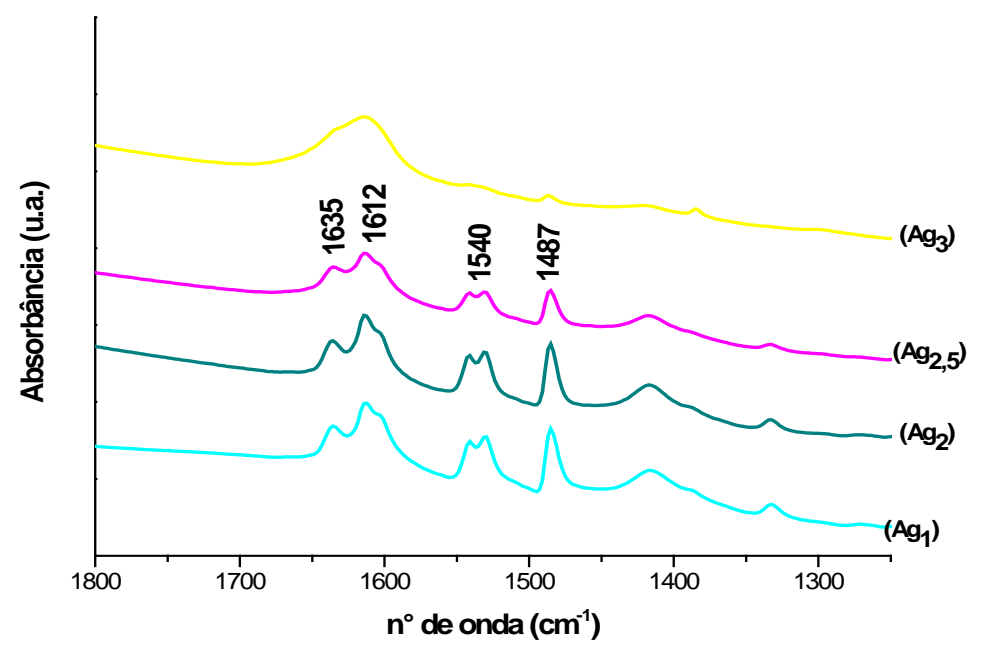

Figura 13. Sítios ácidos dos sais $\mathrm{Ag}_{\mathrm{x}} \mathrm{H}_{3-\mathrm{x}} \mathrm{PW} \mathrm{W}_{12} \mathrm{O}_{40}$ após adsorção de piridina gasosa. 
Estudos com HPW empregando também piridina como molécula sonda, demonstraram que nenhuma acidez de Lewis está presente nos heteropoliácidos e seus sais, com exceção dos preparados com o cátion alumínio. ${ }^{63}$ Portanto, os sais de prata concordam com o que a literatura descreve, prevalecendo os sítios de Brønsted na estrutura. ${ }^{48}$

\subsection{Caracterização da sílica mesoporosa SBA-15}

\subsubsection{Espalhamento de raios $X$ a baixo ângulo - (SAXS)}

As sílicas mesoporosas que utilizam como direcionadores estruturantes o copolímero tribloco P123, por exemplo a SBA-15, apresentam padrões de difração característicos frente à interação com a radiação $X$. Os materiais mesoporosos de sílica, como a SBA-15, não são cristalinos, ${ }^{18}$ o único elemento de ordem estrutural é a disposição periódica dos canais paralelos, ao qual são atribuídas as reflexões observadas no difratograma. ${ }^{49} \mathrm{~A}$ extensão da periodicidade da estrutura ordenada que dá origem ao arranjo de poros é inversamente proporcional ao ângulo de Bragg referente ao plano $\mathrm{d}_{100 .}{ }^{50}$ Estas características resultam num material com elevados diâmetros médios de poros gerando um deslocamento em relação ao ângulo de Bragg referente ao plano $d_{100}$ a uma região baixa, em torno de $2 \theta$ de $0,9^{\circ}$. Dessa forma, não são observadas reflexões em ângulos maiores. ${ }^{19,49,50}$

A Figura 14 ilustra o espalhamento de raios $X$ a baixos ângulos da amostra de SBA-15 calcinada (SBA-15 C). Infere-se, que é semelhante ao padrão de DRX de rede bem ordenada, ${ }^{51}$ apresentando três reflexões de Bragg em baixo ângulo indexada nas posições (100), (110) e (200). A ocorrência dessas reflexões corresponde a sílica mesoporosa cujos sinais de difração observados são atribuidos à disposição periódica dos canais paralelos, sugerindo a formação da mesoestrutura com simetria hexagonal p6mm. ${ }^{17}$ 


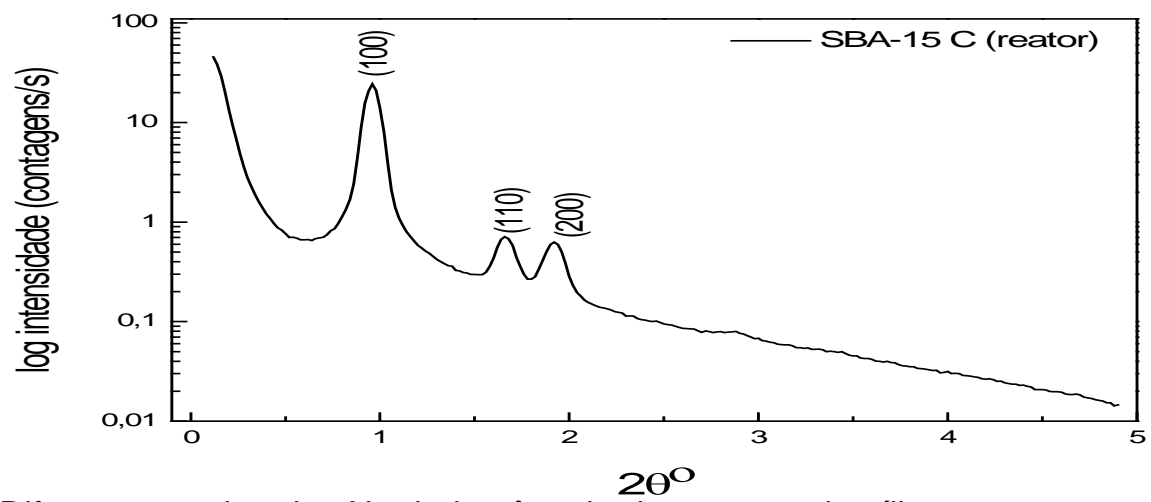

Figura 14. Difratograma de raios $X$ a baixo ângulo da amostra de sílica mesoporosa ordenada SBA15 calcinada.

A estrutura dos materiais mesoporosos é apresentada esquematicamente na Figura 15. A estrutura interna é constituída de um arranjo hexagonal de cilindros mesoporosos, sendo caracterizada por valores de espaçamento interplanar $d_{100}$ e parâmetro de célula unitária hexagonal $a_{0}$.

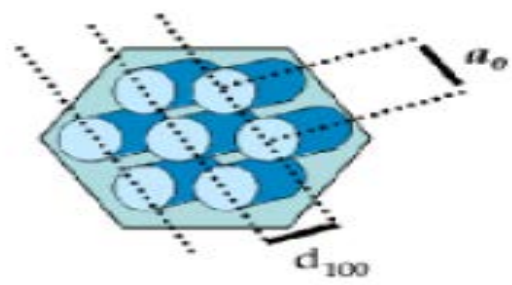

Figura 15. Representação esquemática da estrutura dos materiais mesoporosos hexagonais, com distância interplanar $\left(d_{100}\right)$ e parâmetro de rede $\left(a_{0}\right) .{ }^{49}$

Valores de espaçamento interplanar (d) podem ser obtidos a partir da Equação 7:49

$$
d=\frac{\lambda}{\operatorname{sen} 2 \theta}
$$

Os parâmetros de célula unitária para a rede hexagonal $\left(\mathrm{a}_{0}\right)$ podem ser obtidos a partir da Equação 8: ${ }^{49}$

$$
a_{0}=\frac{2 d_{100}}{\sqrt{3}}
$$


A partir dos dados obtidos na análise de SAXS e dos cálculos realizados de acordo com as Equações 7 e 8, obteve-se as seguintes informações da estrutura da amostra SBA-15 sintetizada. A intensidade do pico (100) reflete um espaçamento interplanar (d) de 9,2 nm para a amostra SBA-15, em acordo com os dados apresentados na Tabela $3^{17,51}$ correspondendo a um parâmetro de célula unitária hexagonal $\mathrm{a}_{0}$, de $10,6 \mathrm{~nm}$.

\subsubsection{Espectroscopia na região do infravermelho}

Esta técnica é amplamente utilizada para se obter informações sobre estados vibracionais de moléculas adsorvidas e investigar a natureza de grupos silanol e água adsorvida. O espectro na região do infravermelho da sílica mesoporosa SBA15 calcinada apresenta absorções características às vibrações da rede de sílica, i.e., em torno de 459, 807, 962 e $1080 \mathrm{~cm}^{-1}$ (Figura 16). ${ }^{53} \mathrm{~A}$ banda em torno de $1080 \mathrm{~cm}^{-1}$ é referente ao estiramento assimétrico do tetraedro da rede mesoporosa da SBA-15 atribuído ao grupo Si-O-Si. A banda em torno de $962 \mathrm{~cm}^{-1}$ é relativa ao estiramento assimétrico de grupos Si-O- $\mathrm{H}^{+}$. A banda em torno de $807 \mathrm{~cm}^{-1}$ é relativa ao estiramento simétrico da ligação (Si-O-Si) e a banda em torno de $459 \mathrm{~cm}^{-1}$ está relacionada ao modo de vibração de deformação (Si-O-Si).

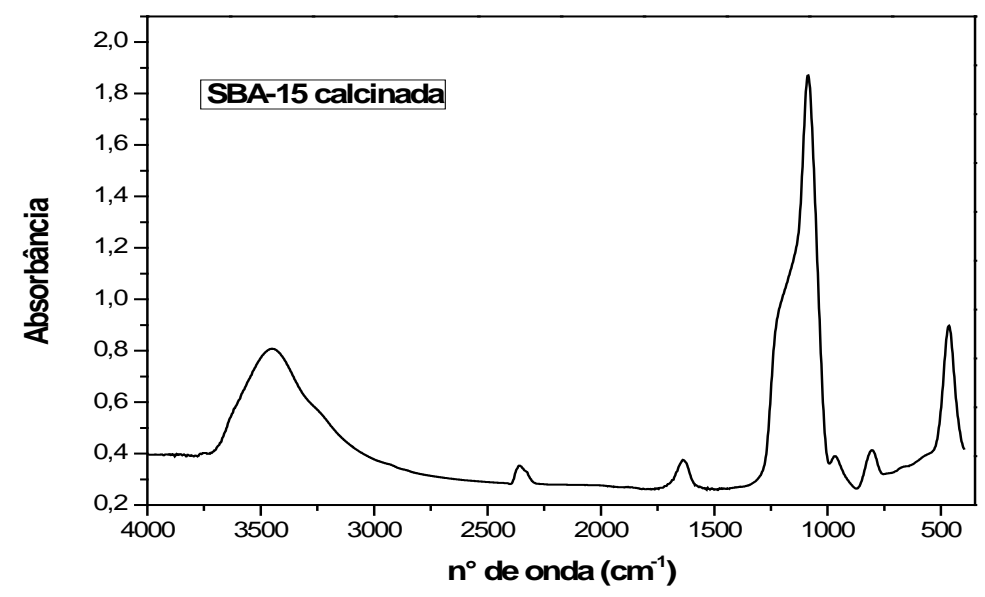

Figura 16. Espectro no infravermelho da amostra SBA-15 calcinada. 
A banda em torno de $1640 \mathrm{~cm}^{-1}$ é atribuída a presença de moléculas de água, provenientes de umidade adquirida pela superfície. A banda larga centrada em 3453 $\mathrm{cm}^{-1}$ relaciona-se aos grupos $\mathrm{OH}$ da água adsorvida sobreposta aos silanóis. ${ }^{43}$

\subsubsection{Ressonância Magnética Nuclear de ${ }^{29}$ Si no Estado Sólido (MAS RMN de} $\left.{ }^{29} \mathrm{Si}\right)$

A ressonância do núcleo de silício $\left({ }^{29} \mathrm{Si}\right)$ permite determinar o ambiente químico deste átomo na rede polimérica inorgânica das sílicas com base nos diferentes deslocamentos químicos. Em uma rede polimérica formada apenas de átomos de sílicio, oxigênio e hidrogênio, quando o átomo de silício está ligado ao átomo de oxigênio os sinais são designados pela letra Q. As espécies Q que o silício pode apresentar na estrutura da sílica sem conter qualquer grupo orgânico estão apresentadas na Figura 17.

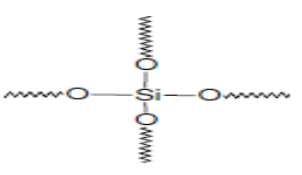

(1)

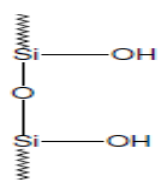

(11)

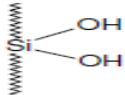

(III)

Figura 17. Estruturas das espécies químicas referentes ao silício na sílica em diferentes ambientes:

$$
\mathrm{Q}^{4}(\mathrm{I}), \mathrm{Q}^{3}(\mathrm{II}) \text { e } \mathrm{Q}^{2}(\mathrm{III}) \text {. }
$$

A espectroscopia de RMN no estado sólido de ${ }^{29} \mathrm{Si}$ fornece informações importantes sobre a composição e estrutura dos silicatos mesoporosos. Os sinais referentes aos deslocamentos químicos das espécies de $\mathrm{Q}^{4}, \mathrm{Q}^{3}$ e $\mathrm{Q}^{2}$ nos espectros de MAS RMN de ${ }^{29}$ Si da SBA-15 sem calcinar são em -91, -101 e -110 ppm, respectivamente (Figura 18). 


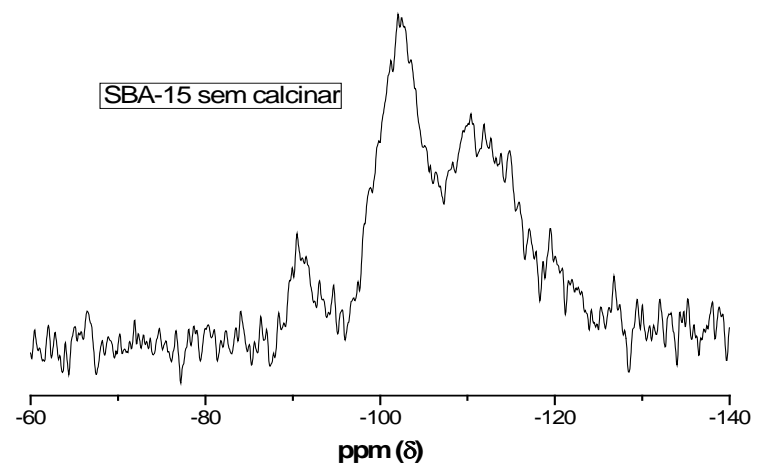

Figura 18. Espectro de MAS RMN de ${ }^{29} \mathrm{Si}$ da amostra de SBA-15 sem calcinar.

A Figura 19 mostra o espectro MAS RMN de ${ }^{29}$ Si da amostra de SBA-15 calcinada. Este espectro foi deconvoluído pela função composta GaussianaLorenztiana e as posíções e as intensidades atribuídas aos diferentes grupos $\mathrm{Q}^{\mathrm{n}}$ $\left(\mathrm{Si}(\mathrm{OSi})_{n}(\mathrm{OH})_{4-n}, \mathrm{n}=2,3,4\right)$ são apresentados na Tabela 8. As áreas abaixo dos sinais deconvoluídos são diretamente proporcionais à espécies das respectivas unidades estruturais da amostra. O espectro da sílica mesoporosa foi deconvoluído e apresentado na Figura 20, com a finalidade de obter mais informações estruturais em relação as espécies $Q^{4}, Q^{3}$ e $Q^{2}$.

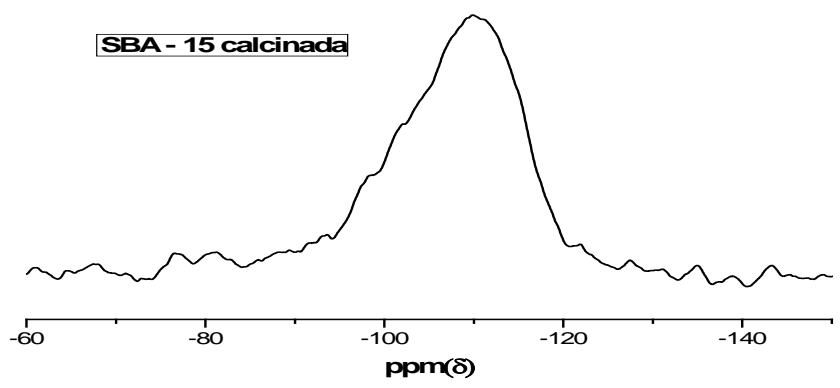

Figura 19. Espectro de MAS RMN de ${ }^{29}$ Si da amostra de SBA-15 calcinada.

Os valores apresentados na Tabela 8, referente a deconvolução do espectro de ${ }^{29} \mathrm{Si}$ da amostra de SBA-15 calcinada, apresentam os deslocamentos químicos 
em aproximadamente -89, -102 e -111 ppm, referente a presença dos três sítios de sílicío $\mathrm{Q}^{2}, \mathrm{Q}^{3}$ e $\mathrm{Q}^{4}$, respectivamente. O sinal assimétrico amplo na amostra sintetizada é observado em -110 ppm. A espécie $\mathrm{Q}^{4}$ é a mais abundante na sílica mesoporosa. Durante o processo de calcinação, alguns dos grupos hidroxila das espécies $\mathrm{Q}^{2}$ e $\mathrm{Q}^{3}$ sofrem condensação, de modo que a intensidade destes sinais diminui em relação à das espécies $Q^{4}$.

Tabela 8. Paramêtros da deconvolução pela função composta Gaussiana - Lorenzitiana.

\begin{tabular}{ccc}
\hline & $\boldsymbol{\delta}(\mathbf{p p m})$ & $\mathbf{I}(\%)$ \\
\hline Q2 & $-89,0$ & 3,0 \\
Q3 & $-102,9$ & 44,5 \\
Q4 & $-111,8$ & 52,5 \\
\hline
\end{tabular}

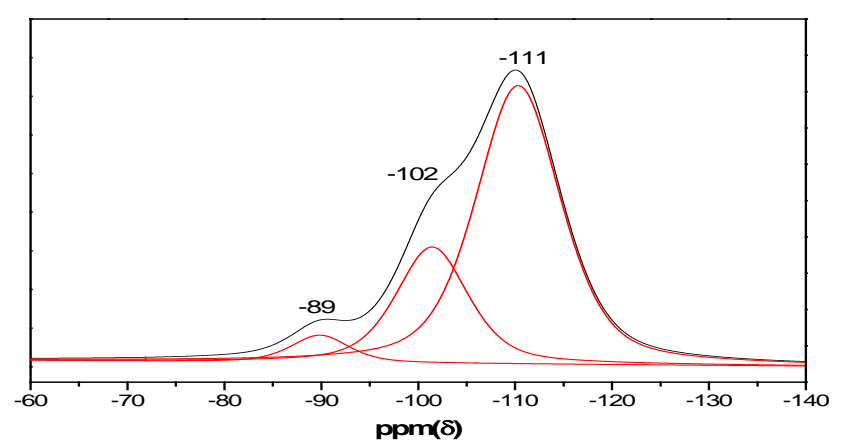

Figura 20. Deconvolução do espectro de MAS RMN de ${ }^{29} \mathrm{Si}$ da amostra de SBA-15 calcinada.

\subsubsection{Análise térmica}

A estabilidade térmica do material foi analisado por TG/DTG. A Figura 21 apresenta a curva termogravimétrica e sua respectiva derivada para a SBA-15.

Tratando-se de sílica mesoporosa calcinada, observa-se que ocorrem dois eventos térmicos, sendo que o primeiro corresponde a uma perda de $12 \%$ da massa 
total que está relacionada com a liberação de moléculas de água fisicamente adsorvidas a uma temperatura de $100{ }^{\circ} \mathrm{C}$. O segundo evento térmico ocorre ao longo de uma ampla faixa de temperatura $\left(100-800{ }^{\circ} \mathrm{C}\right)$, correspondendo a uma perda de apenas 2,7\% do percentual em massa. Este segundo evento possui uma curva bastante sutil e pode estar relacionado com a condensação dos grupos silanóis a siloxanos, levando à perda de água através de um processo endotérmico. ${ }^{54,55}$ Estas moléculas podem estar retidas na estrutura do material, uma vez que a SBA-15 apresenta uma microporosidade intrínseca, que permite a retenção dessas moléculas no interior da rede porosa.

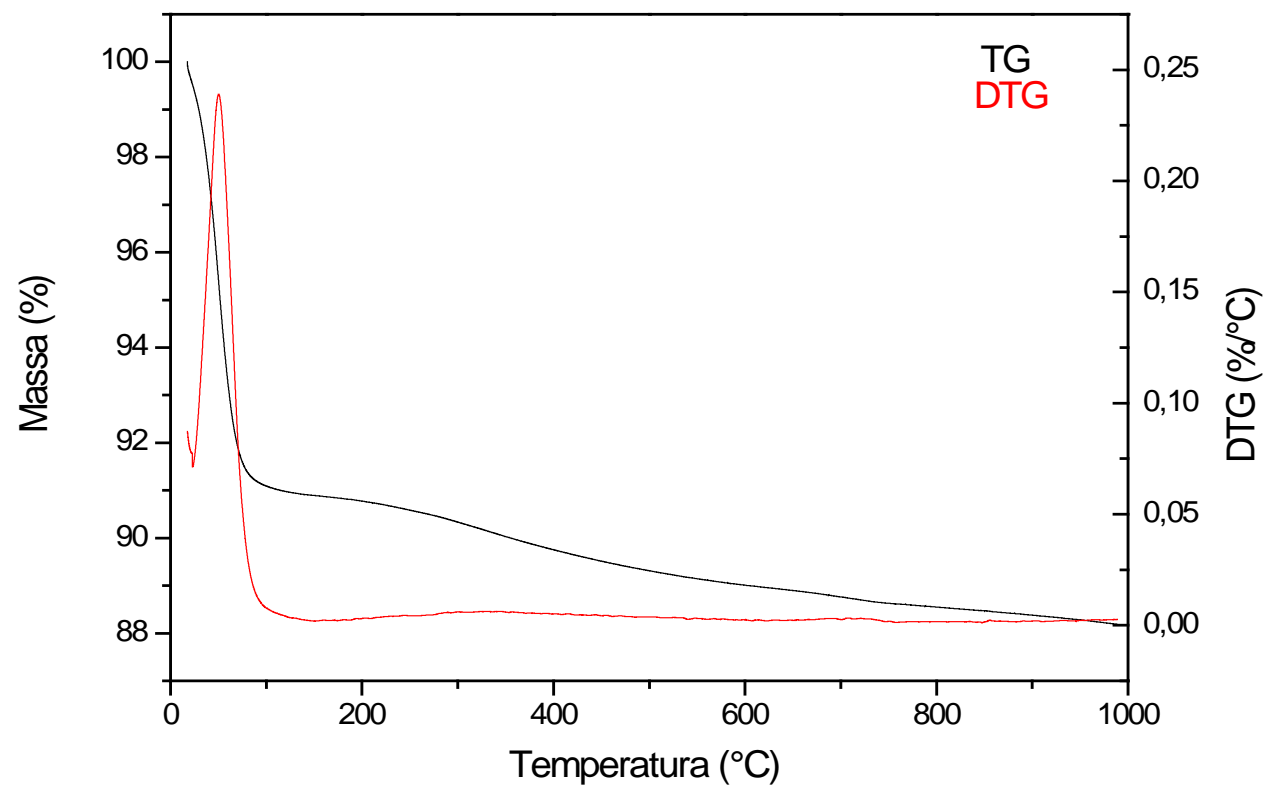

Figura 21. Curvas de TG/DTG da SBA-15 calcinada.

\subsubsection{Microscopia Eletrônica de Varredura (MEV)}

As análises por microscopia eletrônica de varredura são ideais para avaliação das características morfológicas das particulas. A Figura 22 apresenta imagens de microscopia eletrônica de varredura da SBA-15 calcinada. 

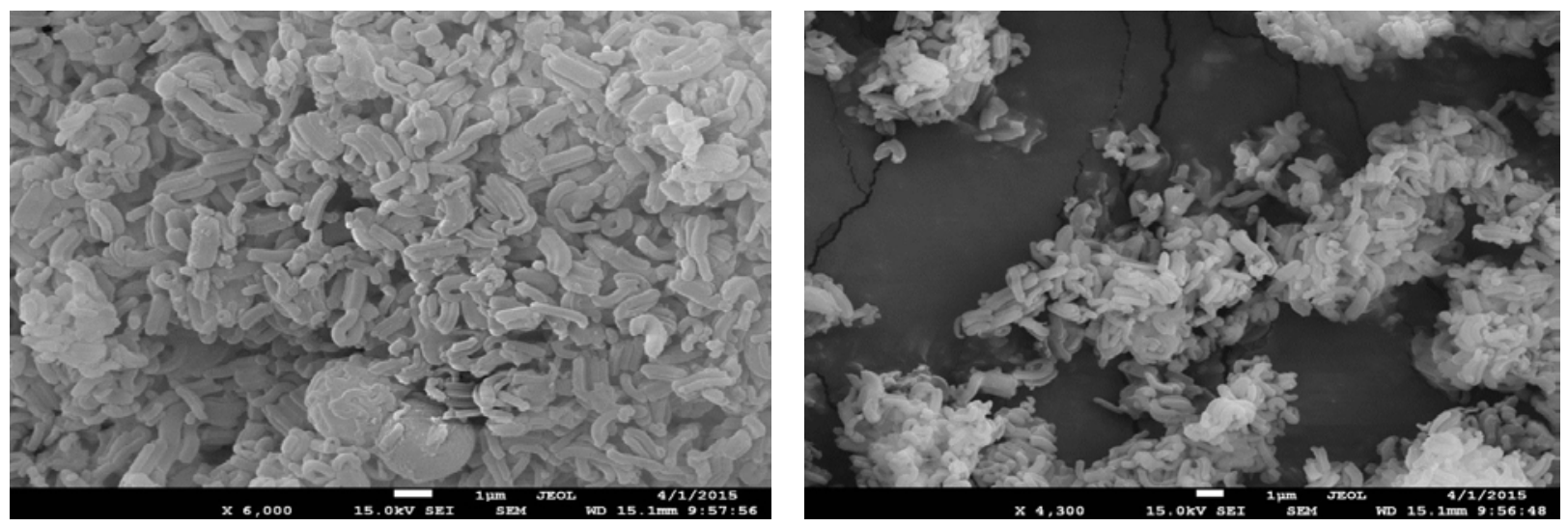

Figura 22. Micrografias por microscopia eletrônica de varredura da SBA - 15.

As imagens revelam que a SBA-15 apresenta morfologia macroscópica tipo vermicular que consiste de muitos agregados tipo corda ("rope-like"), em concordância com a literatura. ${ }^{24}$

\subsubsection{Adsorção de nitrogênio a baixa temperatura}

A adsorção gasosa é uma técnica utilizada para a caracterização das propriedades texturais da amostra de SBA-15, que são verificadas através da determinação dos seguintes parâmetros: área específica, tamanho e volume dos poros, e distribuição de tamanho de poros. A Figura 23 mostra as isotermas de adsorção-dessorção de $\mathrm{N}_{2}$ da SBA-15.

Observa-se que a isoterma apresentada na Figura 23 pode ser classificada como do tipo IV, característica de materiais mesoporosos, com histereses do tipo $\mathrm{H} 1$, conforme classificação da IUPAC, relacionadas aos materiais com poros de seção transversal uniforme. $O$ ponto de inflexão $P / P_{0}$ entre 0,6 e 0,8 confirma esta característica estrutural de mesoporos. ${ }^{56} \mathrm{~A}$ amostra exibe mesoporosidade complementar (mesoporos secundários), como evidenciado pela presença de um 
laço ("loop") de histerese bem definido que surge em $\mathrm{P} / \mathrm{P}_{0}>0,5$ e corresponde à condensação capilar em poros interpartícula. ${ }^{57}$

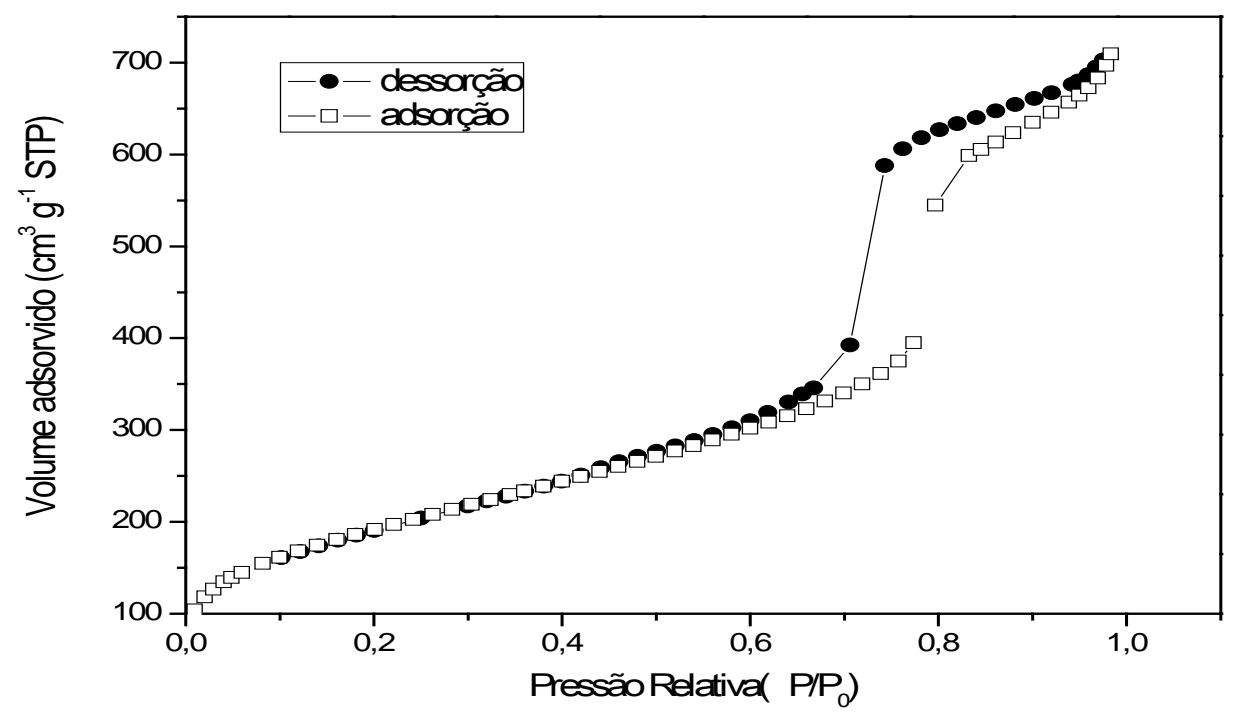

Figura 23. Isotermas de adsorção e dessorção de $\mathrm{N}_{2}$ da amostra de SBA-15.

Tabela 9. Resultados das propriedades texturais da SBA-15 por adsorção de $\mathrm{N}_{2}$.

\begin{tabular}{ccccc}
\hline Amostra & $\begin{array}{c}\mathrm{S}_{\mathrm{BET}} \\
\left(\mathbf{m}^{2} \mathbf{g}^{-1}\right)\end{array}$ & $\begin{array}{c}\mathbf{P}_{\mathrm{s}}(\mathrm{BJH}) \\
(\mathbf{n m})\end{array}$ & $\begin{array}{c}\mathrm{V}_{\mathrm{p}} \\
\left(\mathbf{c m}^{3} \mathbf{g}^{-1}\right)\end{array}$ & $\begin{array}{c}\mathbf{t}_{\mathrm{p}} \\
(\mathbf{n m})\end{array}$ \\
\hline SBA-15 & 687 & 6 & 1,1 & 5 \\
\hline
\end{tabular}

$\mathrm{S}_{\mathrm{BET}}=$ área específica pelo método $\mathrm{BET}$;

$\mathrm{P}_{\mathrm{S}}=$ tamanho de poro pelo método $\mathrm{BJH}$;

$\mathrm{V}_{\mathrm{p}}=$ volume de poro pelo método $\mathrm{BJH}$;

$t_{p}=$ espessura da parede de poros.

Este material tem uma área superficial (BET) de $687 \mathrm{~m}^{2} \mathrm{~g}^{-1} \mathrm{e}$ um volume de poro de $1,1 \mathrm{~cm}^{3} \mathrm{~g}^{-1}$. Estes resultados apresentados na Tabela 9 das propriedades texturais obtidas na SBA-15 sintetizada são completamente satisfatórias, sendo comparáveis com os dados da Tabela 3. De acordo com a literatura, estes materiais podem apresentar uma área superficial na faixa de $600-1000 \mathrm{~m}^{2} \mathrm{~g}^{-1} \mathrm{e}$ um volume de poro obtido quando $P / P_{0}=0,98$ na faixa de $0,8-1,2 \mathrm{~cm}^{3} \mathrm{~g}^{-1}$, com as condições sintéticas de temperatura de envelhecimento na faixa de 90-120 ${ }^{\circ} \mathrm{C}$, taxa de aquecimento de $1{ }^{\circ} \mathrm{C} \mathrm{min}^{-1}$ e temperatura de calcinação de $550{ }^{\circ} \mathrm{C} .{ }^{22,58}$ 
As variáveis sintéticas influenciam diretamente nas propriedades adquiridas pelo material mesoporoso, pois a estrutura pode sofrer grandes variações em função destes parâmetros.

A partir dos valores de diâmetro de poros obtidos dos dados de adsorção, pode-se calcular a espessura da parede de poros (t) através da Equação 9, pela diferença do parâmetro de rede $\left(\mathrm{a}_{0}\right)$, obtido a partir do DRX e diâmetro de poros:

$$
t_{p}=a_{0}-P_{s}
$$

A espessura da parede de poros da SBA-15 sintetizada é de $5 \mathrm{~nm}$, em acordo com a literatura. ${ }^{22}$ Esta propriedade $t_{p}$ está relacionada com a estabilidade hidrotérmica dos materiais. A faixa de espessura apresentada na literatura para estes materiais é entre $4-5 \mathrm{~nm} .^{22}$

\subsection{Catalisador suportado}

\subsubsection{Difração de Raios $X$}

O padrão de DRX do compósito 20\% $\mathrm{Ag}_{2} \mathrm{HPW} / \mathrm{SBA}-15$ é ilustrado na Figura 24. Embora a SBA-15 possa acomodar muita fase ativa devido ao seu grande volume de poros e alta área de superfície específica, não há picos de difração típicos da fase cristalina de HPW no DRX do compósito 20\% $\mathrm{Ag}_{2} \mathrm{HPW} / \mathrm{SBA}-15$. A ausência de padrões característicos de DRX de fases cristalinas do HPW indica que as partículas $\mathrm{Ag}_{2} \mathrm{HPW}$ estão altamente dispersas na peneira molecular SBA-15. ${ }^{16}$

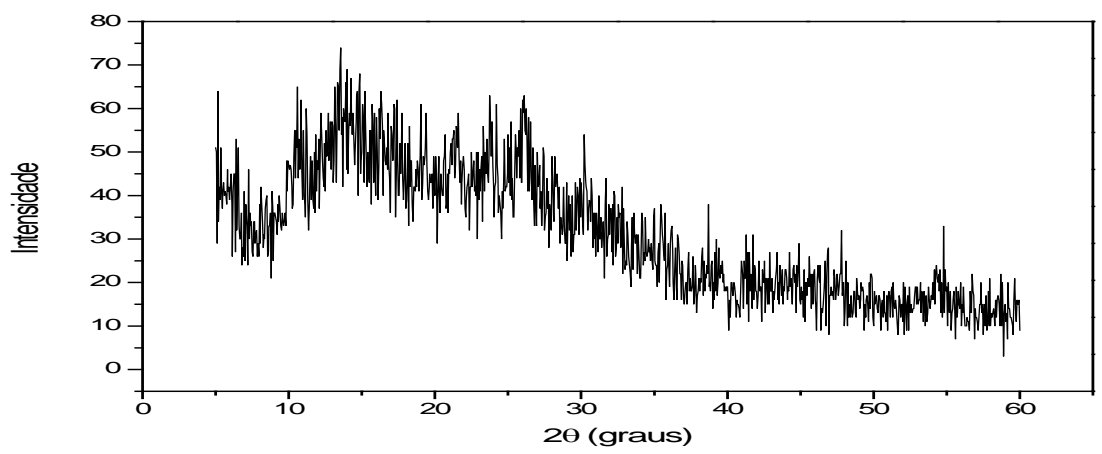

Figura 24. Difratograma do compósito 20\% $\mathrm{Ag}_{2} \mathrm{HPW} / \mathrm{SBA}-15$. 


\subsubsection{Ressonância Magnética Nuclear de ${ }^{31} \mathrm{P}$ no Estado Sólido (MAS RMN de}

$\left.{ }^{31} \mathrm{P}\right)$

A análise de MAS RMN de ${ }^{31} \mathrm{P}$ confirma a manutenção da integridade do catalisador suportado. A amostra mostrou somente um sinal característico em -15,2 ppm do $\mathrm{Ag}_{2} \mathrm{HPW}$ após os processos de impregnação e calcinação. Esse sinal de ressonância está relacionado à manutenção da estrutura de Keggin e é dependente do seu grau de hidratação. ${ }^{45}$ Segundo Kozhevnikov, ${ }^{9}$ os catalisadores de HPA preparados por impregnação com uma solução de metanol contêm exclusivamente um único sinal do tipo Keggin. Os dados indicaram que nenhuma decomposição foi observada na amostra. O espectro da amostra contendo 20\% $\mathrm{Ag}_{2} \mathrm{HPW} / \mathrm{SBA}-15$ evidencia tal fato (Figura 25).

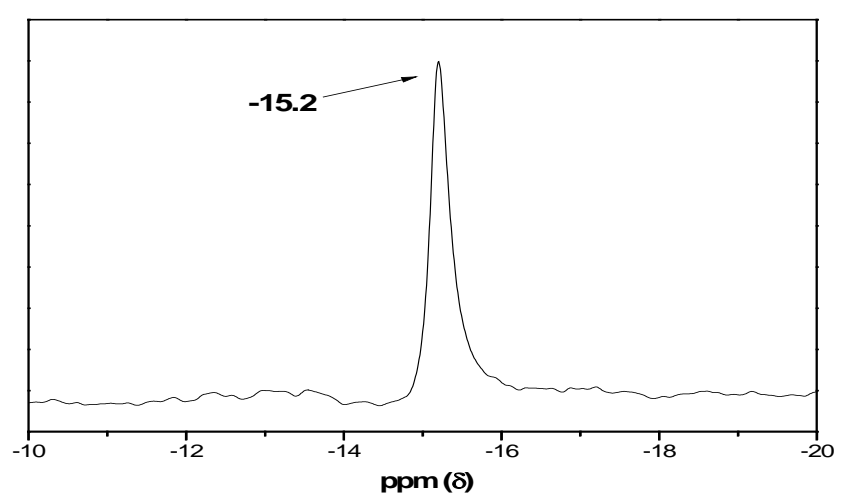

Figura 25. Espectro de MAS RMN de ${ }^{31} \mathrm{P}$ do catalisador $20 \% \mathrm{Ag}_{2} \mathrm{HPW} / \mathrm{SBA}-15$ calcinado.

\subsubsection{Adsorção de nitrogênio a baixa temperatura}

O catalisador suportado $20 \% \mathrm{Ag}_{2} \mathrm{HPW} / \mathrm{SBA}-15$ também apresentou isoterma de adsorção/dessorção de $\mathrm{N}_{2}$ do tipo IV, tal como definido pela IUPAC, característico de materiais mesoporosos (Figura 26). ${ }^{18}$ 


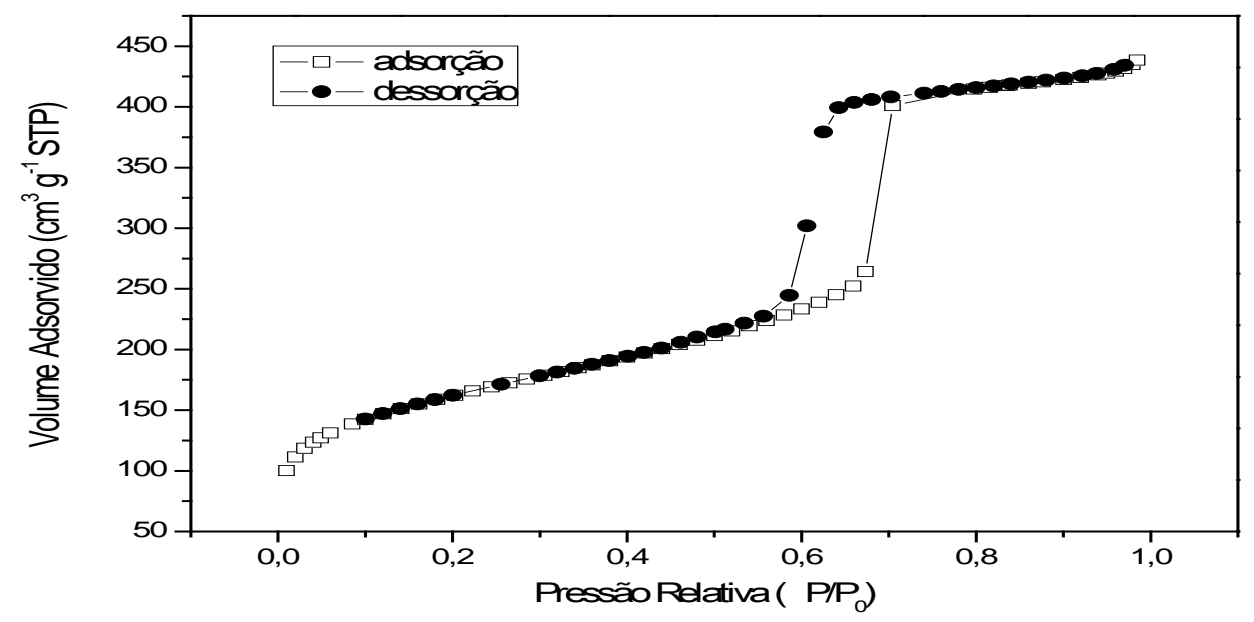

Figura 26. Isotermas de adsorção/dessorção de $\mathrm{N}_{2}$ da amostra de 20\% $\mathrm{Ag}_{2} \mathrm{HPW} / \mathrm{SBA}-15$.

A caracterização estrutural do compósito foi determinada a partir da isoterma, utilizando o método BET para área superficial especifica e o método BJH para o volume de poro e diâmetro de poro, sendo estes dados sumarizados na Tabela 10, que mostra as alterações desses parâmetros após a deposição de $\mathrm{Ag}_{2} \mathrm{HPW}$.

Tabela 10. Propriedades texturais do $\mathrm{Ag}_{2} \mathrm{HPW}$, SBA-15 e 20\% $\mathrm{Ag}_{2} \mathrm{HPW} / \mathrm{SBA}-15$.

\begin{tabular}{lccc}
\hline \multicolumn{1}{c}{ Amostras } & $\begin{array}{c}\mathbf{S}_{\mathrm{BET}} \\
\left(\mathbf{m}^{2} \mathbf{g}^{-1}\right)\end{array}$ & $\begin{array}{c}\mathbf{D}_{\mathbf{p}} \\
(\mathbf{n m})\end{array}$ & $\begin{array}{c}\mathbf{V}_{\mathbf{p}} \\
\left(\mathbf{c m}^{\mathbf{3}^{-1}} \mathbf{g}^{-1}\right)\end{array}$ \\
\hline $\mathrm{Ag}_{2} \mathrm{HPW}^{16}$ & 4,6 & 3,1 & 0,01 \\
& & & \\
SBA-15 & 687 & 6,1 & 1,10 \\
& & & \\
20\% $\mathrm{Ag}_{2}$ HPW/SBA-15 & 576 & 6,0 & 0,89 \\
\hline
\end{tabular}

O sal $\mathrm{Ag}_{2} \mathrm{HPW}$ apresenta uma área superficial especifica de $4,6 \mathrm{~m}^{2} \mathrm{~g}^{-1}$, o volume de poro de $0,01 \mathrm{~cm}^{3} \mathrm{~g}^{-1}$ e o diâmetro de poro de $3,1 \mathrm{~nm} .^{16}$ Os dados mostram que a fase ativa melhora consideravelmente a sua área de superfície específica por incorporação no substrato mesoporoso. O aperfeiçoamento desta propriedade é importante para a atividade catalítica dos materiais obtidos. 
Geralmente, após a incorporação de HPW e seus sais em matriz de sílica mesoporosa, o volume de poros das amostras diminui com a concentração de fase ativa e também a área de superfície diminui com diferentes proporções de HPW. ${ }^{64}$ Um comportamento diferente é observado para o compósito 20\% $\mathrm{Ag}_{2} \mathrm{HPW} / \mathrm{SBA}-15$, constantando que a área específica e volume de poros tem valores aproximados da sílica mesoporosa pura, pois deve ser levado em consideração que o compósito tem em sua composição $80 \%$ de SBA-15. Uma possível explicação para este comportamento inesperado é que a fase ativa teve uma elevada dispersão na superfície e nos poros do suporte durante o processo de impregnação, e o não bloqueio, evidentemente, dos poros por partículas de $\mathrm{Ag}_{2} \mathrm{HPW}$. Por conseguinte, não houve aglomeração de móleculas da fase ativa na superfície externa do material mesoporoso, resultando em não bloqueio dos poros.

Os tamanhos dos mesoporos são tão grandes que os cristálitos de HPA chegam facilmente a superfície interna e dispersam nela. A diminuição na área superficial depende da razão de microporos para mesoporos. Quanto maior for a quantidade de poros com tamanhos menores, maior será a redução na área de superfície por causa do fácil preenchimento e bloqueio de poros menores. ${ }^{16}$

\subsubsection{Microscopia Eletrônica de Varredura}

As micrografias do catalisador suportado $20 \% \quad A_{2}{ }_{2} \mathrm{HPW} / \mathrm{SBA}-15$ são apresentadas na Figura 27. O compósito 20\% $\mathrm{Ag}_{2} \mathrm{HPW} / \mathrm{SBA}-15$ apresenta morfologia semelhante a SBA-15, sendo uma forma macroscópica tipo vermicular que consiste de muitos agregados tipo corda ("rope-like"), em concordância com a literatura. $^{16}$ 

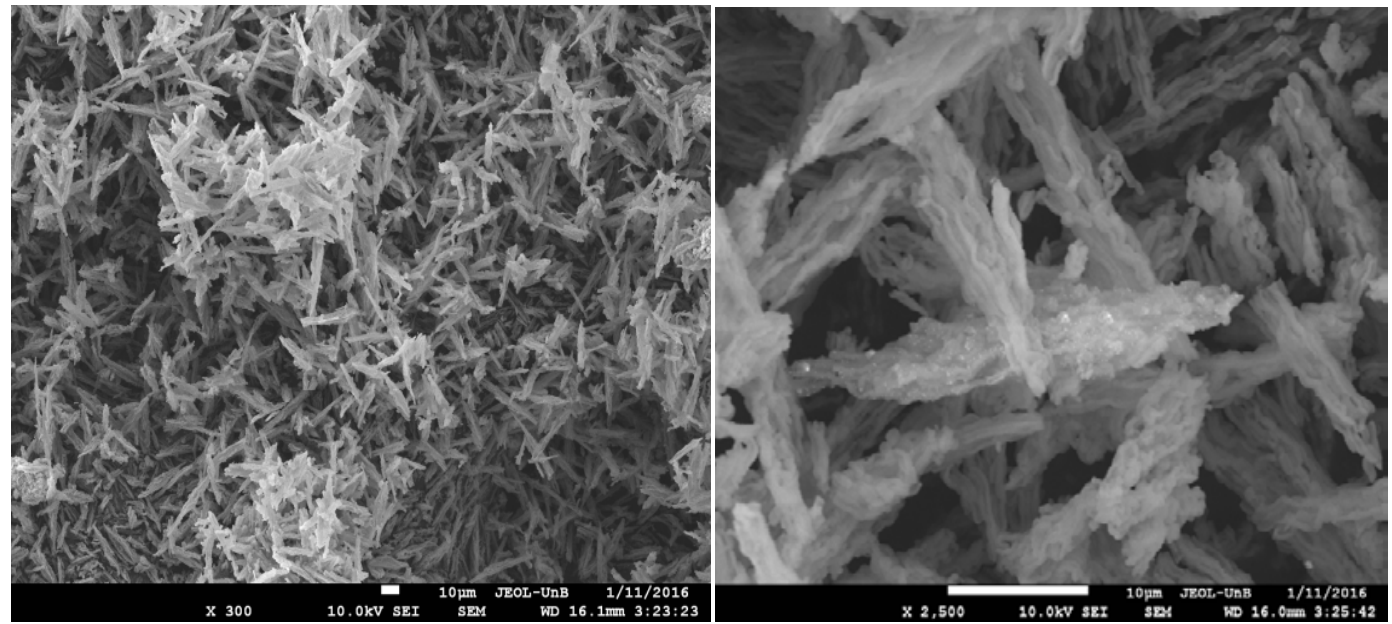

Figura 27. Micrografias por microscopia eletrônica de varredura da 20\% $\mathrm{Ag}_{2} \mathrm{HPW} / \mathrm{SBA}-15$.

\subsection{Teste catalítico}

A conversão dos sais $\mathrm{Ag}_{x} \mathrm{H}_{3-\mathrm{x}} \mathrm{PW}_{12} \mathrm{O}_{40}$, (sendo $\mathrm{x}=2,0 ; 2,5 ; 3,0$ ) foram avaliadas na reação de desidratação de etanol, a uma temperatura de $300{ }^{\circ} \mathrm{C}$, tendo como objetivo a formação de etileno. Antes do ensaio catalítico, as amostras foram ativadas a $300{ }^{\circ} \mathrm{C}$ durante $1 \mathrm{~h}$. Na série dos sais de prata estudados, foi observado que a conversão do catalisador $\mathrm{Ag}_{2} \mathrm{HPW}$ demonstrou-se mais elevada em relação aos demais sais sintetizados. Diante deste comportamento do sal $\mathrm{Ag}_{2} \mathrm{HPW}$, foi realizado um estudo do efeito da temperatura na faixa de $400,350,300,250,200{ }^{\circ} \mathrm{C}$. Por conseguinte, este sal foi escolhido para ser suportado em SBA-15 e avaliada a sua conversão a 300 e $400{ }^{\circ} \mathrm{C}$.

A conversão de etanol está relacionada com a presença de prótons do HPW e os prótons gerados a partir da água coordenada com os cátions de prata, conforme mostra a equação 6 , sendo a conversão claramente dependente da acidez dos catalisadores. Quanto maior é a quantidade de cátions de $\mathrm{Ag}^{+}$substituídos no HPW, mais baixa é a acidez dos catalisadores. ${ }^{14}$ 
Os prótons do heteropoliácido e os prótons gerados por dissociação de água coordenada dos átomos de prata influenciam o rendimento de etileno, quanto mais água presente nas amostras, mais etileno formado.

O sal $\mathrm{Ag}_{2} \mathrm{HPW}$ é mais ativo do que a amostra $\mathrm{Ag}_{2,5} \mathrm{HPW}$, que está de acordo com o número de prótons destes sais. A atividade catalítica do sal $\mathrm{Ag}_{3} \mathrm{HPW}$ pode estar relacionada com os prótons residuais. ${ }^{33} \mathrm{O}$ comportamento excepcional do catalisador $\mathrm{Ag}_{2} \mathrm{HPW}$ pode estar relacionado a alta mobilidade dos prótons. ${ }^{43}$

A conversão dos sais podem ser dispostos na ordem: $\mathrm{Ag}_{2} \mathrm{HPW}>\mathrm{Ag}_{2,5} \mathrm{HPW}>$ $\mathrm{Ag}_{3} \mathrm{PW}$, conforme os resultados apresentados na Tabela 11.

Tabela 11. Conversão e seletividade de etileno e dietiléter dos catalisadores $\mathrm{Ag}_{\mathrm{x}} \mathrm{HPW}(\mathrm{x}=2 ; 2,5$ e 3 ).

\begin{tabular}{c|c|c|c}
\hline Amostra & Conversão (\%) & $\begin{array}{c}\text { Seletividade para } \\
\text { etileno (\%) }\end{array}$ & $\begin{array}{c}\text { Seletividade para } \\
\text { dietiléter (\%) }\end{array}$ \\
\hline $\mathbf{A g}_{2} \mathbf{H P W}$ & 25,8 & 97,1 & 2,9 \\
$\mathbf{A g}_{2,5} \mathrm{HPW}$ & 13,2 & 96,1 & 3,9 \\
$\mathbf{A g}_{3} \mathrm{PW}$ & 4,1 & 94,9 & 5,1 \\
\hline
\end{tabular}

* Esses testes catalíticos foram realizados utilizando $\mathrm{m}=10 \mathrm{mg}$ para analisar qual sal de prata derivado do HPW apresentaria um melhor resultado de conversão para posteriormente ser suportado na sílica mesoporosa SBA-15.

No heteropoliácido neutro $\left(\mathrm{Ag}_{3} \mathrm{PW}\right)$ a ausência de prótons geradores de acidez de Brønsted pode ser contornada por meio de um pré-tratamento do sólido com vapor de água, originando um catalisador bifuncional quando a reação em questão não fornecer umidade suficiente para formar esses sítios ácidos. ${ }^{35,62}$

Em um trabalho de Gurgul e colaboradores, foi estudada a influência de duas diferentes condições de umidade relativa do ar, 2 e 9\%, na atividade catalítica do AgPW e do $\mathrm{Ag}_{3}\left[\mathrm{PMO}_{12} \mathrm{O}_{40}\right]$ (AgPMo) durante sua aplicação na reação de 
desidratação de etanol. ${ }^{35}$ De acordo com os autores, a variação da umidade praticamente não influenciou nas conversões obtidas pelo AgPMo (de até 20\%), em contraste com os resultados obtidos para o sal de AgPW. Com o ânion de tungstênio, maiores porcentagens de umidade relativa do ar provocaram um aumento da conversão de $75 \%$ para $100 \%$ em temperaturas reacionais a $220{ }^{\circ} \mathrm{C}$ e aumentaram também a seletividade para etileno. Entretanto, estudos de Varisli e colaboradores ${ }^{67}$ mostraram que mais de $10 \%$ de água em etanol geraram uma diminuição da atividade catalítica do AgPW, possivelmente porque a água passou a ser adsorvida mais fortemente em relação ao etanol na superfície do catalisador, causando uma redução na quantidade de sítios disponíveis.

Outra alteração, percebida por Matachowski e colaboradores, diz respeito à influência de moléculas de água na composição e estrutura do $\mathrm{AgPW}^{41}$ Segundo eles, quando possui $10 \%$ de umidade, há a formação de uma estrutura secundária em que uma molécula de água está ligada a cada cátion $\mathrm{Ag}^{+}$. Além disso, dados de termogravimetria (TG) mostraram que temperaturas reacionais acima de $160{ }^{\circ} \mathrm{C}$ provocam a perda das moléculas de água coordenadas aos cátions de prata e, consequentemente, a estrutura terciária do AgPW também é afetada, formando poros com diâmetros menores devido à aproximação dos íons de Keggin. Esse fato interfere diretamente na atividade catalítica dos heteropolissais.

A seletividade para etileno e éter diétilico obtido na reação de desidratação de etanol com o sal $\mathrm{Ag}_{2} \mathrm{HPW}$ é exibido na Tabela 12. Este estudo confirma a dependência de seletividade dos produtos versus temperatura de reação durante a desidratação de etanol. Em temperatura mais baixa que $180{ }^{\circ} \mathrm{C}$ o éter diétilico é o produto principal, enquanto a temperaturas mais elevadas a formação de etileno predomina. ${ }^{14,43}$ 
A alta \% conversão/seletividade para amostra de $\mathrm{Ag}_{2} \mathrm{HPW}$ pode ser explicada pelo fato da geração de prótons adicionais de água coordenada com os cátions de $\mathrm{Ag}^{+}$. Haber e colaboradores ${ }^{14}$ relataram que o aquecimento de sais $\mathrm{Ag}_{\mathrm{x}} \mathrm{H}_{3-\mathrm{x}} \mathrm{PW}_{12} \mathrm{O}_{40}$ a cerca de $250^{\circ} \mathrm{C}$ provocou a liberação dos prótons de água coordenada a prata. A água coordenada com cátions de $\mathrm{Ag}^{+}$aumenta com o aumento da incorporação de $\mathrm{Ag}^{+}$. Os autores também observaram que os prótons gerados por dissociação de água coordenado aos átomos de Ag influencia no rendimento do etileno, i.e., quanto mais água coordenada mais etileno será formado. ${ }^{14}$

Tabela 12. Estudo do efeito da temperatura na atividade do catalisador $\mathrm{Ag}_{2} \mathrm{HPW}$.

\begin{tabular}{cccc}
\hline Temperatura $\left({ }^{\circ} \mathbf{C}\right)$ & Conversão (\%) & $\begin{array}{c}\text { Seletividade para } \\
\text { etileno (\%) }\end{array}$ & $\begin{array}{c}\text { Seletividade para } \\
\text { dietiléter (\%) }\end{array}$ \\
\hline $\mathbf{4 0 0}$ & 77,1 & 99,4 & 0,6 \\
$\mathbf{3 5 0}$ & 69,9 & 99,2 & 0,8 \\
$\mathbf{3 0 0}$ & 63,5 & 95,2 & 4,8 \\
$\mathbf{2 5 0}$ & 50,2 & 91,5 & 8,5 \\
$\mathbf{2 0 0}$ & 27,6 & 72,6 & 27,4 \\
\hline
\end{tabular}

* Massa utilizada na reação: $\mathrm{m}=100 \mathrm{mg}$

Com o aumento da temperatura, a conversão de etanol cresce, mas a seletividade para o éter dietílico diminuiu e a seletividade para etileno aumenta devido à decomposição de éter dietílico.

No entanto, a influência do aumento da temperatura sobre a força ácida dos prótons pode ser considerada. ${ }^{43}$ Foi estabelecido anteriormente para o $\mathrm{HPW}^{59,60}$ que a força ácida dos prótons $\mathrm{H}^{+}$medido por indicadores Hammet aumentou de -8,2 para $\mathrm{HPW} \cdot 6 \mathrm{H}_{2} \mathrm{O}$, de $-12,0$ para $\mathrm{HPW} \cdot 4 \mathrm{H}_{2} \mathrm{O}$, de $-12,7$ para $\mathrm{HPW} \cdot 2 \mathrm{H}_{2} \mathrm{O}$ e $-13,7$ para $\mathrm{HPW} \cdot \mathrm{H}_{2} \mathrm{O}$. Ele mostra que a força ácida dos prótons no HPW é função da quantidade de água de hidratação dos prótons, o que pode ser determinado pela 
temperatura da reação catalítica. ${ }^{61}$ Também foi relatado anteriormente que no HPW, sob fluxo de nitrogênio a $100{ }^{\circ} \mathrm{C}$, os prótons monohidratados $\mathrm{H}_{3} \mathrm{O}^{+}$coexistem com os prótons diidratados $\mathrm{H}_{5} \mathrm{O}_{2}{ }^{+}$, principalmente, enquanto em temperatura maior de $200{ }^{\circ} \mathrm{C}$ os cátions $\mathrm{H}_{3} \mathrm{O}^{+}$coexistem com os prótons $\mathrm{H}^{+}$(principalmente). ${ }^{33,61}$ Assim, pode-se supor que o aumento observado na seletividade para etileno com o aumento da temperatura pode resultar do aumento da força ácida dos prótons.

Tabela 13. Tabela comparativa dos resultados da reação do $20 \% \mathrm{Ag}_{2} \mathrm{HPW} / \mathrm{SBA}-15$ e $\mathrm{Ag}_{2} \mathrm{HPW}$.

\begin{tabular}{l|c|c|c}
\hline \multicolumn{1}{c|}{ Amostra } & $\begin{array}{c}\text { Temperatura } \\
\left({ }^{\circ} \mathbf{C}\right)\end{array}$ & $\begin{array}{c}\text { Conversão } \\
\mathbf{( \% )}\end{array}$ & $\begin{array}{c}\text { Seletividade } \\
\text { etileno (\%) }\end{array}$ \\
\hline \multirow{2}{*}{$\mathbf{A g}_{2} \mathrm{HPW}$} & 300 & 63 & 95 \\
\cline { 2 - 4 } & 400 & 77 & 99 \\
\hline $\mathbf{2 0 \%} \mathbf{A g}_{2}$ HPWISBA-15 & 300 & 86 & 88 \\
\cline { 2 - 4 } & 400 & 100 & 100 \\
\hline
\end{tabular}

*Condições de análise: temperatura de ativação: $300{ }^{\circ} \mathrm{C}$ e $\mathrm{m}=100 \mathrm{mg}$.

Observa-se que a conversão de etanol aumenta consideravelmente para este catalisador suportado em relação ao sal $\mathrm{Ag}_{2} \mathrm{HPW}$. A melhora na conversão pode ser explicada pelo aumento da área específica de superfície obtida por incorporação da fase ativa no suporte mesoporoso. O compósito apresenta maior seletividade para etileno que a fase ativa pura.

Haber e colaboradores estudaram os catalisadores $\mathrm{Ag}_{\mathrm{x}} \mathrm{H}_{3-\mathrm{x}} \mathrm{PW}_{12} \mathrm{O}_{40}$ e $\mathrm{K}_{\mathrm{x}} \mathrm{H}_{3-}$ ${ }_{x} \mathrm{PW}_{12} \mathrm{O}_{40}(x=1-3)$ suportados em $\mathrm{SiO}_{2}$ na reação de desidratação de etanol em um reator de fluxo contínuo, os resultados mostraram atividade decrescente na desidratação do etanol com o aumento de x, a uma temperatura abaixo de $200{ }^{\circ} \mathrm{C} .{ }^{14}$ $\mathrm{Na}$ série dos sais de prata derivados do ácido 12-tungstofosfórico $\left(\mathrm{Ag}_{\mathrm{x}} / \mathrm{SiO}_{2}\right)$ as atividades catalíticas de $\mathrm{Ag}_{1}$ e $A g_{3}$ são semelhantes. $\mathrm{A}$ atividade do sal $\mathrm{Ag}_{2}$ é muito 
mais elevada, até mais alta do que a atividade do heteropoliácido puro. ${ }^{14} \mathrm{Um}$ resultado similar é observado para os sais $\mathrm{Cs}_{2,5}$, sendo este resultado relacionado a sua grande área de superfície. ${ }^{3}$

Holclajtner-Antunovic e colaboradores sintetizaram o compósito $30 \% \mathrm{Ag}_{2} \mathrm{HPW} / \mathrm{SBA}-15$ e aplicaram na reação de desidratação de etanol a $300{ }^{\circ} \mathrm{C}$, em um reator de leito fixo, utilizando uma massa de $100 \mathrm{mg}$. Esses pesquisadores conseguiram ótimos resultados, sendo uma conversão de 99,6\% e seletividade para etileno acima de $90 \% .{ }^{16}$ Os resultados catalíticos do compósito $30 \% \mathrm{Ag}_{2} \mathrm{HPW} / \mathrm{SBA}$ 15 apresentado por estes pesquisadores não são comparáveis ao descrito neste trabalho, pois as condições experimentais são diferentes, tais como os reatores utilizados para processar as reações e as proporções da fase ativa utilizadas nos compósitos, sendo que o catalisador $30 \% \mathrm{Ag}_{2} \mathrm{HPW} / \mathrm{SBA}-15$ possui uma acidez mais elevada.

Trakarnpruk estudou o efeito da substituição dos prótons do HPW pelos átomos de cobre e cério no suporte MCM-41 (20 e 30\% CuHPW/MCM-41 e 20 e 30\% CeHPW/MCM-41), sendo estes compósitos aplicados na reação de desidratação de etanol a $300^{\circ} \mathrm{C}$ em um reator de leito fixo, utilizando uma massa de $6 \mathrm{~g}$ de catalisador. ${ }^{66}$ Os catalisadores suportados foram sintetizados por um método de impregnação em duas etapas.

O catalisador 20\% CeHPW/MCM-41 exibiu uma atividade mais elevada do que o 20\% CuHPW/MCM-41. Os catalisadores 20\% CeHPW/MCM-41 e 20\% CuHPW/MCM-41 apresentaram conversões de etanol de 83,2 e 75,4\%, respectivamente. O sal 30\% CeHPW/MCM-41, que possui acidez mais elevada, apresentou maior conversão de etanol (88,3\%) com $85,0 \%$ de seletividade para 0 éter diétilico a $300{ }^{\circ} \mathrm{C}$. O compósito 30\% CuHPW/MCM-41 apresentou uma 
conversão de $81,0 \%$ e seletividade para éter diétilico de $78,3 \%$. A variação na atividade catalítica em função da temperatura de reação dos catalisadores $30 \%$ CeHPW/MCM-41 e 30\% CuHPW/MCM-41 foram também estudadas. A conversão aumentou com a temperatura e atingiu 91,5 e 86,6\% para 30\% CeHPW/MCM-41 e $30 \%$ CuHPW/MCM-41, respectivamente a $350{ }^{\circ} \mathrm{C} .66$

Para efeito de comparação, à mesma temperatura $\left(300^{\circ} \mathrm{C}\right)$, foi relatado que $\mathrm{Cu}_{0,5} \mathrm{H}_{2,5} \mathrm{PMO}_{12} \mathrm{O}_{40}$ apresentou uma conversão de $88,0 \%$ e $82,3 \%$ de seletividade para o éter diétilico ${ }^{65}$, enquanto o catalisador $18 \% \mathrm{HPW} / \mathrm{SiO}_{2}$ apresentou $90 \%$ de conversão comparado a $78 \%$ para $\mathrm{Ag}_{2} \mathrm{HPW}_{\mathrm{SiO}}$ com etileno como o principal produto. $^{14}$

Apesar das boas seletividades e conversões apresentadas nos trabalhos reportados na literatura que são descritos acima, deve ser observado à quantidade de catalisador utilizada nas reações, pois este critério evidência que a atividade dos materiais propostos muitas vezes são baixa. Outra questão a ser levada em consideração é o tipo de reator utilizado. Os estudos e caracterizações dos catalisadores acima mencionados são conduzidos por meio de reações em reatores de leito fixo com fluxo contínuo de reagentes. ${ }^{62}$

Os reatores com fluxo contínuo apresentam um alto gasto de reagentes e gases de arraste e utilizam uma quantidade realtivamente grande de amostra para gerar bons resultados, além de provocarem uma rápida desativação do catalisador ${ }^{62}$ Já o microrreator de pulso que foi desenvolvido e utilizado para estudar as reações neste trabalho visa à economia do processo nos experimentos. Ele envolve pulsos/injeções de quantidades conhecidas de um fluído ao longo de um microleito de catalisador ativado. Assim, é possível quantificar de forma eficaz a conversão do reagente por meio da técnica de cromatografia gasosa. ${ }^{62}$ São poucos os trabalhos 
que empregam os microrreatores de pulso nos experimentos de catálise heterogênea. 


\section{Conclusões}




\section{CONCLUSÕES}

Os sais de prata derivados do HPW, preparados pelo método de troca iônica, preservaram a estrutura de Keggin após a troca, parcial ou total, de prótons ácidos por cátions de prata, sendo confirmadas por FT-IR e difração de raios X.

O compósito mesoporoso $\mathrm{Ag}_{2} \mathrm{HPW} / \mathrm{SBA}-15$ foi sintetizado por dois passos sequenciais de impregnação e caracterizado por vários método físico-químicos e foram avaliadas as suas características catalíticas pela reação de desidratação de etanol. Os resultados obtidos foram comparados com as propriedades dos sais de prata puros, derivados do HPW sintetizados. Como um resultado da interação dos heteropoliácidos e o suporte, a área superficial específica da fase ativa é aumentada.

Pode-se concluir que $\mathrm{Ag}_{2} \mathrm{HPW}$ suportado em SBA-15 exibiu alta conversão e seletividade na reação de desidratação de etanol. Portanto, 20\% $\mathrm{Ag}_{2} \mathrm{HPW} / \mathrm{SBA}-15$ é promissor como um catalisador sólido ácido para este tipo de reação. 


\section{Referências}




\section{REFERÊNCIAS}

1. Gupta, P.; Paul, S.; Catal. Today. 2014, 236, 153.

2. Arantes, A. C. C.; Bianchi, M. L; Rev. Virt. Quim. 2013, 5, 959.

3. Misono, M.; Heterogeneous Catalysis of Mixed Oxides, Perovskite and Heteropoly Catalysts; Elsevier; Tokyo, 2013, 176, 98.

4. Santos, J. S.; Dias, J. A.; Dias, S. C. L.; Garcia, F. A. C.; Macedo, L. J.; Sousa, F. S. G.; Almeida, L. S.; Appl. Catal. A. 2011, 394, 138.

5. Pope, M. T.; Heteropoly and Isopoly Oxometalates, Berlin: Springer, 1983.

6. Greenwood, N. N.; Earnshaw, A. Chemistry of the Elements, Pergmon Press, Oxford, 1994.

7. Santos, J. S.; Dissertação de Mestrado, Universidade de Brasília, Brasil, 2008.

8. Kozhevnikov, I. V.; Catalyts for Fine Chemical Synthesis, Vol. 2 - Catalysis by Polyoxometalates. John Wiley \& Sons Ltda: Chichester, 2002.

9. Kozhevnikov, I. V.; Chem. Rev. 1998, 98, 171.

10. Okuhara, T.; Mizuno, N.; Misono, M.; Adv. Catal. 1996, 41, 113

11. Mioc, U.B.; Todorovic, M.R.; Davidovic, M.; Colombam, P.; HolclajtnerAntunovic, I.; Solid States Ionics, 2005, 176, 3005.

12. Mizuno, N.; Misono, M.; Chem. Rev. 1998, 98, 199.

13. Rao,P. M.; Wolfson, A.; Kababya, S.; Vega, S.; Landau, M.V.; J. Catal. 2005, $232,210$.

14. Haber, J.; Pamim, K.; Matachowski, L.; Napruszewska, B.; Poltowicz, J.; J. Catal., 2002, 207, 296.

15. Moffat, J. B.; McGarvey, C. B.; J. Catal. 1991, 128, 69.

16. Holclajtner-Antunovic, I.; Bajuk-Bogdanovic, D.; Popa, A.; Sasca, V.; Vasiljevic, B. N.; Rakic, A.; Uskokovic - Markovic, S.; Mater.Chem. Phys. 2015, 160, 359. 
17. Zieba, A.; Matachowski, L.; Gurgul, J.; Bielanska, E.; Drelinkiewicz, A.; J. Mol. Catal. A, 2010, 316, 30

18. Ciesla, U.; Schuth, F.; Micropor. Mesopor. Mater. 1999, 27, 131.

19. Filha, V. L. S. A.; Tese de Doutorado, Universidade Federal da Paraíba, Brasil, 2011.

20. Vartuli, J.C.; Roth, W.J.; Degnan, T.F. In Dekker Encyclopedia of Nanoscience and Nanotechnology; Schwarz, J.A., Contescu, C.I., Putyera, K., Eds.; Taylor and Francis: New York, NY, USA, 2008; 1797.

21. Kresge, C. T.; Leonowicz, M. E.; Roth, W. J.; Vartuli, J. C.; Beck, J. S.; Nature. $1992,359,710$.

22. Zhao, D., Feng, J., Huo, Q.; Melosh, N.; Fredrickson.G. H; Chmelka, B. F.; Stucky, G. D.; Science. 1998, 279, 548.

23. Zhao, D.; Sun, J.; Li, Q.; Stucky, G. D.; Chem. Mater. 2000, 12, 275.

24. Zhao, D.; Huo, Q.; Feng, J.; Chmelka, B.F.; Stucky, G.D.; J. Am. Chem. Soc. $1998,120,6024$.

25. Magalhães, D.; Tese de Doutorado, Universidade de São Paulo, Brasil, 2011.

26. Huo, Q.; Margolese, D. J.; Ciesla, U.; Demuth, D. G.; Feng, P.; Gier, T. E.; Sieger, P.; Firouzi, A.; Chmelka, B. F.; Schu th, F.; Stucky, G. D. Chem. Mater. 1994, 6, 1176.

27. Soler-Illia, G. J. D. A. A.; Sanchez, C.; Lebeau, B.; Patarin, J; Chem. Rev. 2002, $102,4093$.

28. Perego, C.; Millini, R.; Chem. Soc. Rev. 2013, 42, 3956.

29. Park, Y.; Shin, W. S.; Choi S.; Chem. Eng. J. 2013, 220, 204.

30. Taguchi, A.; Schuth, F.; Micropor. Mesopor. Mater. 2005, 77, 1.

31. Moritz, M.; Malgorzata, G.; Mater. Sci. Eng., C. 2015, 49, 114. 
32. Damyanova, S.; Gómez, L. M.; Banares, M. A.; Fierro, J. L. G.; Chem. Mater. $2000,12,501$.

33. Matachowski, L.; Drelinkiewicz, A.; Lalik, E.; Ruggiero-Mikołajczyk, M.; Mucha,D.; J. Krysciak - Czerwenka, J.; Appl. Catal. A. 2014, 469, 290.

34. Junior, G. E. L.; Melo, A.C.R.; Lima, S.H.; Araujo, A. S.; Junior, V. J. F.; Quim. Nova. 2010, 33, 1646.

35. Gurgul, J.; Zimowska, M.; Mucha, D.; Socha, R. P.; Matachowski, L.; J. Mol. Catal. A: Chem. 2011, 351, 1.

36. Destro, P.; Dissertação de Mestrado, Universidade Federal de Lavras, Brasil, 2012.

37. Alharbi, W.; Brown, E.; Kozhevnikova, E. F.; Kozhevnikov, I. V.; J. Catal. 2014, 319, 174.

38. Muller, J. M.; Mesquita, G. C.; Franco, S. M.; Borges, L. D.; Macedo, J. L.; Dias, J. A.; Dias, S. C. L.; Micropor. Mesopor. Mater. 2015, 204, 50.

39. Ghesti, G.F.; Macedo, J.L.; Parente, V.C.I.; Dias, J.A.; Dias, S.C.L.; Micropor. Mesopor. Mater. 2007, 100, 27.

40. Mucha, D.; Matachowski, L.; Machej, T.; Gurgul, J.; Socha, R. P.; Solid State Sci. 2011, 13, 1276.

41. Matachowski, L.; Zimowska, M.; Mucha, D.; Machej, T.; Appl. Catal. B. 2012, $123,448$.

42. Zhu, S.; Gao, X.; Dong, F.; Zhu, Y.; Zheng, H.; Li, Y.; J. Catal. 2013, 306, 163.

43. Mohamed Mokhtar, M.; Basahel, S. N.; Ali, T. T.; J. Ind. Eng. Chem. 2014, 20, 46. 
44. Holclajtner-Antunovic, I.; Bajuk-Bogdanovic, D.; Popa, A.; Vasiljevic, B. N.; Krstic, J.; Mentus, S.; Uskokovic - Markovic, S.; Applied Surface Science. 2015, $328,466$.

45. Dias, J. A.; Caliman, E.; Dias, S. C. L.; Micropor. Mesopor. Mater. 2004, 76, 221.

46. Okuhara, T.; Mizuno, N.; Misono, M; Adv. Catal, 1996, 41, 113.

47. Parry, E. P. J. Catal. 1963, 2, 371.

48. Braga, P. R. S.; Tese de Doutorado, Universidade de Brasília, Brasil, 2011.

49. Fenelonov, V.B.; Romannikov, V.N.; Derevyankin. A.Y.; Micropor. Mesopor. Mater. 1999, 28, 57.

50. Oliveira, F. J. V. E.; Tese de Doutorado, Universidade de Campinas, Brasil, 2009.

51. Meynem, V; Cool, P.; Vansant, E.F.; Micropor. Mesopor. Mater. 2009, 125, 170.

52. Beck, J.S.; Vartuli, J. C.; Roth, W. J.; Leonowicz, M. E.; Kresge, C. T.; Schmitt, K. D.; Chu, C. T-W.; Olson, D. H.; Sheppard, E. W.; McCullen, S. B.; Higgins, J. B.; Sclenkert, J. L.; J. Am. Chem. Soc.1992, 114, 10834.

53. Rocchiccioli-Deltcheff, C.; Fournier, M.; Franck, R.; Thouvenot, R.; Vibrational investigations of polyoxometalates. 2. Evidence for anion-anion interactions in molybdenum( $\mathrm{VI})$ and tungsten $(\mathrm{VI})$ compounds related to the Keggin structure, Inorg. Chem. 1983, 22, 207.

54. De Farias, R.; Airoldi, C.; J. Therm. Anal. Calorim. 1998, 53, 751.

55. Van der voort, P.; Gillis-d'hamers, I.; Vansant, E. F. J. Chem. Soc. 1990, 86, 3751.

56. Sing, K. S. W.; Everett, D. H.; Haul, R. A. W.; Moscou, L.; Pierotti, R. A.; Rouquerol, J.; Siemieniewska, T. ; Pure Appl. Chem. 1985, 57, 603.

57. Kruk, M.; Jaroniec, M.; Sayari, A. Langmuir. 1997, 13, 6267. 
58. Yang, C.; Zibrowius, B.; Schmidt, W.; Schuth, F.; Chem. Mater. 2004, 16, 2918.

59. He, S.; Liu, X.; Xie, S.; Wang, Q.; Xu, Y.; Xu, L. Catal. Commun. 2003, 4, 585.

60. Du, Z. X.; He, Y. G.; Min, E. Z. Acta Petrolei Sin. 1999,15, 61.

61. Essayem, N.; Tong, Y. Y.; Jobic, H.; Vedrine, J. C. Appl. Catal. A: Gen. 2000, 194, 109.

62. Borges, L. D.; Tese de Doutorado, Universidade de Brasília, Brasil, 2014.

63. Parent, M. A.; Moffat, J. B.; Catal. Let. 1997, 48, 135.

64. Park, Y.; Shin, S. W.; Choi, S.; Chem. Eng. J. 2013, 220, 204.

65. Ali, T. T.; Al-Thabaiti, S. A.; Alyoubi, A. O.; Mokhtar, M. J. Alloys Compd. 2010, 496, 553.

66. Trakarnpruk, W.; Mendeleev Commun, 2013, 23, 168.

67. Varisli, D.; Dogu, T.; Dogu, G.; Chem. Eng. Sci. 2007, 62, 5349.

68. Pozniczek, J.; Lebanska, A.; Micek-IInicka, A. Mucha, D.; Lalik, E.; Bielanski, A. Appl. Catal. A Gen. 2006, 298, 217.

69. Marme, F.; Couderier, G. Védrine, J. C. Micropor. Mesopor. Mater. 1998, 22, 151.

70. Holclajtner-Antunovic, I.; Popa, A.; Bajuk-Bogdanovic, D.; Mentus, S.; Vasiljevic, B. M. N.; Uskokovic - Markovic, S.; Inorg. Chim. Acta. 2013, 407, 197.

71. Filek, U.; Kirpszaa, A.; Micek-IInickaa, A.; Lalika, E.; Bielanski, A. J. Mol.Catal. A. 2015, 407, 152. 


\section{Anexos}




\section{ANEXOS}

\subsection{Curva Analítica (UV-Vis) do HPW}

A curva analítica do HPW foi feita com soluções ácidas de HPW em diferentes concentrações (Tabela A1) em um espectrofotômetro UV-Vis utilizando-se uma cubeta de quartzo de $1,0 \mathrm{~cm}$ de caminho ótico e $1 \mathrm{~mL}$ de volume. ${ }^{7}$ A determinação quantitativa da quantidade de ácido 12-tungstofosfórico na solução é baseada no fato de que os ânions de Keggin tem uma banda de transferência de carga em 260 nm. ${ }^{14}$ Os dados experimentais (Tabela A1) foram ajustados por meio de uma curva de regressão linear. Para o gráfico gerado foi obtido um bom coeficiente de correlação linear $(R=0,9999)$. A equação da reta ajustada pode ser descrita pela seguinte expressão: $Y=4,2171 \times 10^{4} X+0,0057$. Os dados experimentais e a curva calculada são apresentados na Figura A 1.

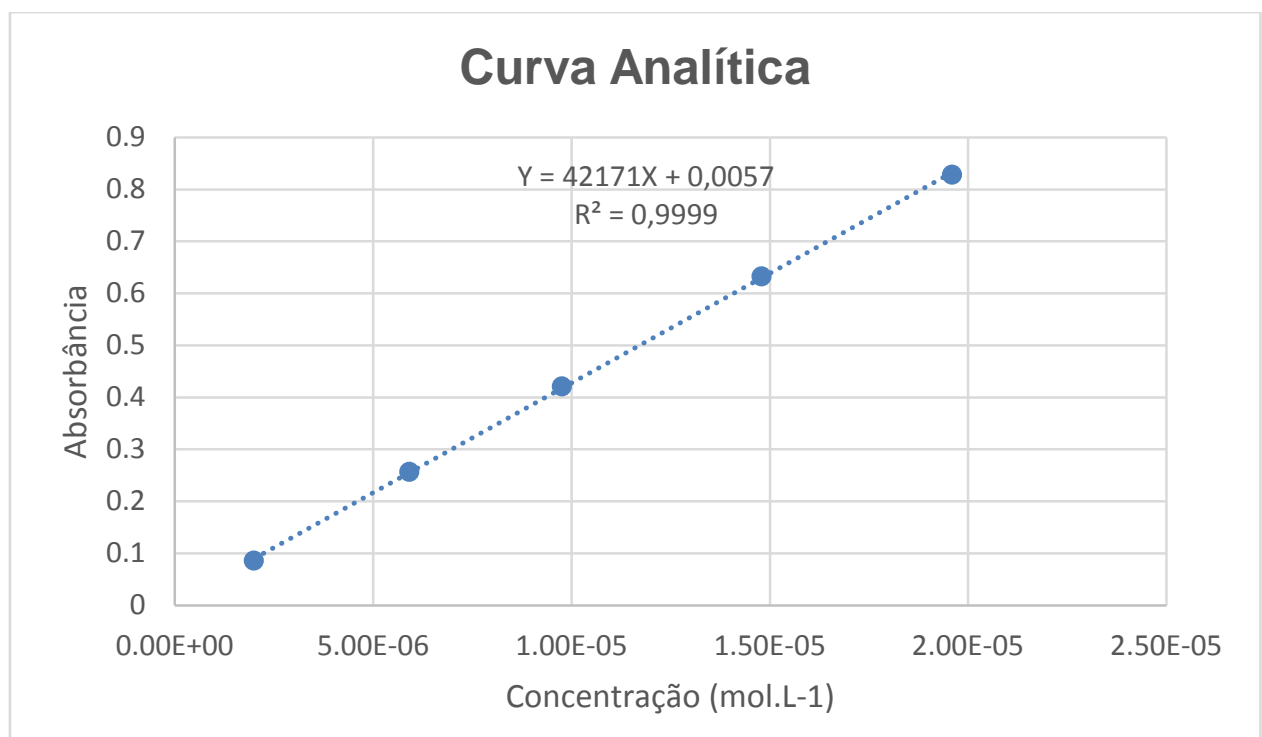

Figura A 1: Curva analítica do HPW em solução aquosa ácida $\left(0,1 \mathrm{~mol} \mathrm{~L}^{-1}\right.$ de $\left.\mathrm{HCl}\right)$ obtida no espectrômetro de UV-Vis, em $\lambda=260 \mathrm{~nm}$. 
Tabela A 1: Dados da curva analítica do HPW obtidos por UV-Vis $(\lambda=260 \mathrm{~nm})$.

\begin{tabular}{cc}
\hline Concentração (mol L & Absorbância \\
\hline $2.00 \times 10^{-06}$ & 0.08615 \\
$5.92 \times 10^{-06}$ & 0.25681 \\
$9.76 \times 10^{-06}$ & 0.42073 \\
$1.48 \times 10^{-05}$ & 0.63257 \\
$1.96 \times 10^{-05}$ & 0.82834 \\
\hline
\end{tabular}




\subsection{Espectros de FT-IR do HPW e dos seus derivados salinos de prata}

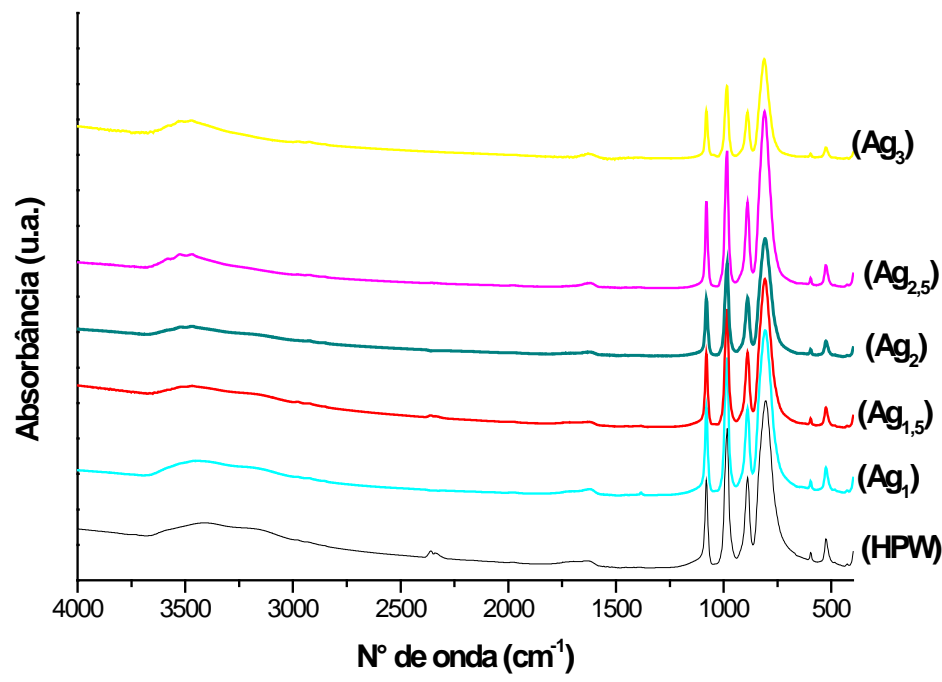

Figura A2. Espectros de FT-IR do HPW e dos seus derivados salinos de prata, calcinados a $300{ }^{\circ} \mathrm{C}$. 